\title{
Reactions of Styrylmalonates with Aromatic Aldehydes: Detailed Synthetic and Mechanistic Studies
}

Denis D. Borisov, Roman A. Novikov, ${ }^{*}$ and Yury V. Tomilov*

N. D. Zelinsky Institute of Organic Chemistry, Russian Academy of Sciences, 47 Leninsky prosp., 119991 Moscow, Russian Federation

`E-mail: novikovff@@bk.ru. `E-mail: tom@ioc.ac.ru

\section{SUPPORTING INFORMATION}

Part 2

Table of contents:

\begin{tabular}{|c|l|c|}
\hline Entry & \multicolumn{1}{|c|}{ Description } & Page \\
\hline 1 & $\begin{array}{l}\text { 1. XRD data for new compounds 3'c and 10e } \\
\text { Table 7. Crystal data and structure refinement for indene 3'c } \\
\text { Table 8. Crystal data and structure refinement for diene 10e }\end{array}$ & S2 \\
\hline 2 & $\begin{array}{l}\text { 2. Copies of NMR spectra for the new isolated } \\
\text { compounds }\end{array}$ & S5 \\
\hline 3 & $\begin{array}{l}\text { 3. Copies of NMR, MS and HRMS spectra for }{ }^{18} \text { O labeled } \\
\text { compound 6a }\end{array}$ & S76 \\
\hline
\end{tabular}




\section{XRD data for new compounds 3 'c and 10e}

Table 7. Crystal data and structure refinement for indene $\mathbf{3}$ 'c.

Empirical formula

Formula weight

Temperature

Wavelength

Crystal system

Space group

Unit cell dimensions

Volume

Z

Density (calculated)

Absorption coefficient

$\mathrm{F}(000)$

Crystal size

Theta range for data collection

Index ranges

Reflections collected

Independent reflections

Completeness to theta $=28.32^{\circ}$

Absorption correction

Refinement method

Data / restraints / parameters

Goodness-of-fit on $\mathrm{F}^{2}$
$\mathrm{C}_{19} \mathrm{H}_{15} \mathrm{NO}_{6}$

353.32

120(2) K

$0.71073 \AA$

Triclinic

$\mathrm{P}-1$

$$
\begin{array}{ll}
\mathrm{a}=7.6037(7) \AA & \alpha=88.550(2)^{\circ} . \\
\mathrm{b}=8.7555(8) \AA & \beta=84.068(2)^{\circ} . \\
\mathrm{c}=12.1844(10) \AA & \gamma=81.400(2)^{\circ} .
\end{array}
$$

2

$1.471 \mathrm{Mg} / \mathrm{m}^{3}$

$0.111 \mathrm{~mm}^{-1}$

368

$0.16 \times 0.14 \times 0.03 \mathrm{~mm}^{3}$

2.35 to $28.32^{\circ}$

$-10<=\mathrm{h}<=10,-11<=\mathrm{k}<=11,-16<=\mathrm{l}<=16$

12593

$3967[\mathrm{R}(\mathrm{int})=0.0638]$

$99.9 \%$

None

Full-matrix least-squares on $\mathrm{F}^{2}$

3967 / 0 / 240

1.024

Final R indices [for 2582 rfln with I $>2$ sigma(I)] 0.1065

$$
\mathrm{R} 1=0.0522, \mathrm{wR} 2=
$$

$\mathrm{R}$ indices (all data)

$\mathrm{R} 1=0.0943, \mathrm{wR} 2=0.1218$ 


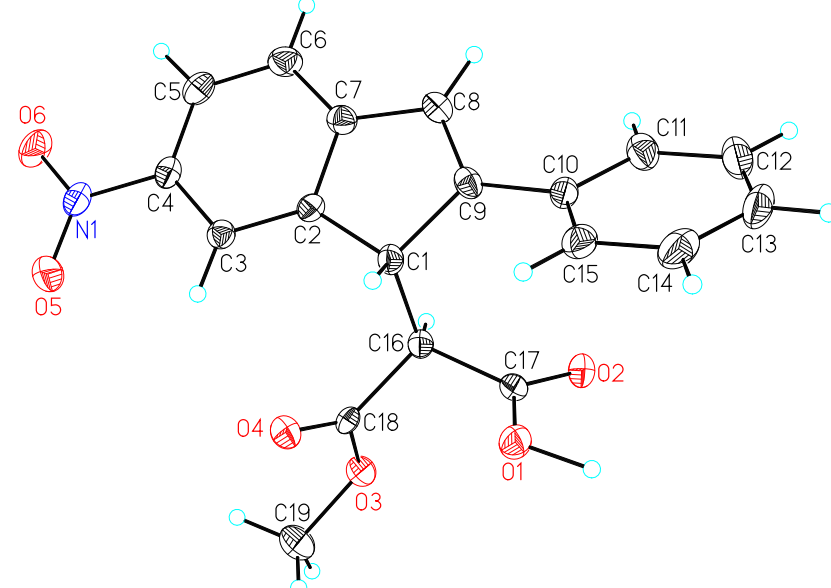

X-Ray crystallographic data of $\mathbf{3}$ 'a. $50 \%$ ellipsoid probability

Table 8. Crystal data and structure refinement for diene $\mathbf{1 0 e}$.

Empirical formula

$\mathrm{C}_{17} \mathrm{H}_{13} \mathrm{NO}_{7}$

Formula weight

343.28

Temperature

120(2) K

Wavelength

$0.71073 \AA$

Crystal system

Monoclinic

Space group

P 21/n

Unit cell dimensions

$$
\begin{array}{ll}
\mathrm{a}=8.7988(8) \AA & \alpha=90^{\circ} . \\
\mathrm{b}=15.9621(15) \AA & \beta=100.304(2)^{\circ} . \\
\mathrm{c}=11.4269(11) \AA & \gamma=90^{\circ} .
\end{array}
$$

Volume

$$
1579.0(3) \AA 3
$$

Z

4

Density (calculated) 
Absorption coefficient

$\mathrm{F}(000)$

Crystal size

Theta range for data collection

Index ranges

Reflections collected

Independent reflections

Completeness to theta $=29.00^{\circ}$

Absorption correction

Refinement method

Data / restraints / parameters

Goodness-of-fit on $\mathrm{F}^{2}$

Final $\mathrm{R}$ indices [I>2sigma(I)]

$\mathrm{R}$ indices (all data)

Largest diff. peak and hole
$0.114 \mathrm{~mm}^{-1}$

712

$0.12 \times 0.02 \times 0.01 \mathrm{~mm}^{3}$

2.22 to $29.00^{\circ}$.

$-12<=\mathrm{h}<=11,-21<=\mathrm{k}<=21,-15<=\mathrm{l}<=15$

25009

$4186[\mathrm{R}(\mathrm{int})=0.1028]$

$99.8 \%$

None

Full-matrix least-squares on $\mathrm{F}^{2}$

4186 / 0 / 231

1.008

$\mathrm{R} 1=0.0542, \mathrm{wR} 2=0.0900$

$\mathrm{R} 1=0.1094, \mathrm{wR} 2=0.1099$

0.336 and -0.251 e. $\AA^{-3}$

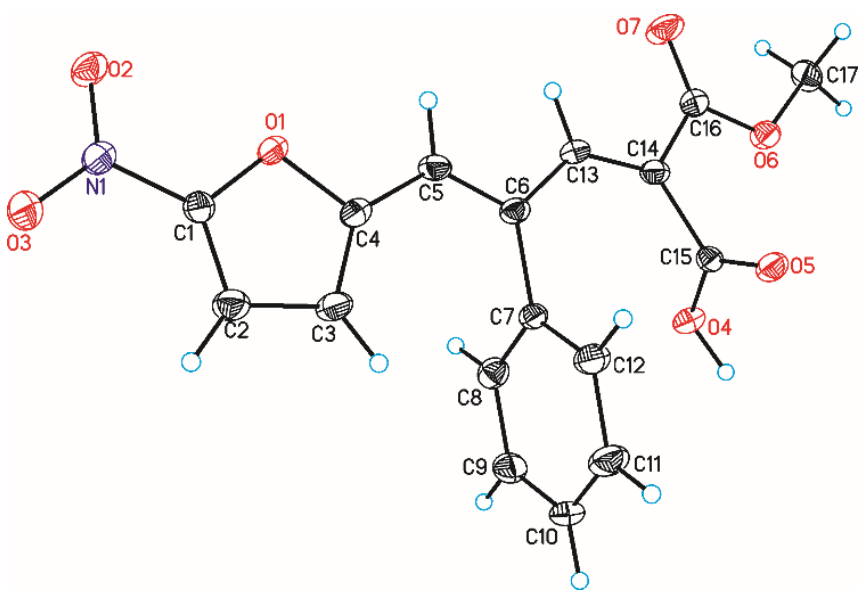

X-Ray crystallographic data of 10e. $50 \%$ ellipsoid probability 


\section{Copies of NMR spectra for the newisolated compounds}

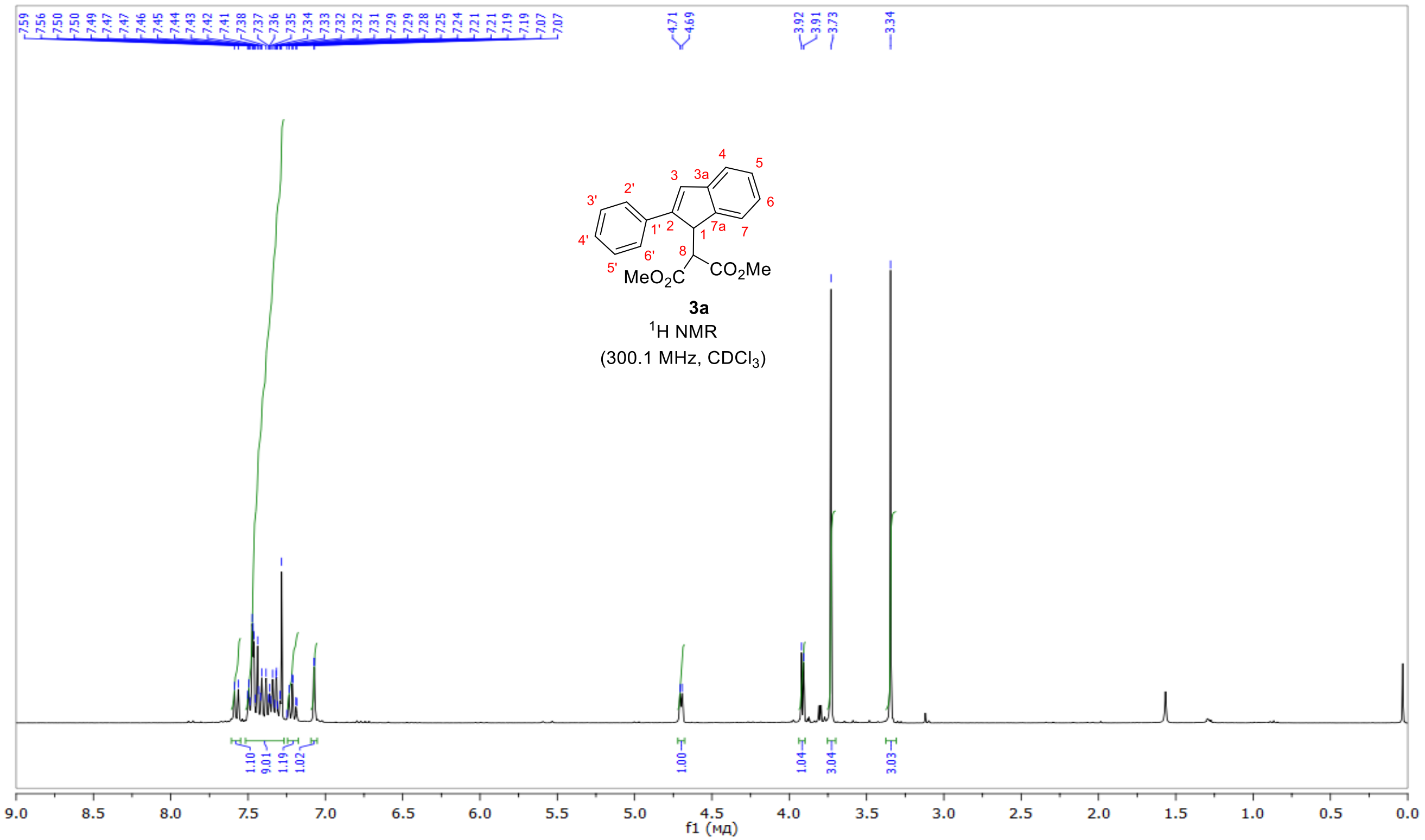




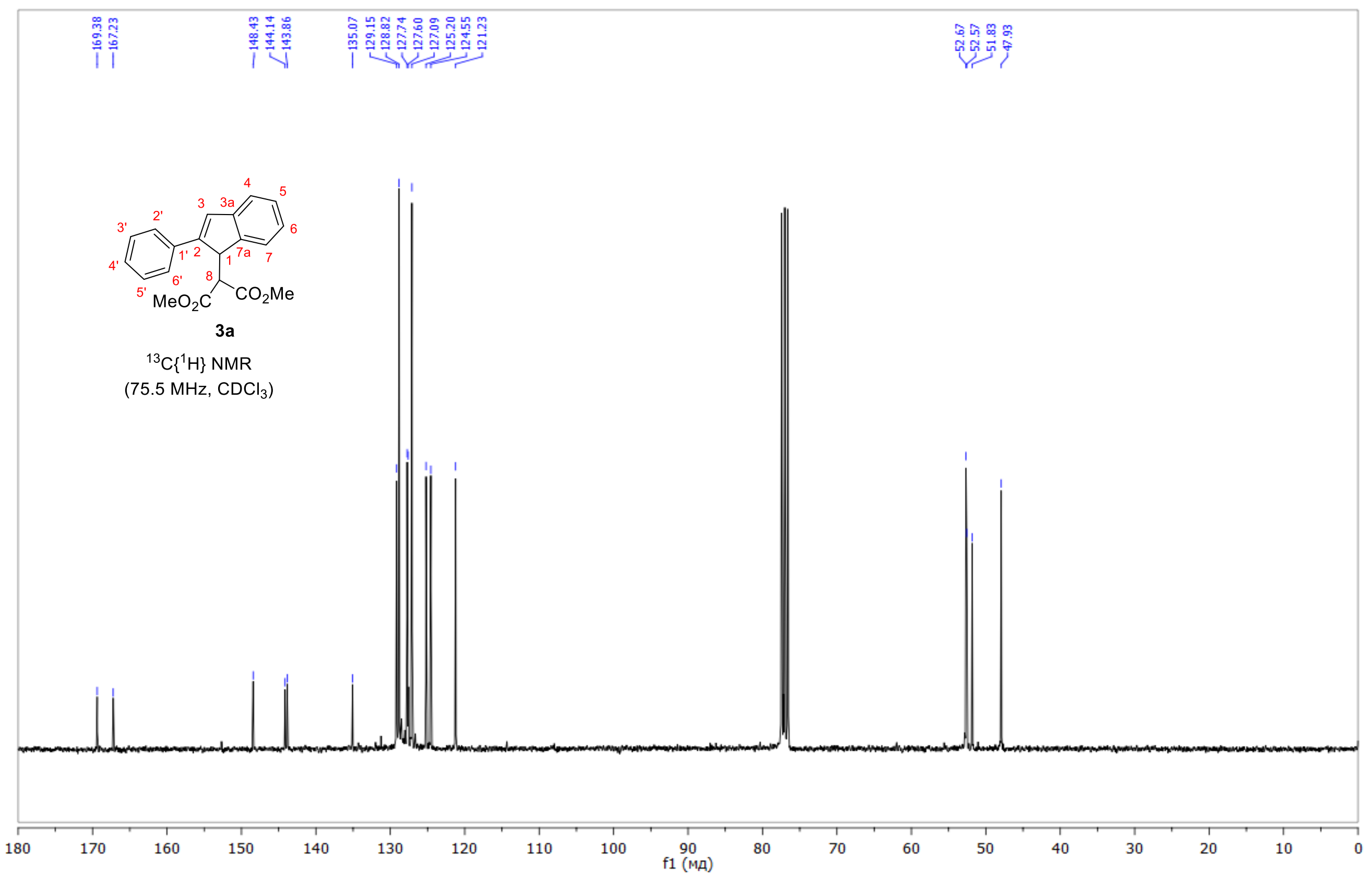




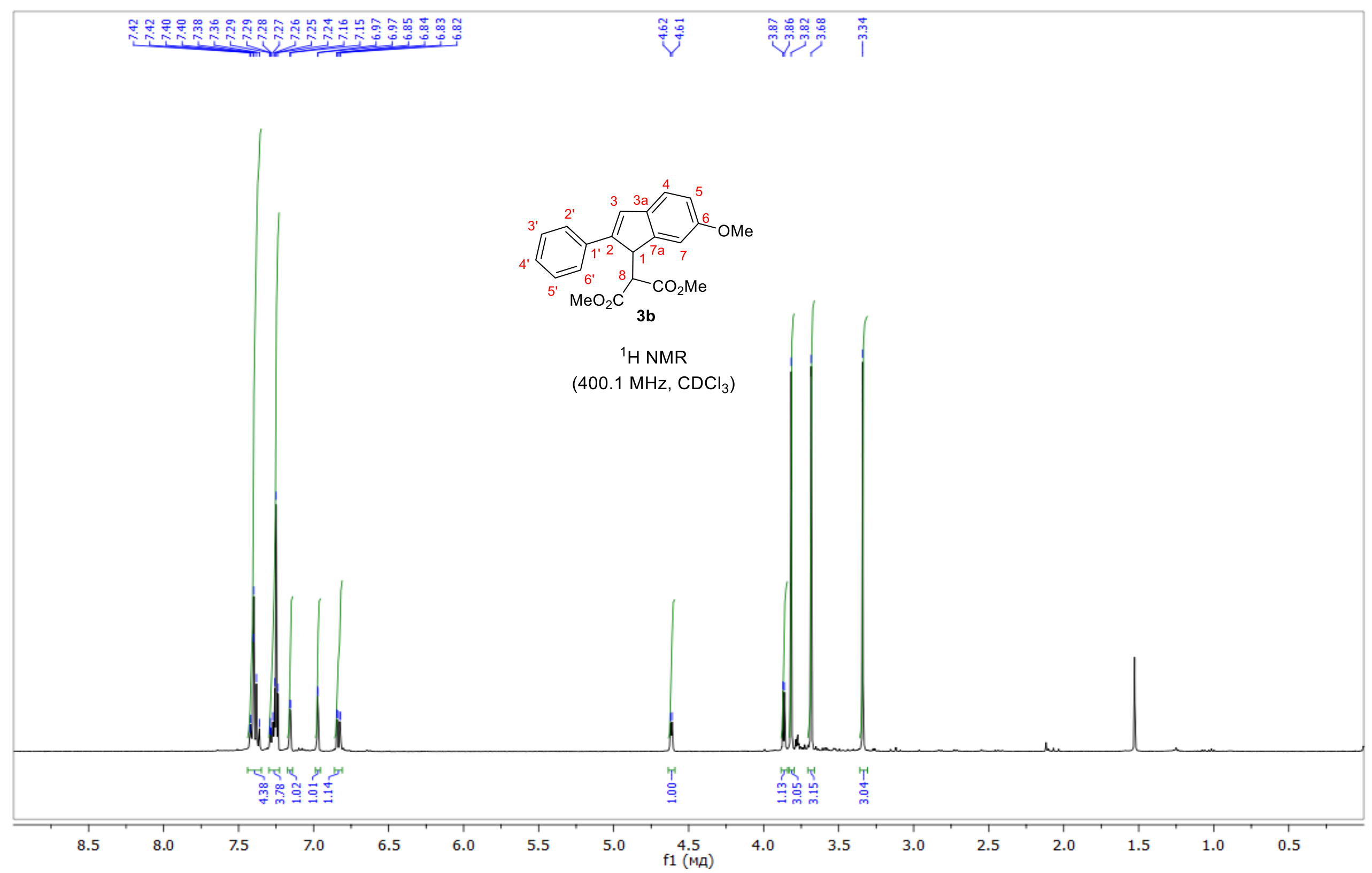




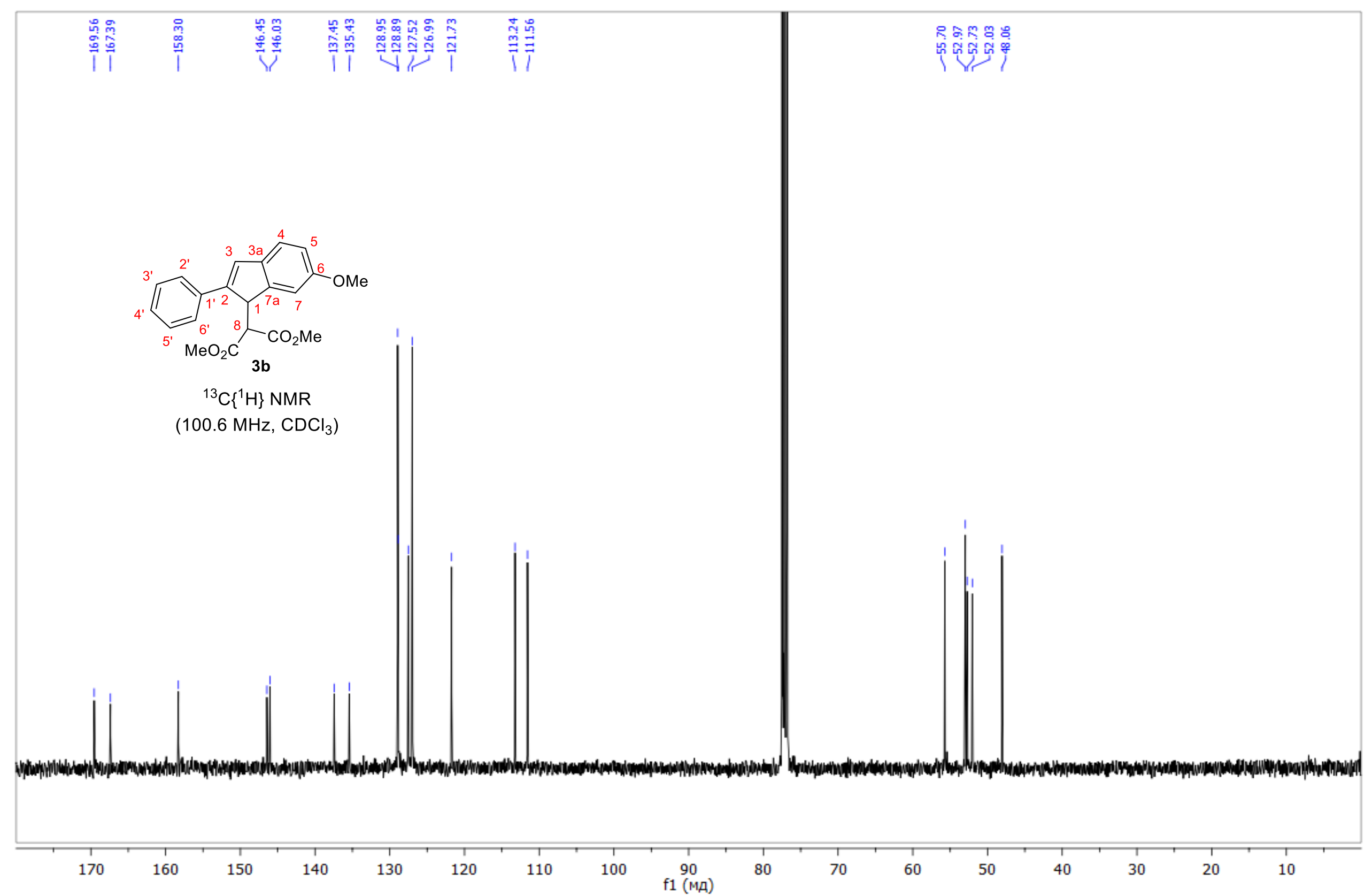




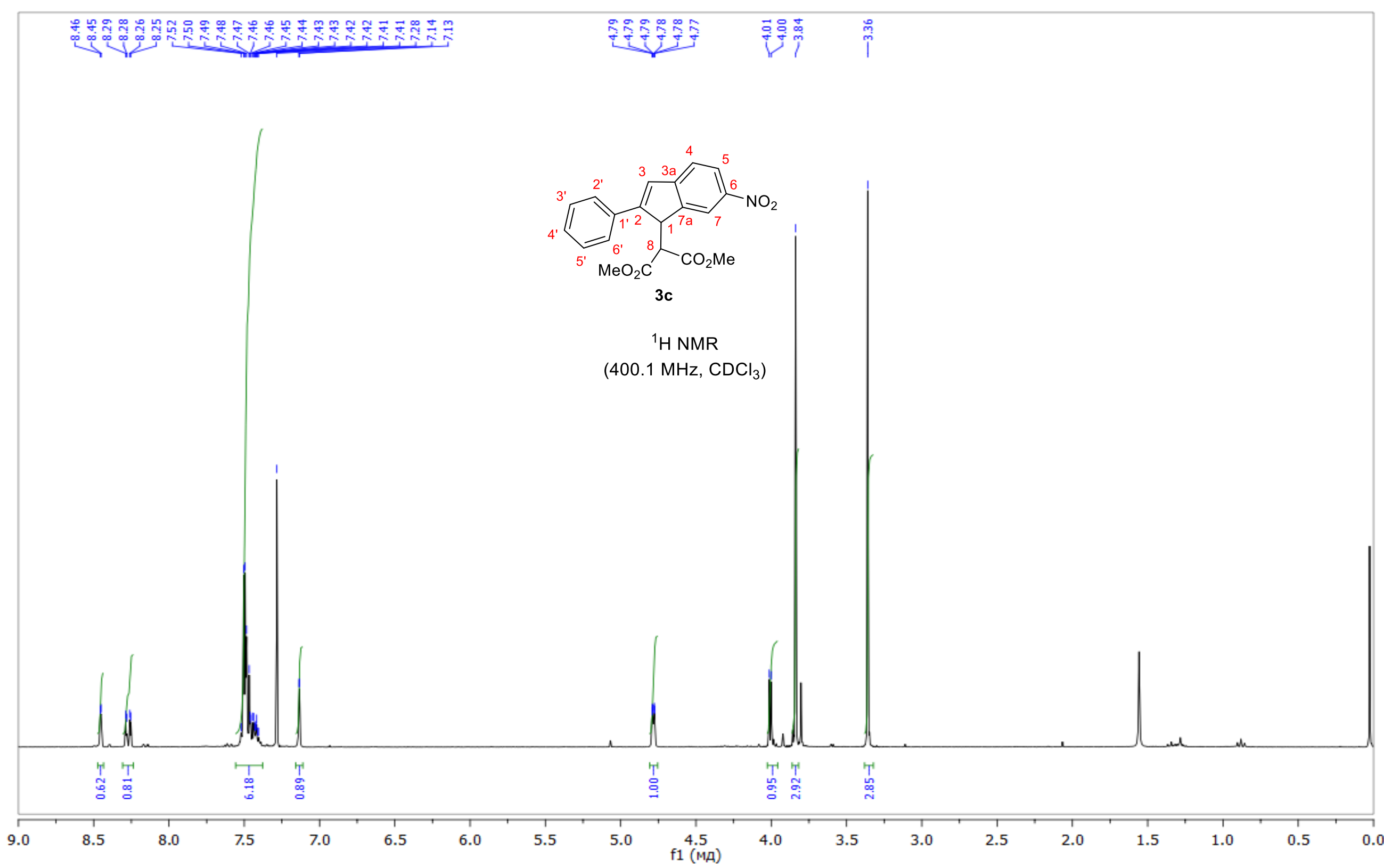




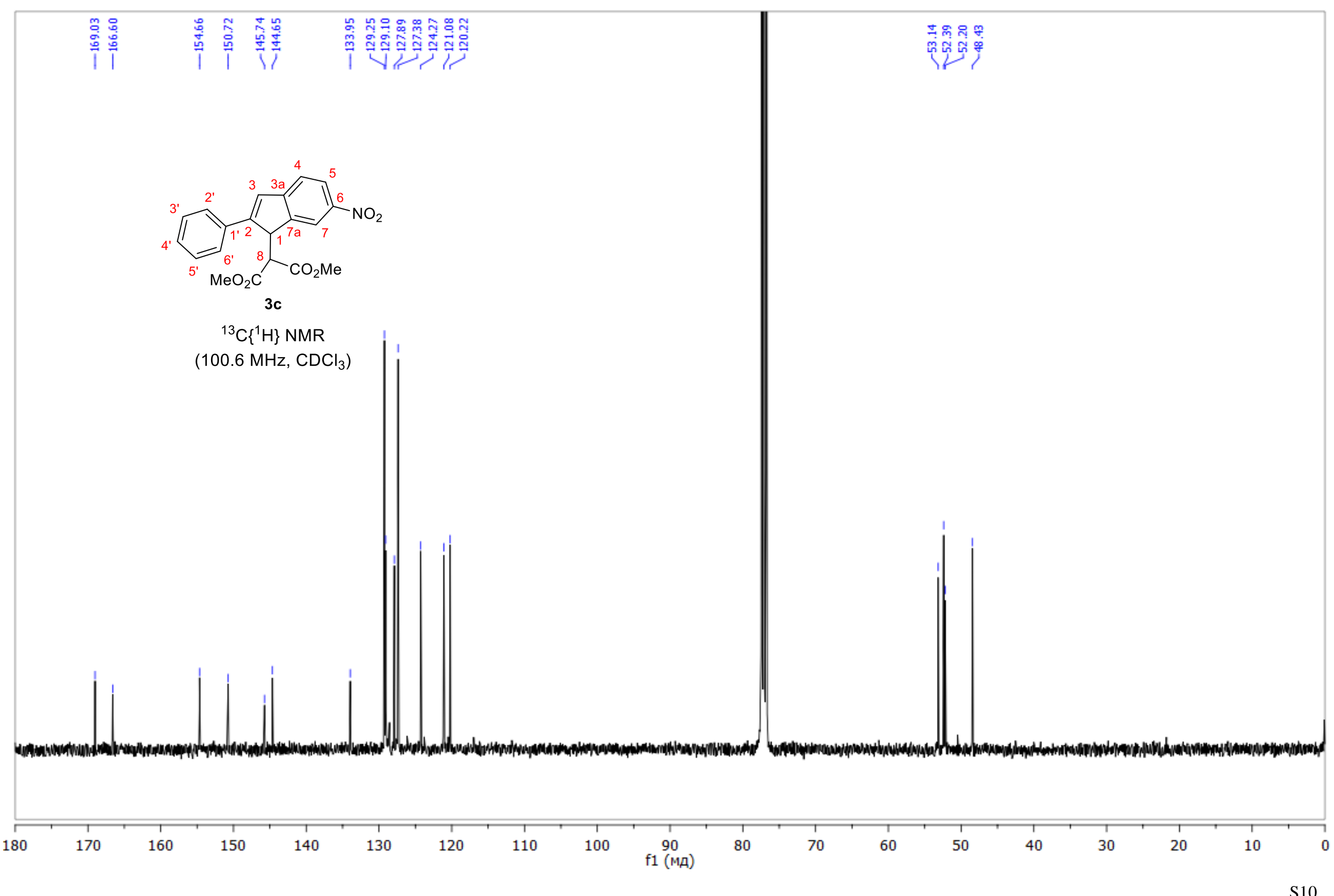




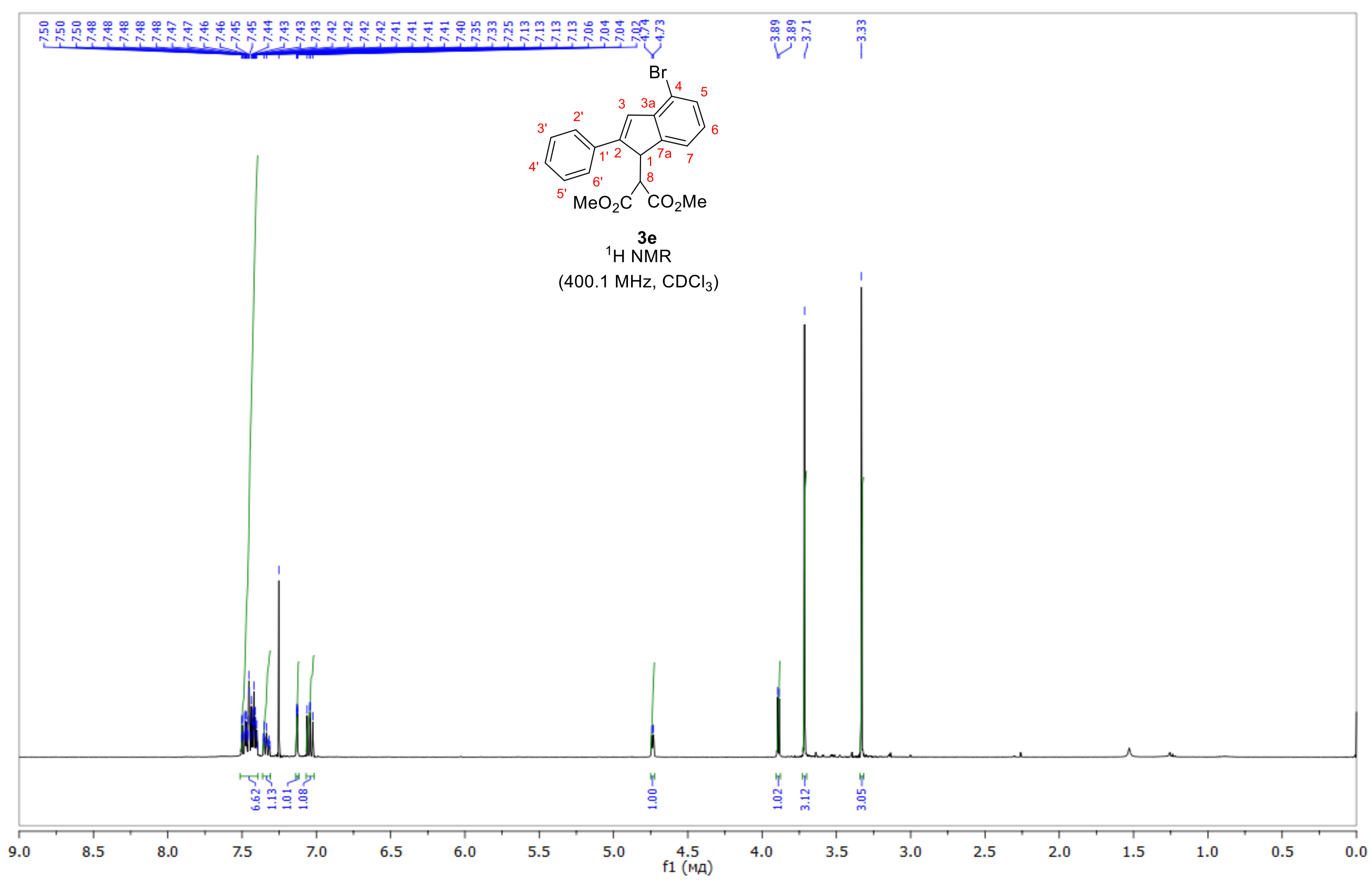




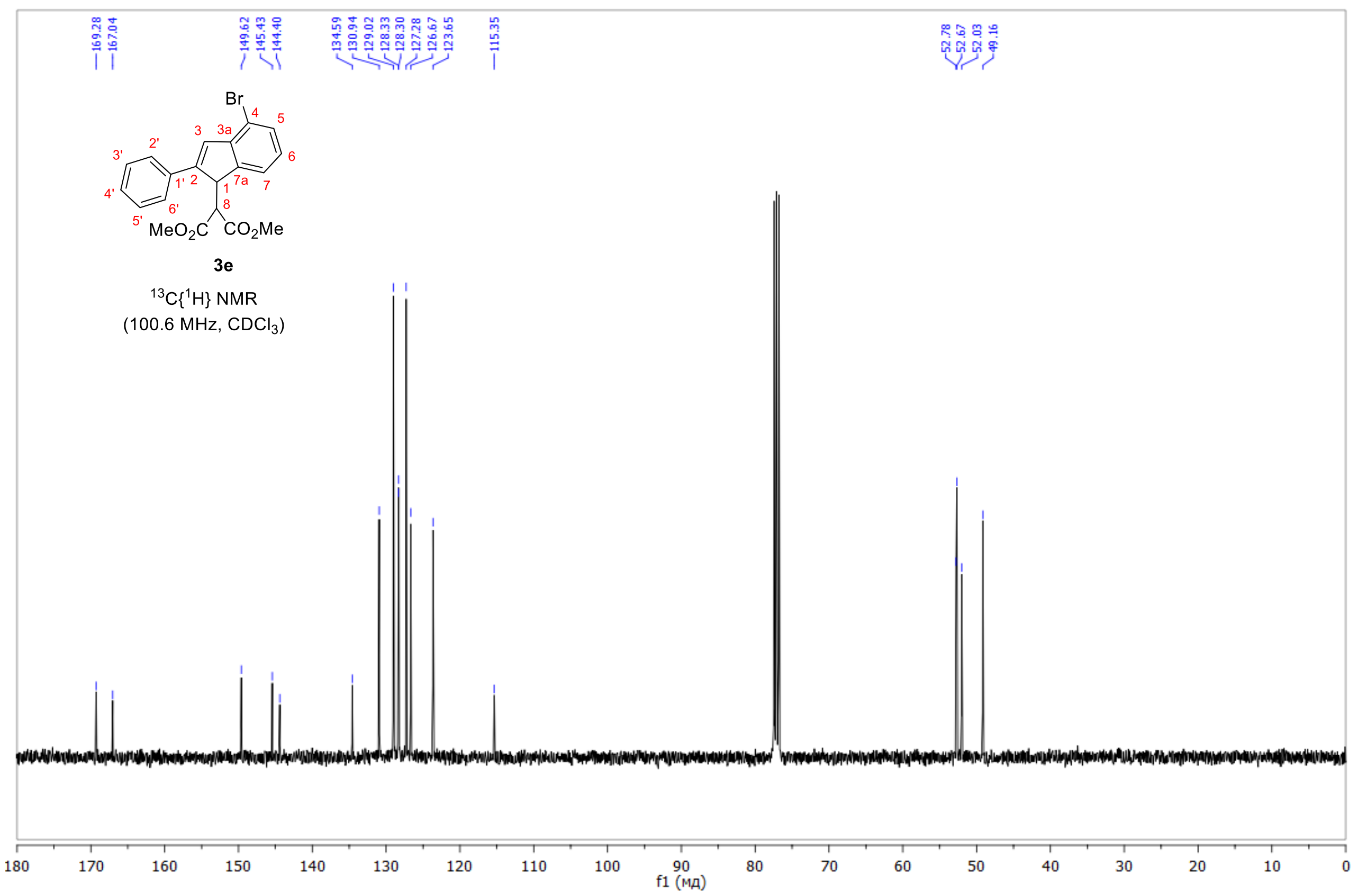




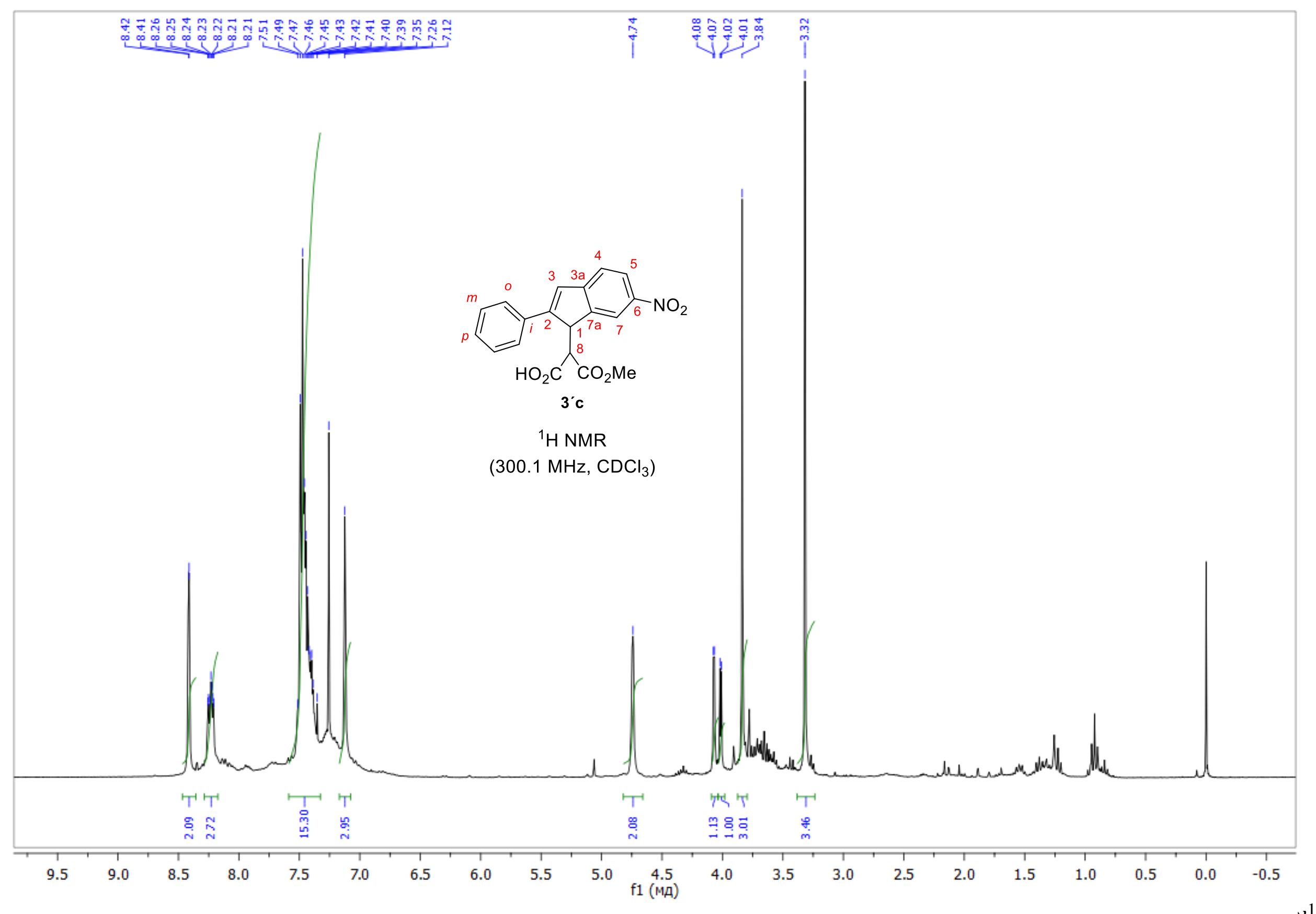




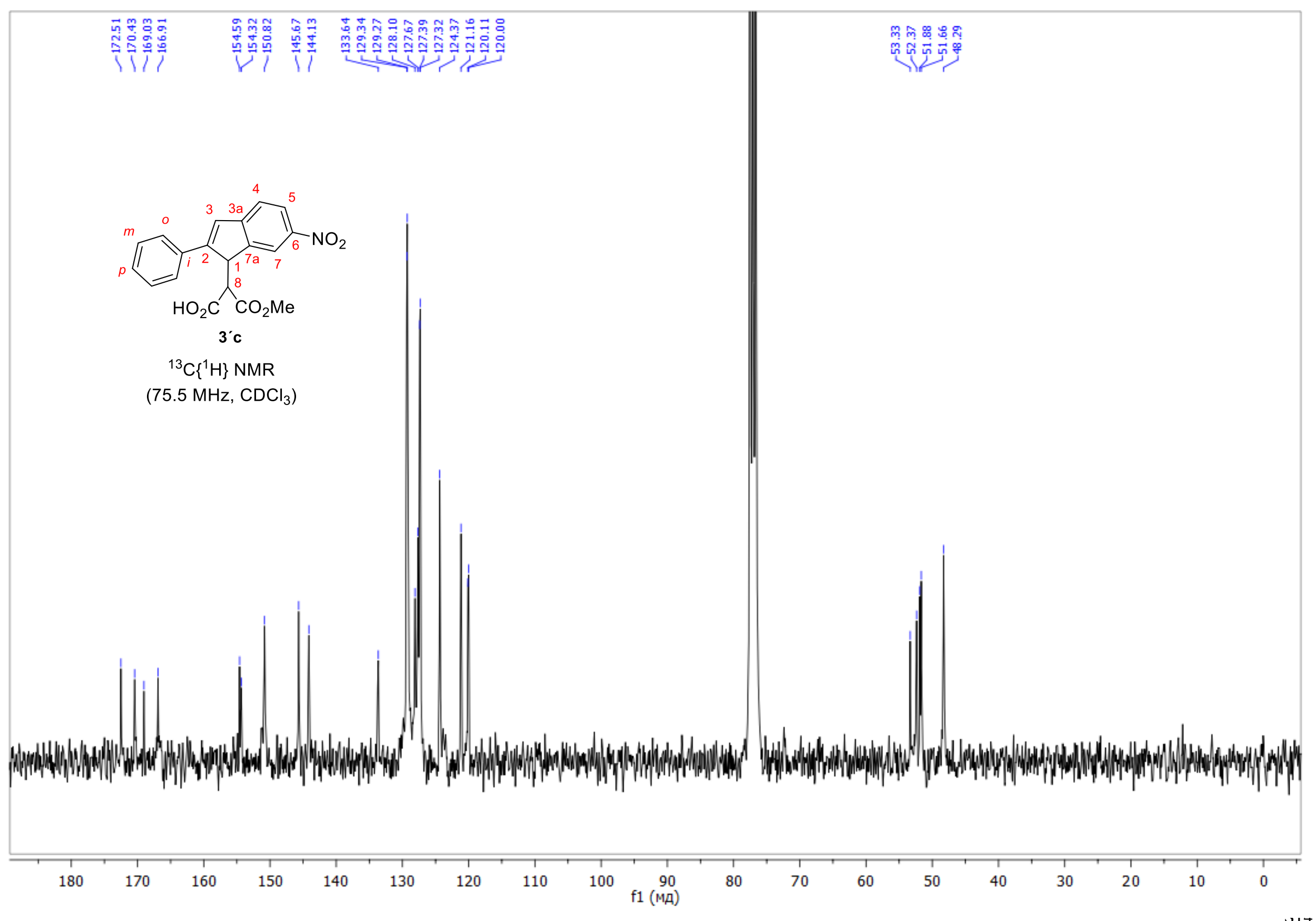




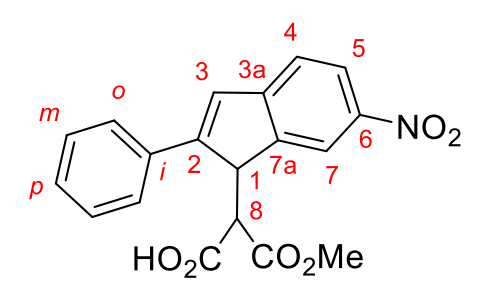

$\mathrm{HO}_{2} \mathrm{C} \quad \mathrm{CO}_{2} \mathrm{Me}$

3'c

${ }^{1} \mathrm{H},{ }^{1} \mathrm{H}-\mathrm{COSY}$

(300.1 MHz, $\mathrm{CDCl}_{3}$ )
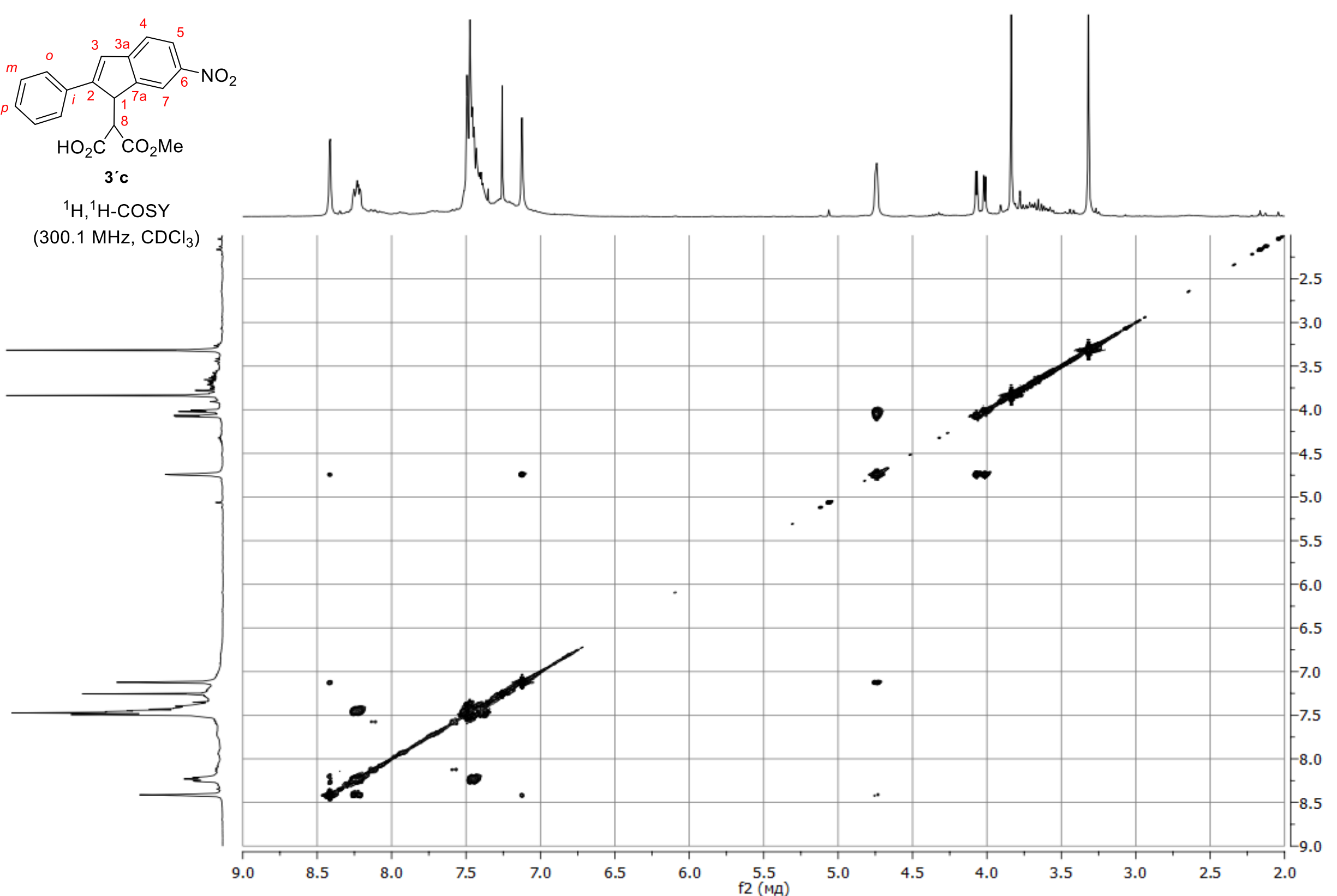

$\underset{4}{\stackrel{\frac{\pi}{2}}{5}}$ 


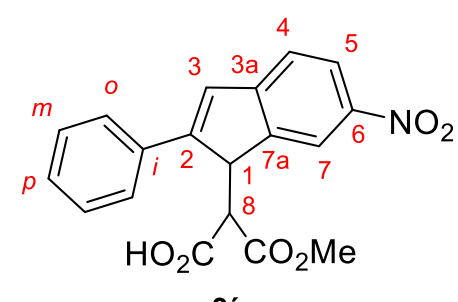

3'c

${ }^{1} \mathrm{H},{ }^{1} \mathrm{H}$-NOESY

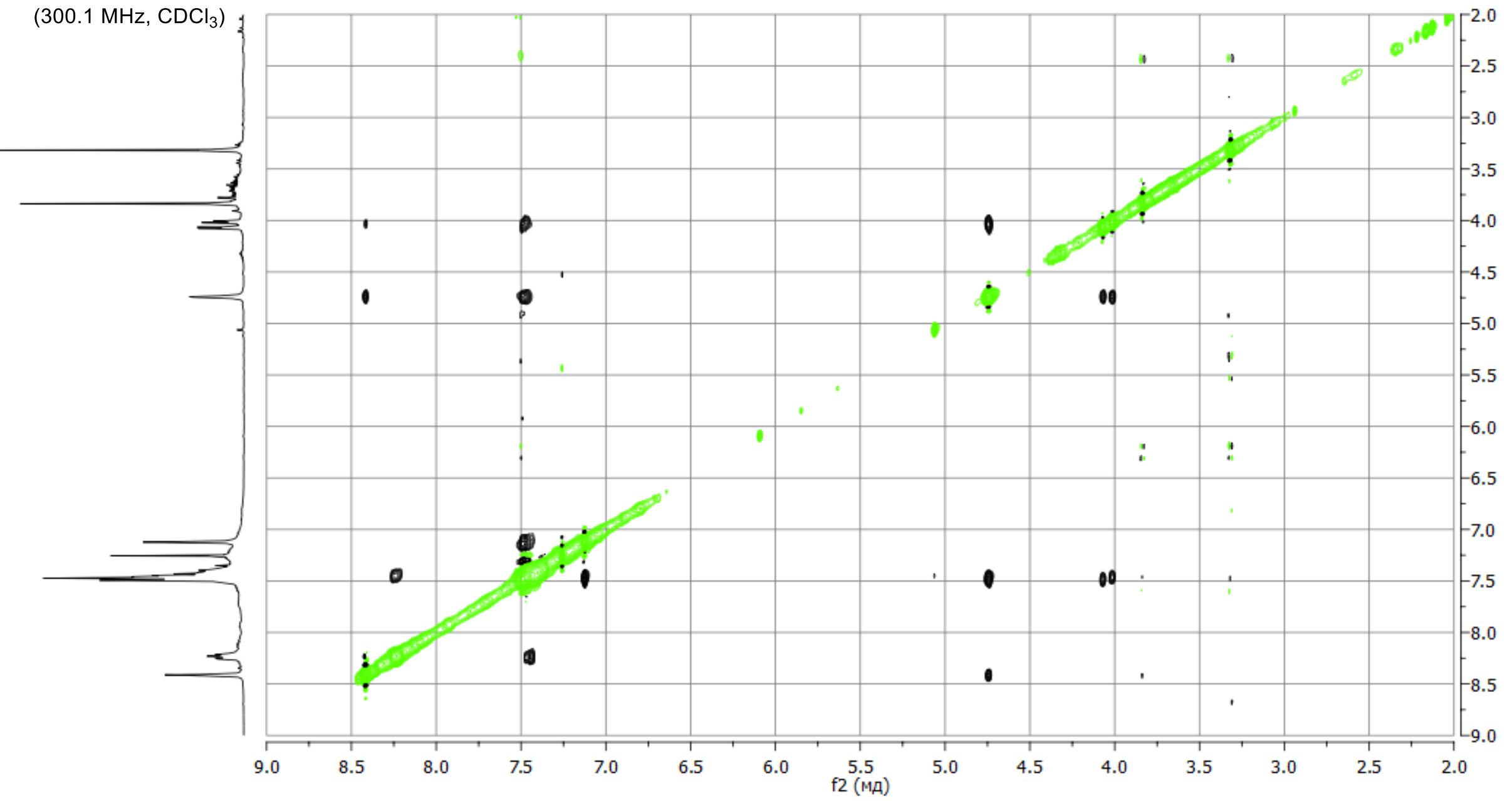


<smiles>COC(=O)C(C(=O)O)C1C(c2ccccc2)=Cc2ccc([N+](=O)[O-])cc21</smiles>

$$
\begin{gathered}
{ }^{1} \mathrm{H},{ }^{13} \mathrm{C}-\mathrm{HSQC} \\
\left({ }^{1} \mathrm{H}: 300.1 \mathrm{MHz},\right. \\
{ }^{13} \mathrm{C}: 75.5 \mathrm{MHz}
\end{gathered}
$$

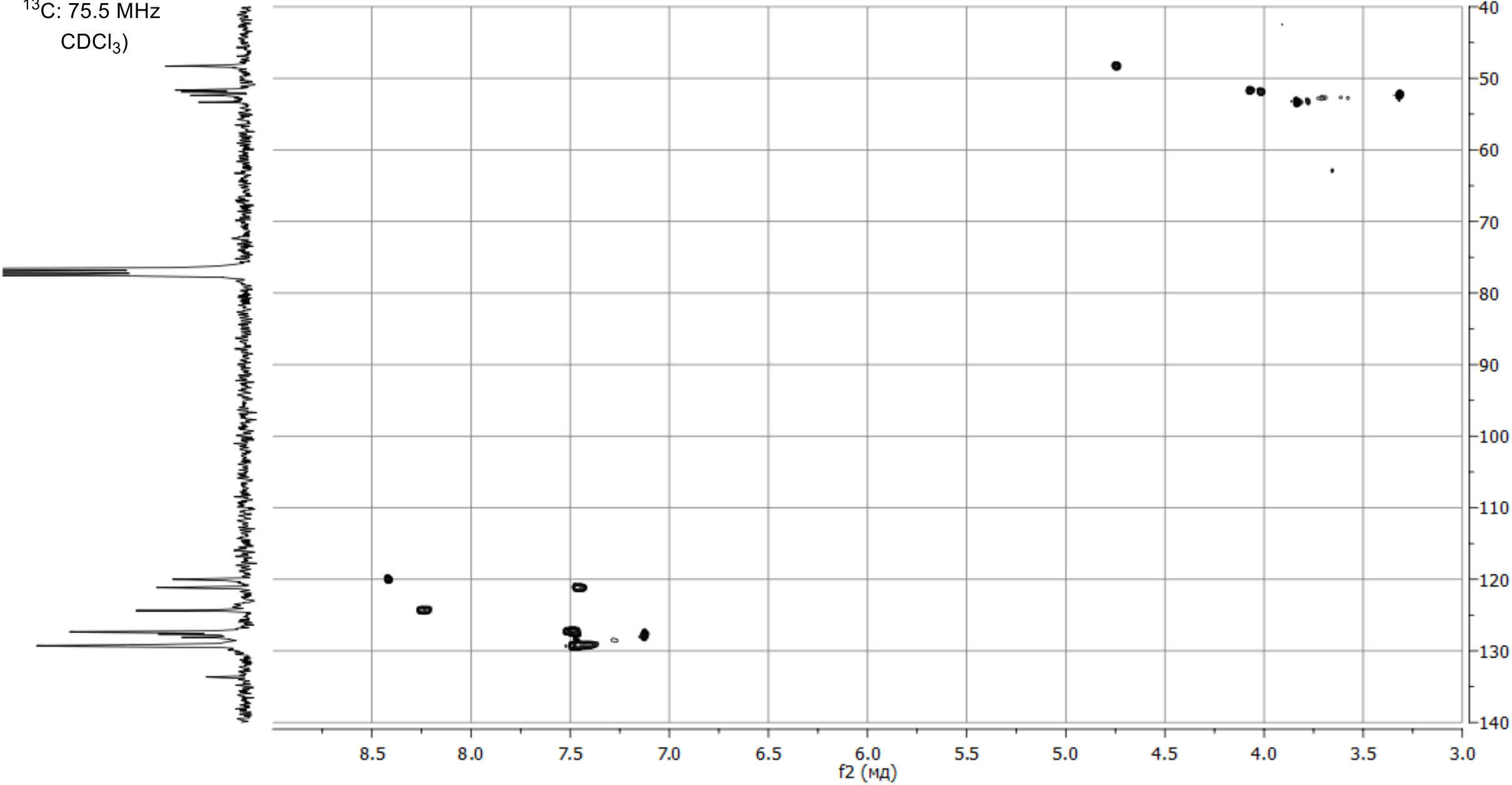

S17 


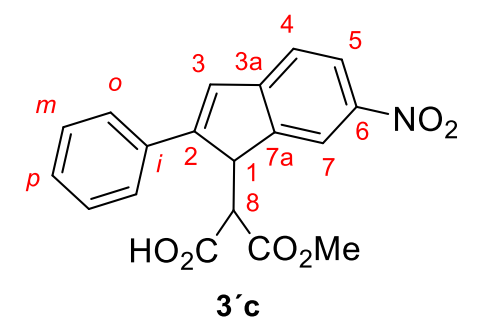

${ }^{1} \mathrm{H},{ }^{13} \mathrm{C}-\mathrm{HMBC}$

$\left({ }^{1} \mathrm{H}: 300.1 \mathrm{MHz}\right.$,

${ }^{13} \mathrm{C}: 75.5 \mathrm{MHz}$

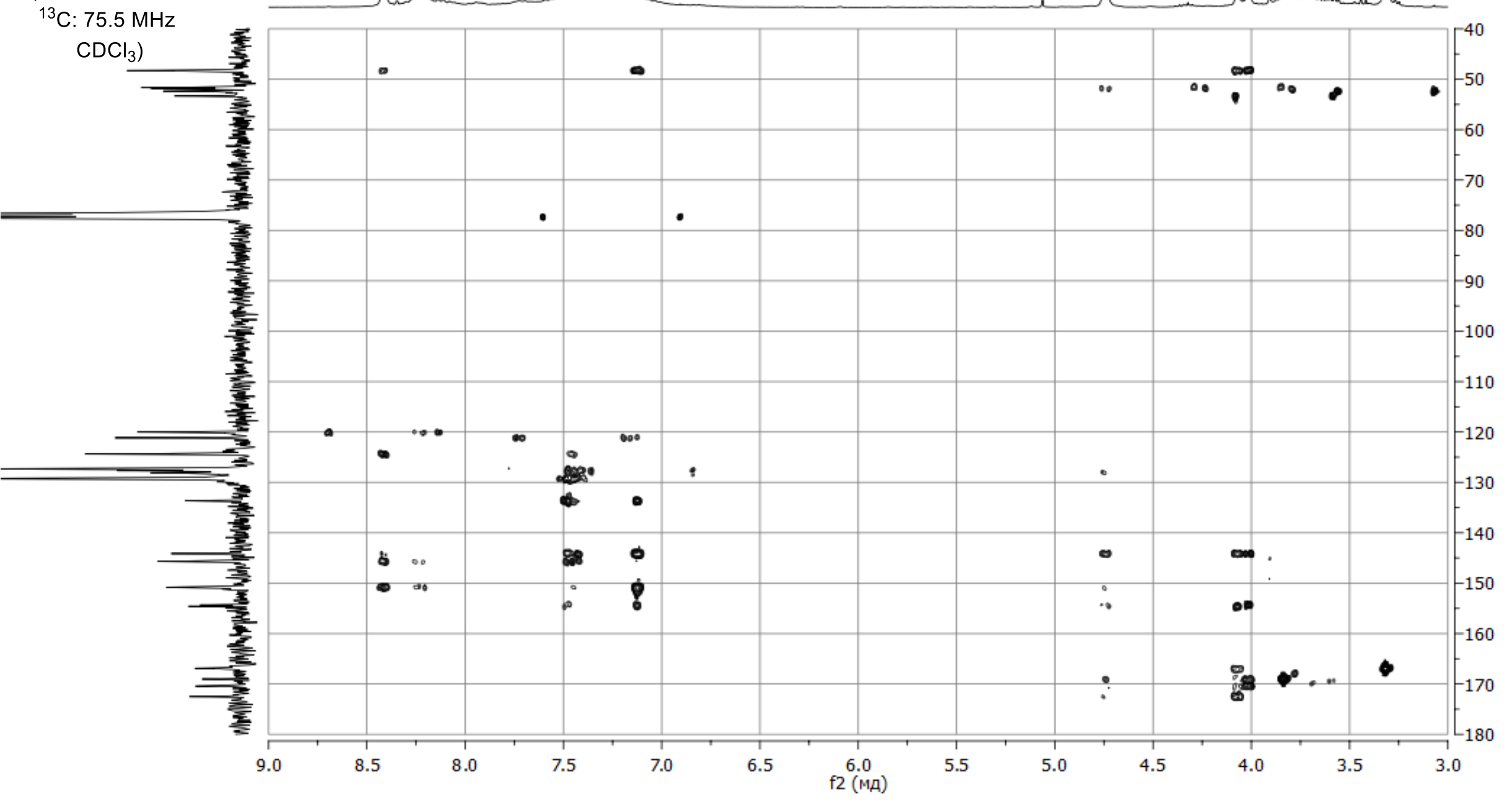




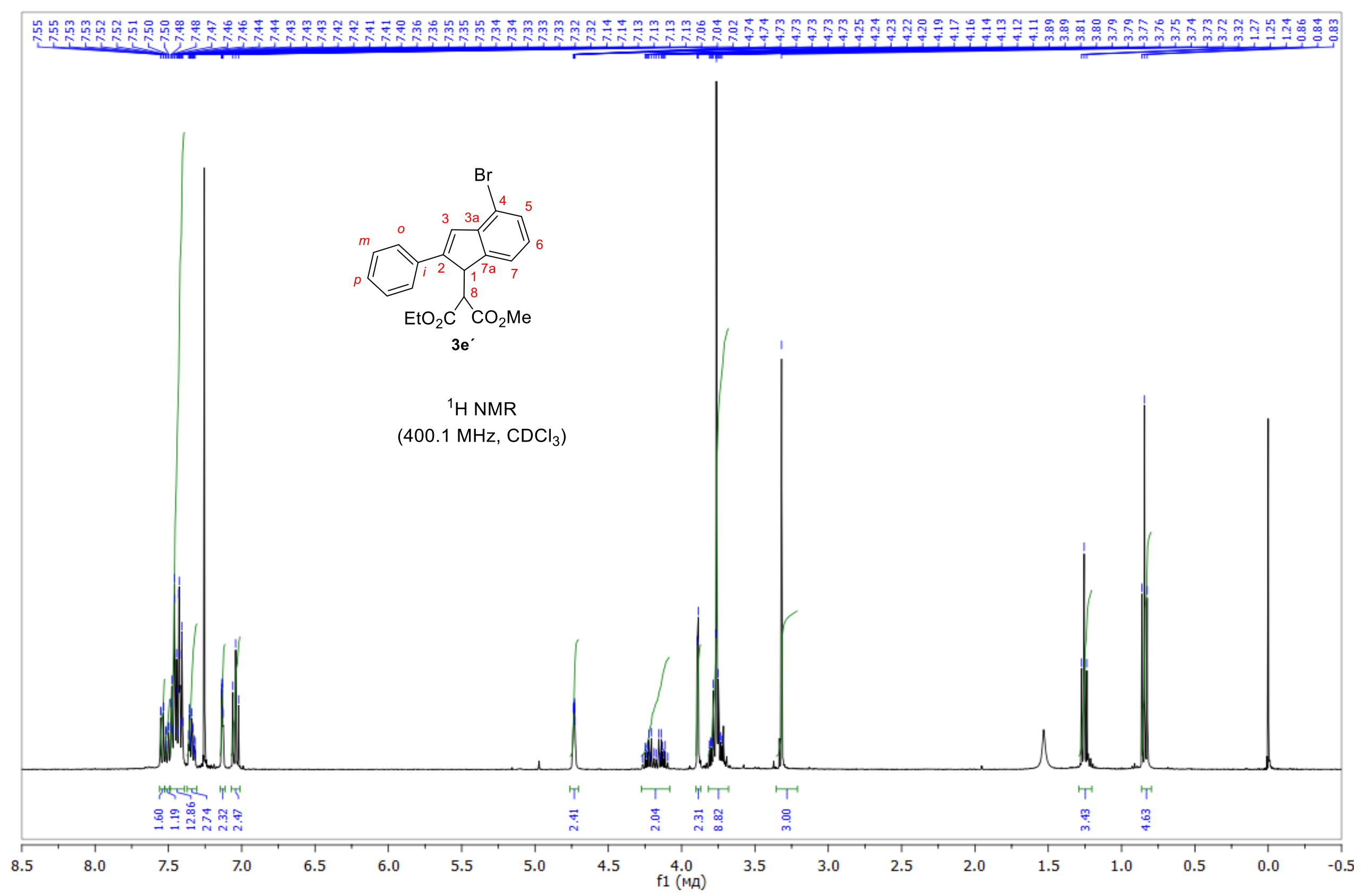




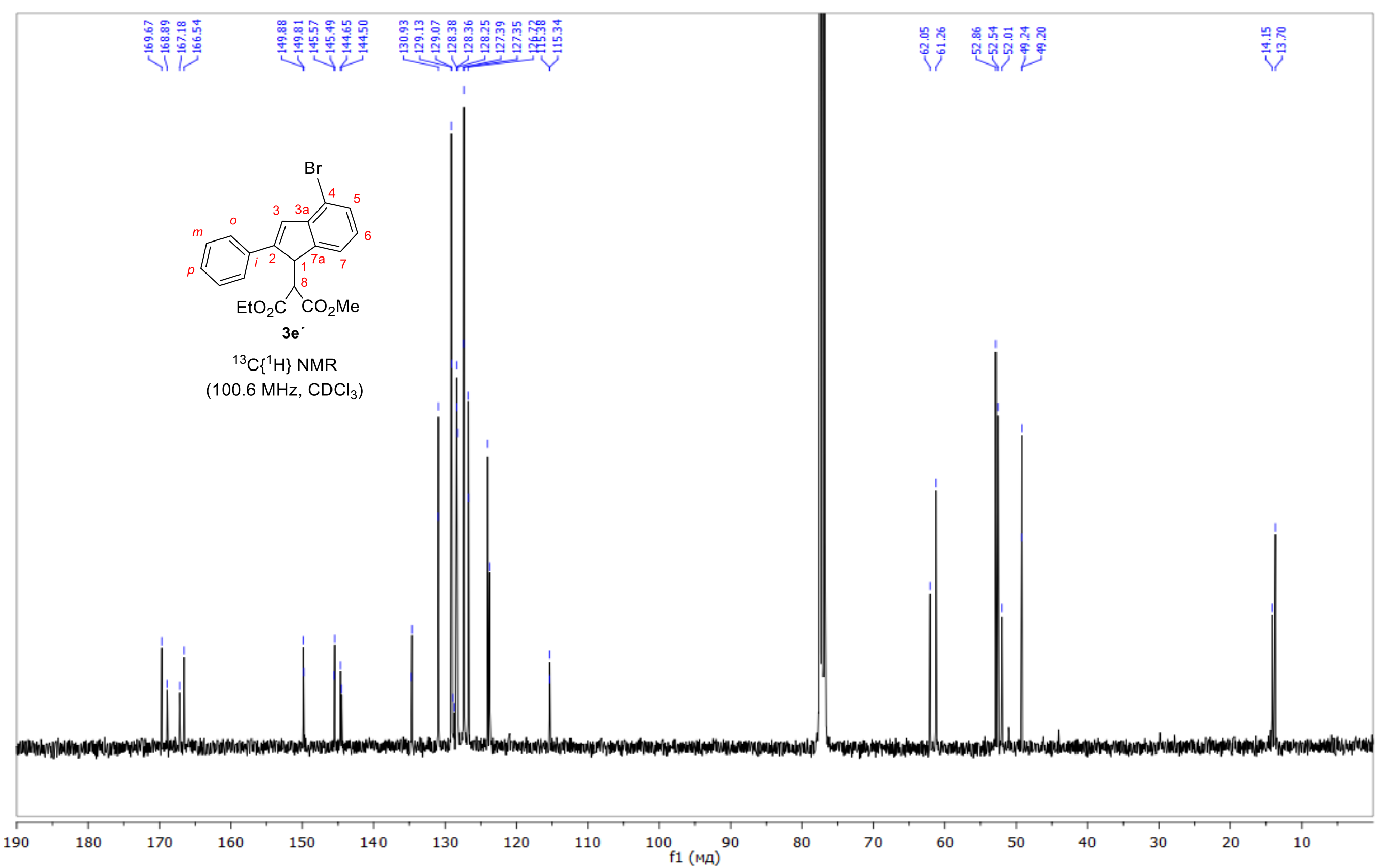




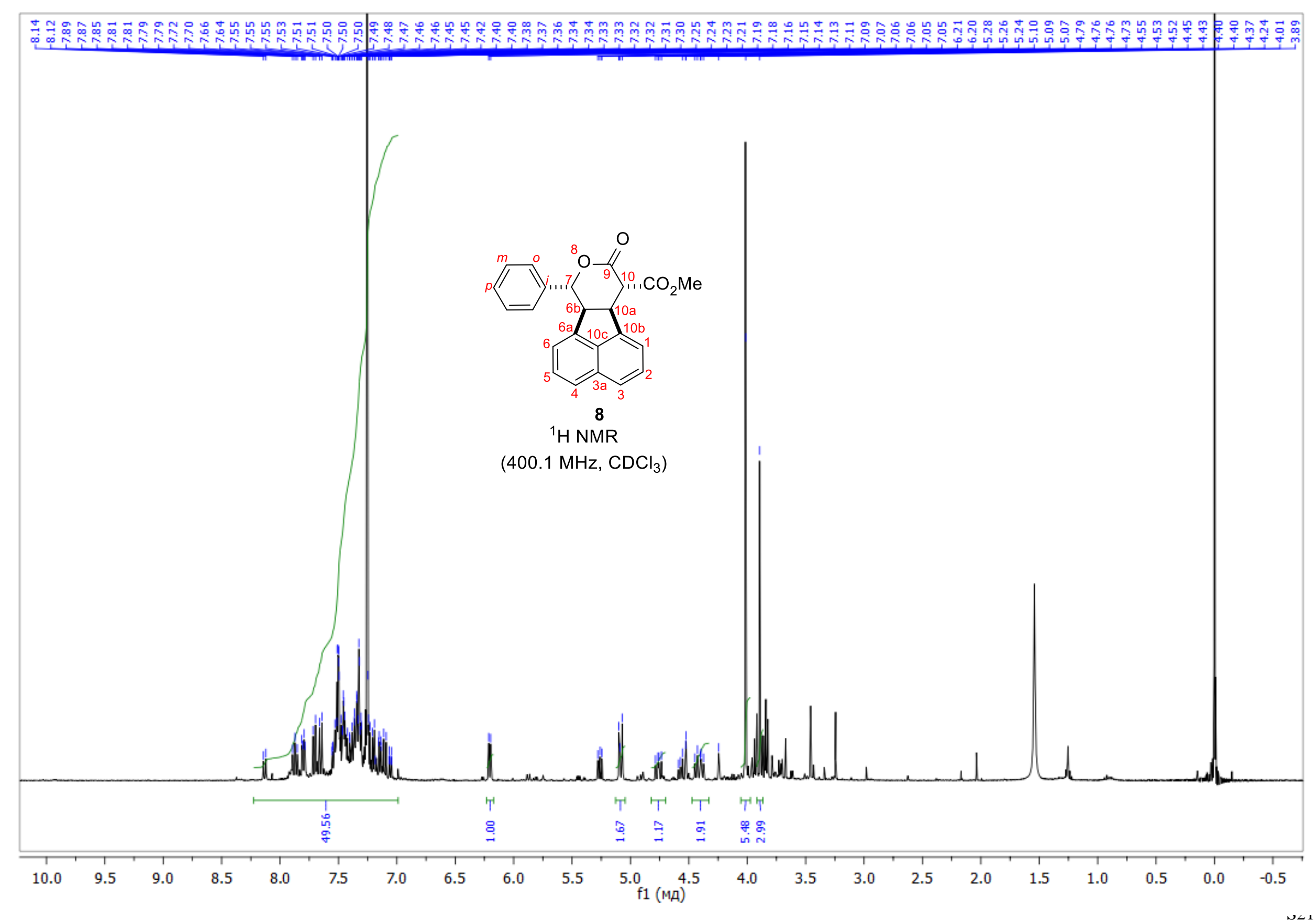




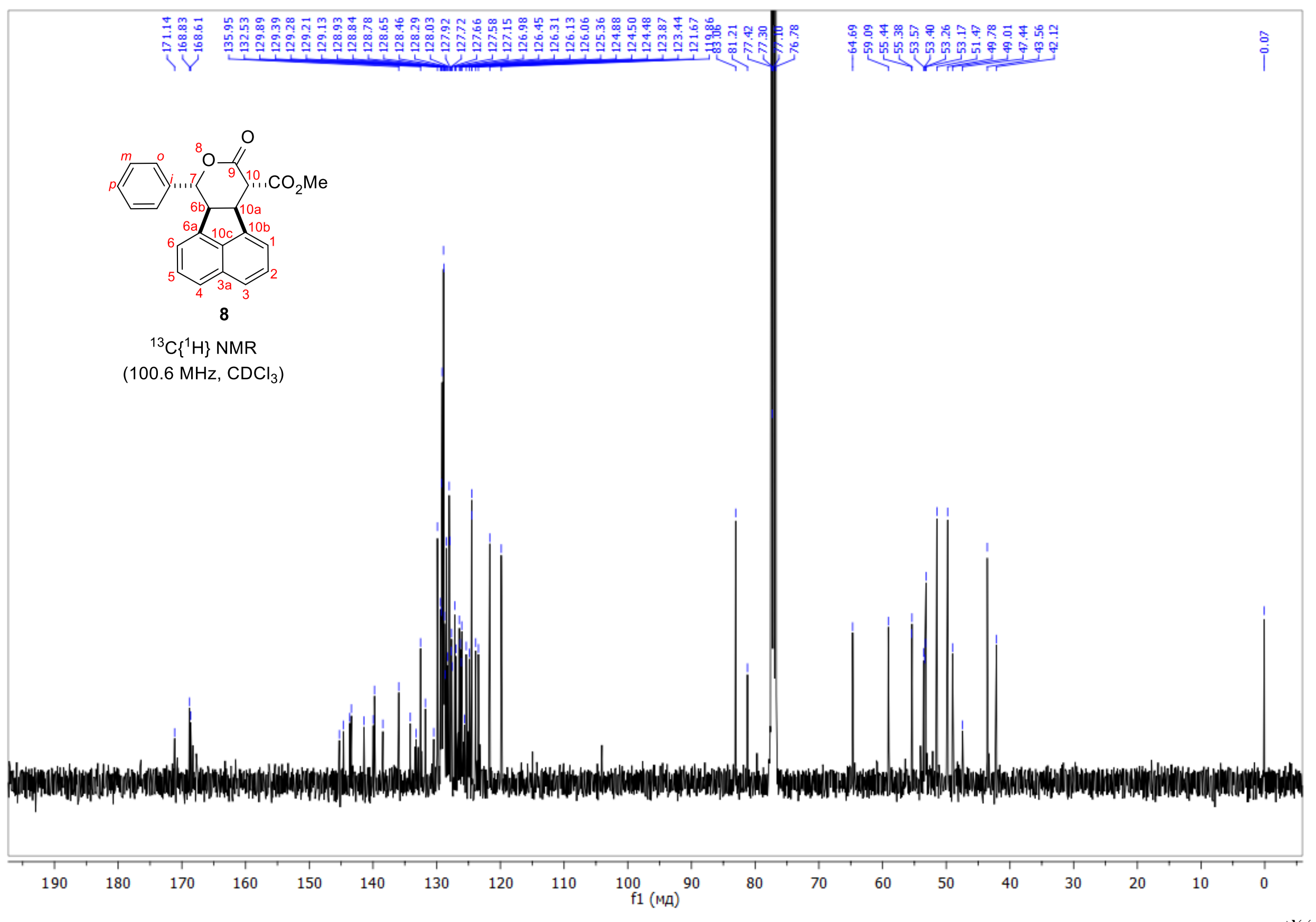




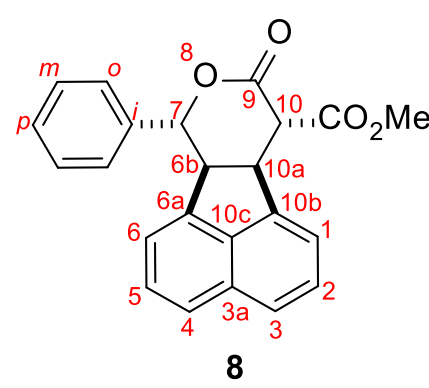

${ }^{1} \mathrm{H},{ }^{1} \mathrm{H}-\mathrm{COSY}$

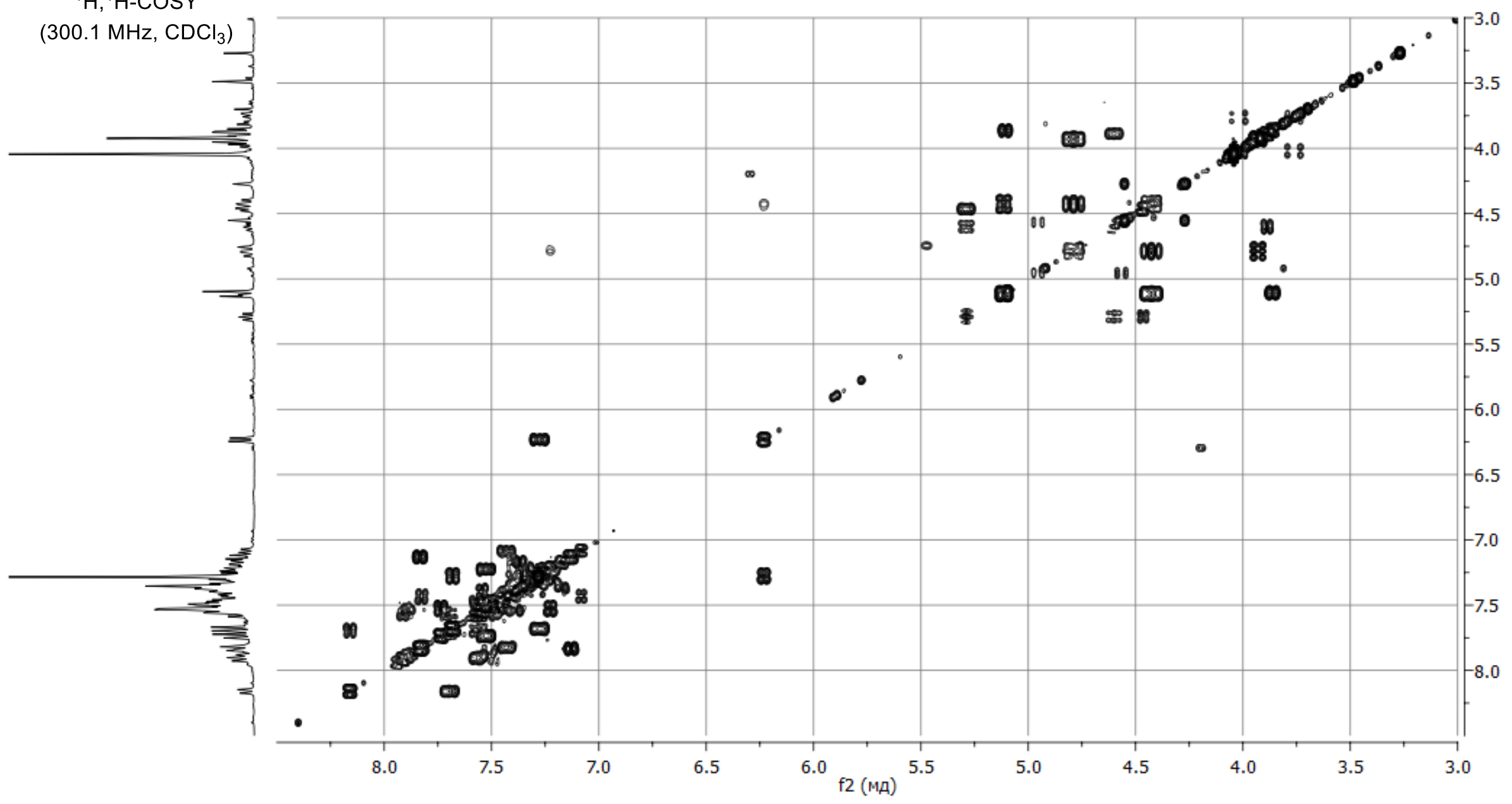




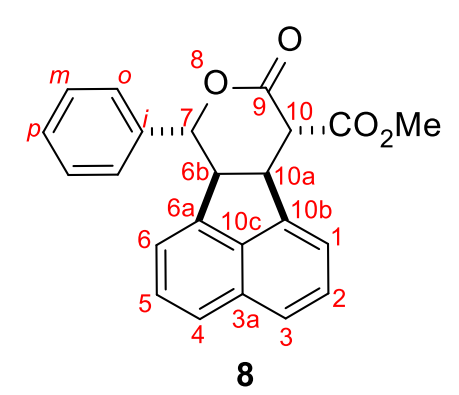

${ }^{1} \mathrm{H},{ }^{1} \mathrm{H}$-NOESY

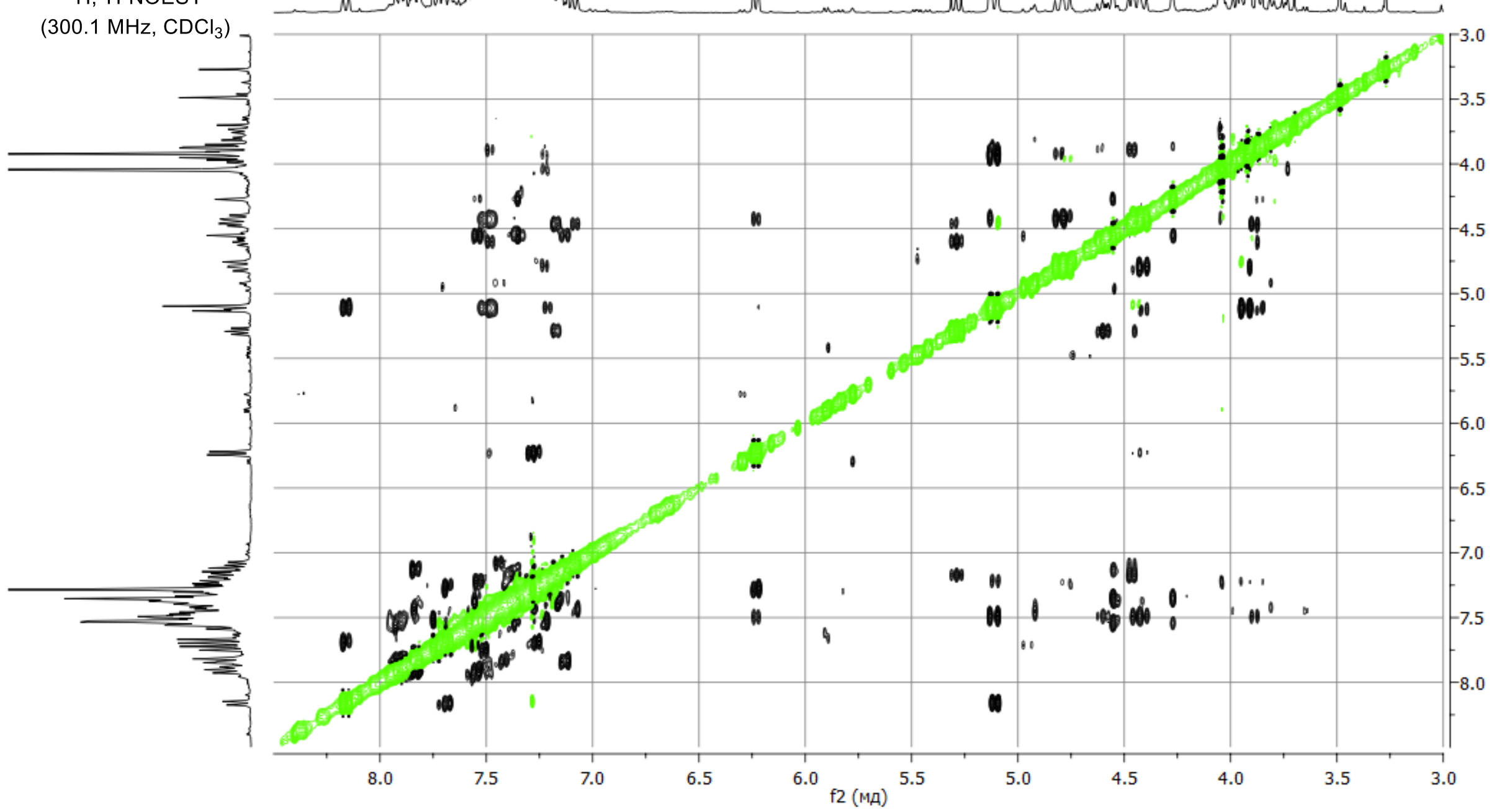




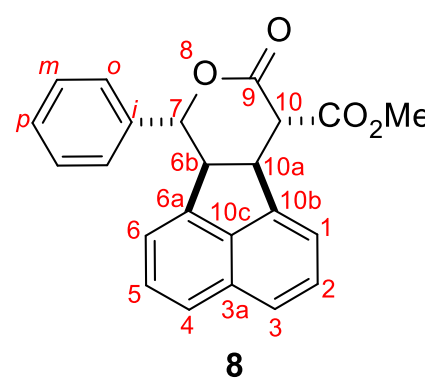

${ }^{1} \mathrm{H},{ }^{13} \mathrm{C}$-edited-HSQC-SI $\left({ }^{1} \mathrm{H}: 300.1 \mathrm{MHz}\right.$,

${ }^{13} \mathrm{C}: 75.5 \mathrm{MHz}$
$\left.\mathrm{CDCl}_{3}\right)$
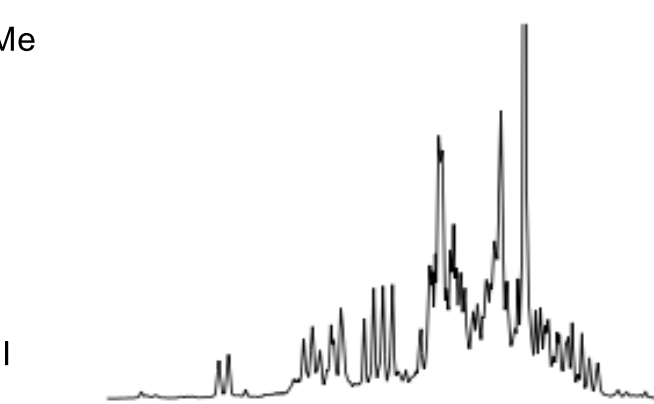

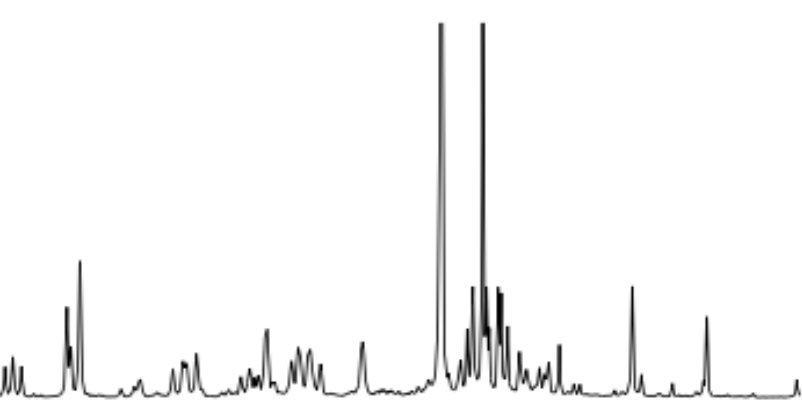

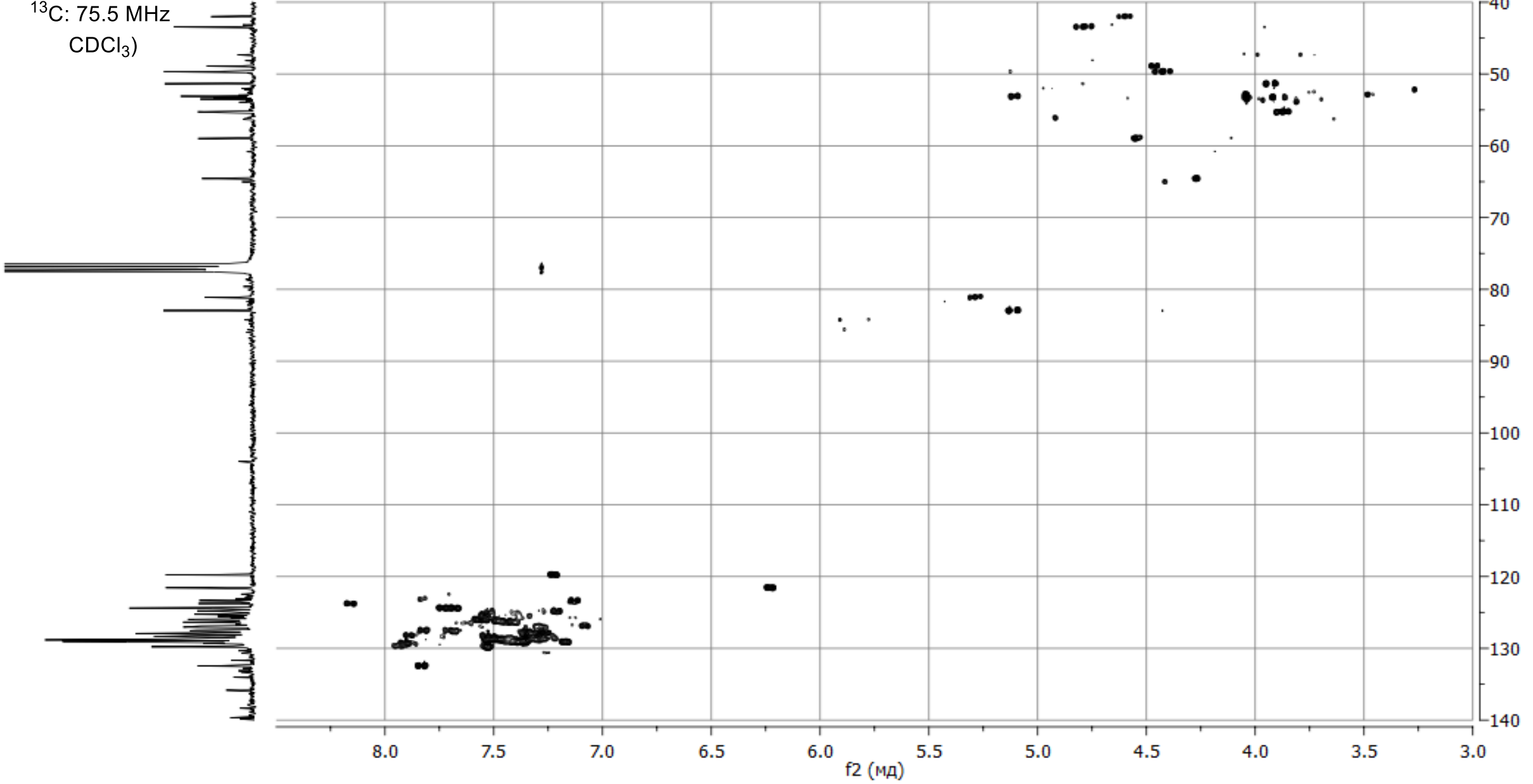




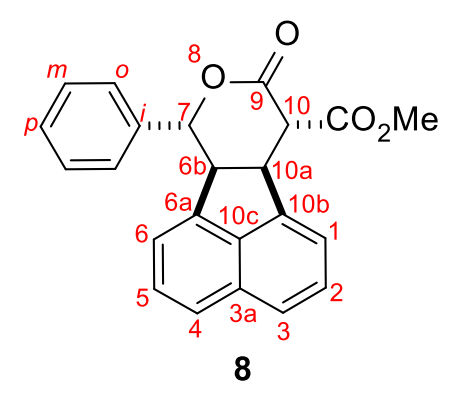

${ }^{1} \mathrm{H},{ }^{13} \mathrm{C}-\mathrm{HMBC}$ ( ${ }^{1} \mathrm{H}: 300.1 \mathrm{MHz}$, ${ }^{13} \mathrm{C}: 75.5 \mathrm{MHz}$ $\mathrm{CDCl}_{3}$ )
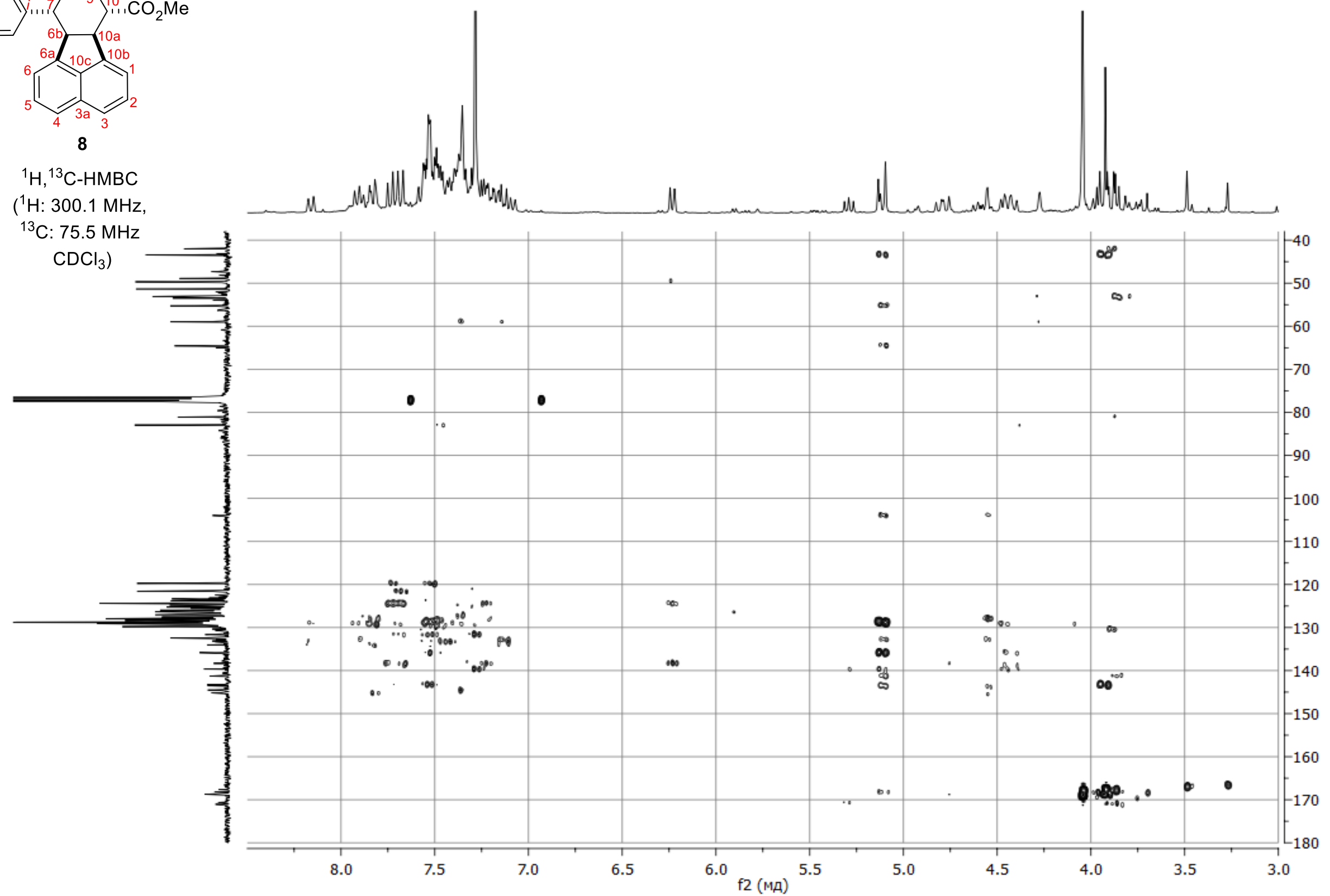


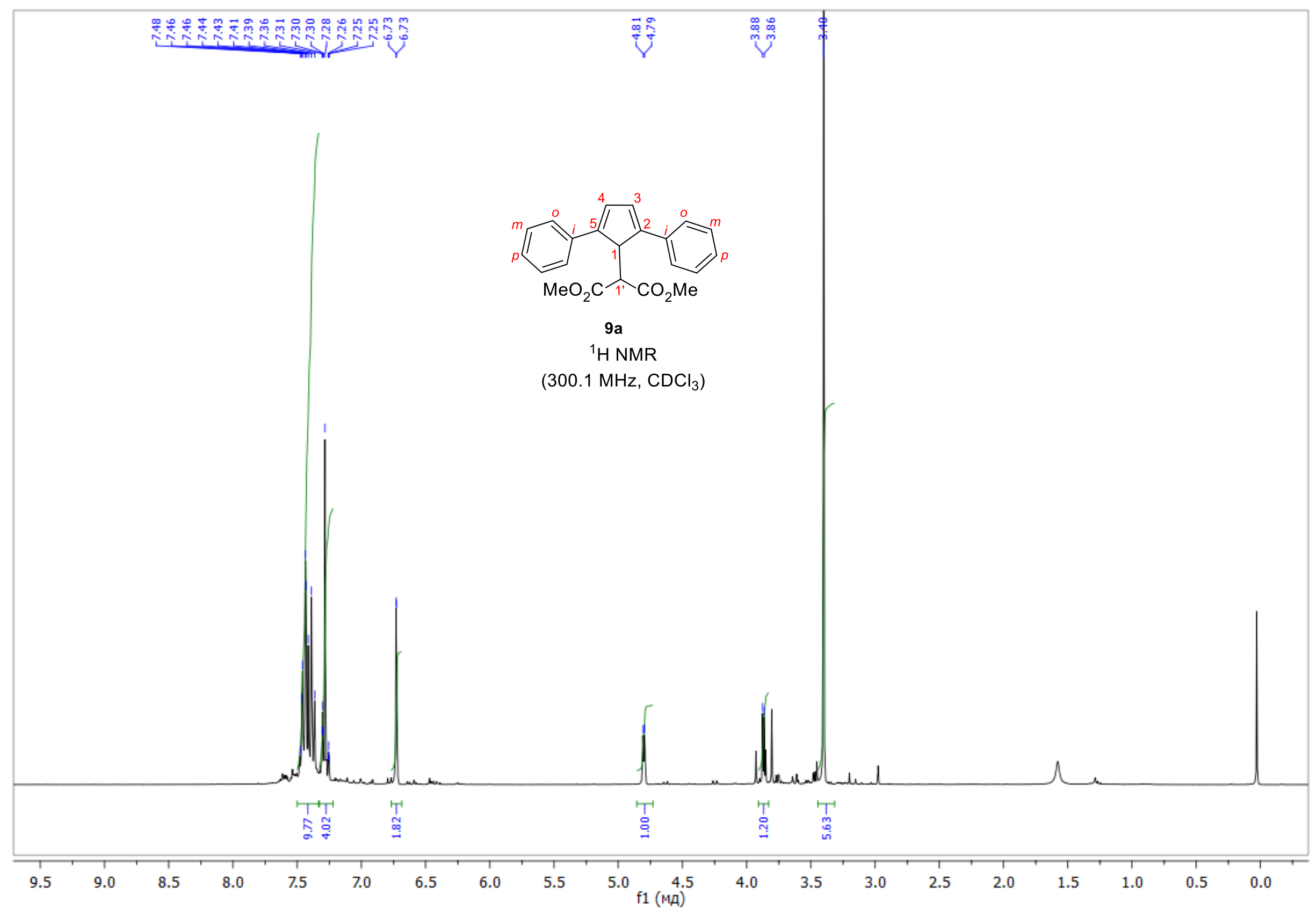




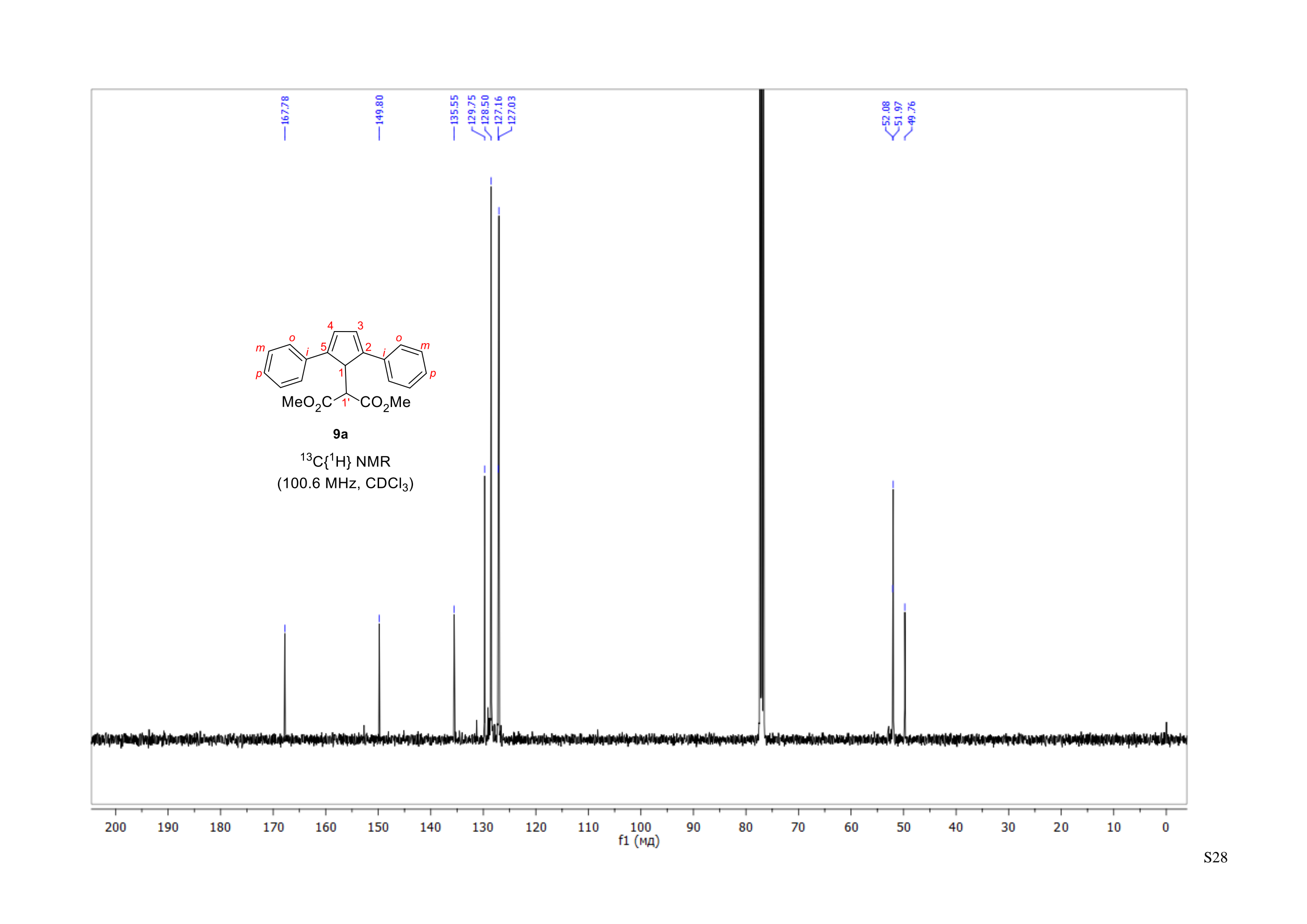




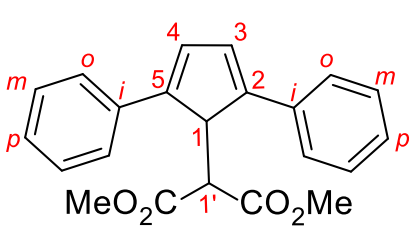

$9 a$

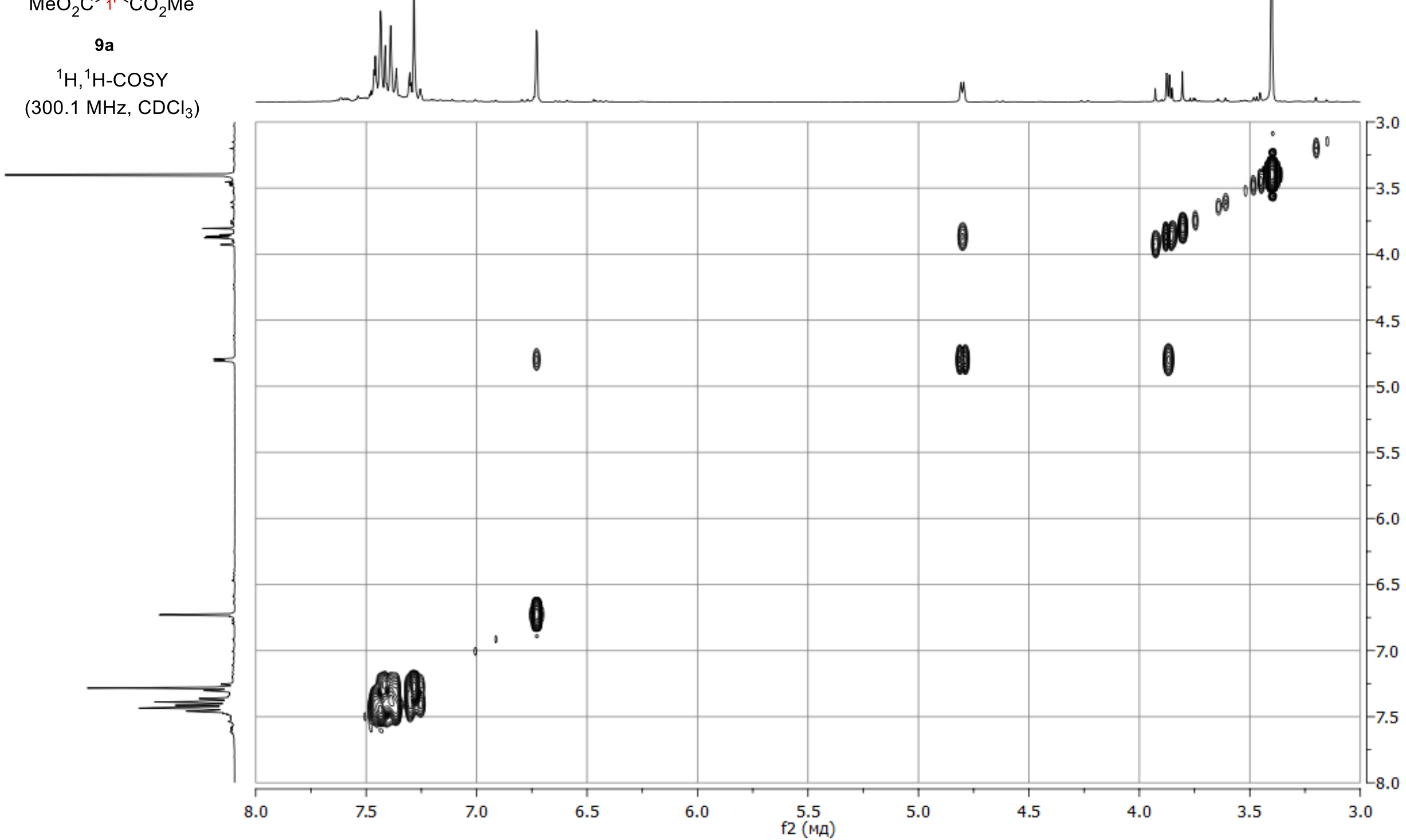

S29 


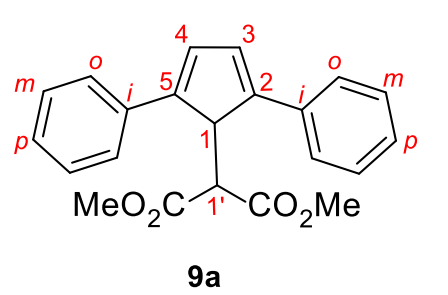

${ }^{1} \mathrm{H},{ }^{1} \mathrm{H}-\mathrm{NOESY}$

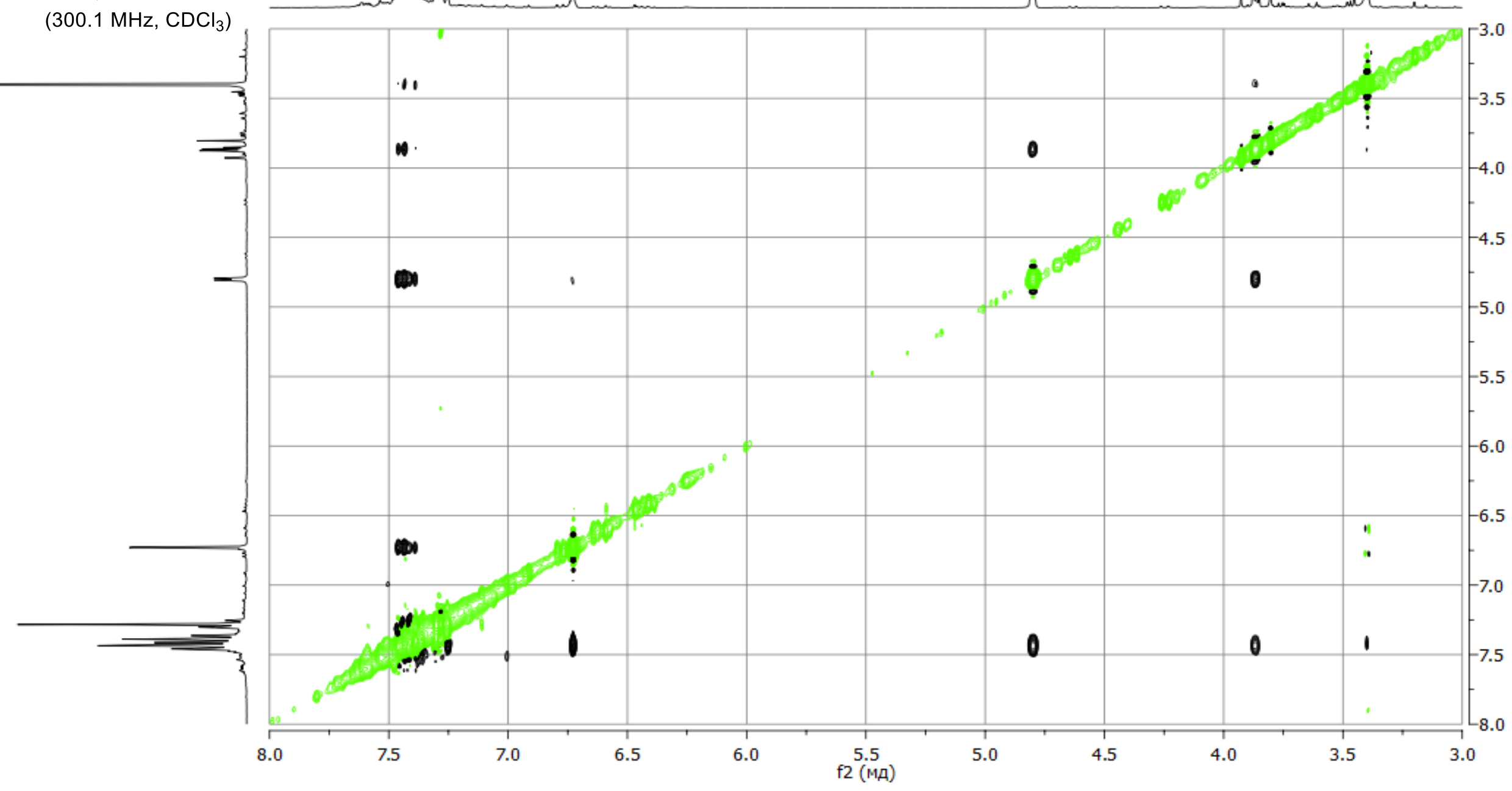




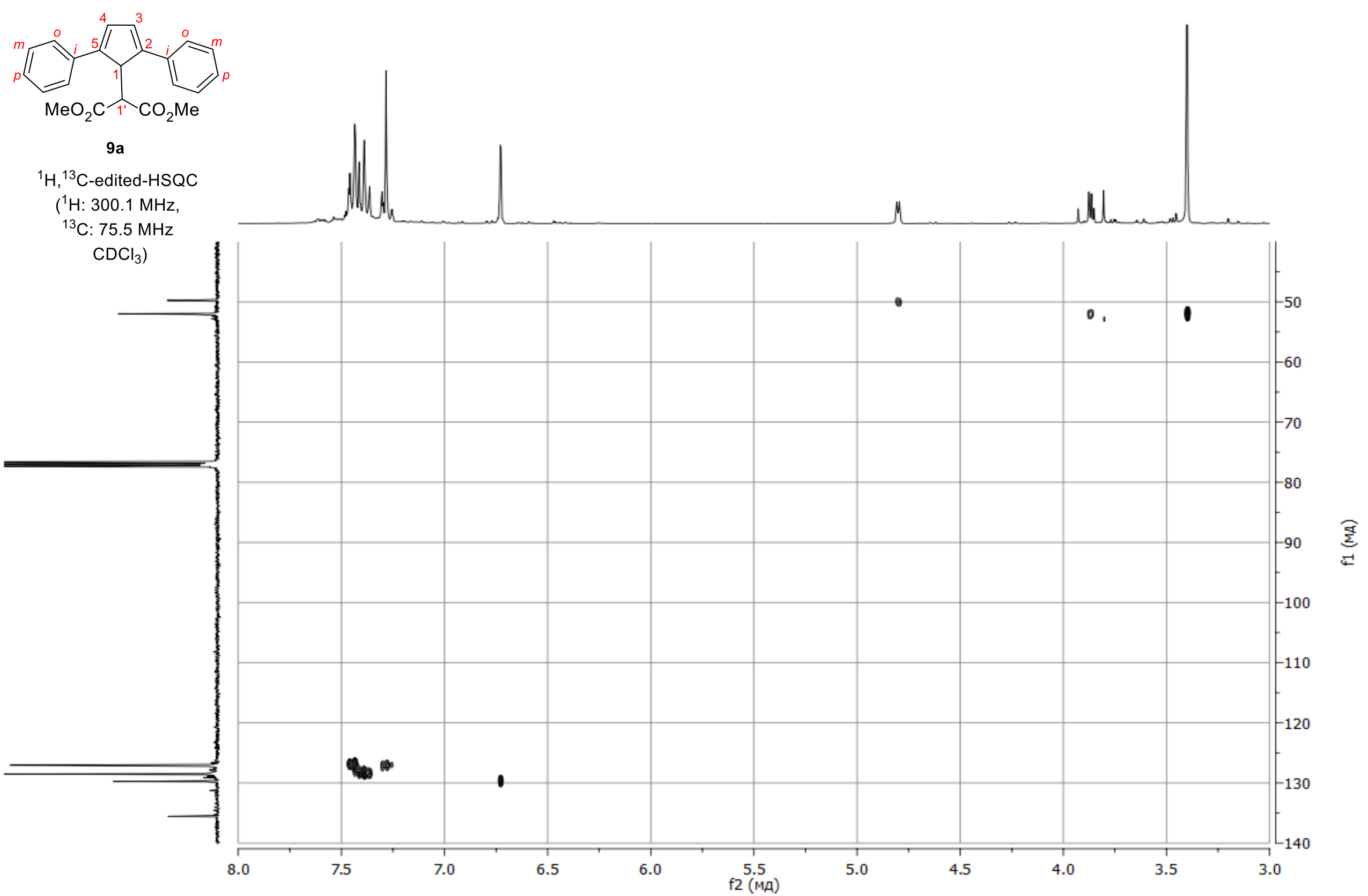




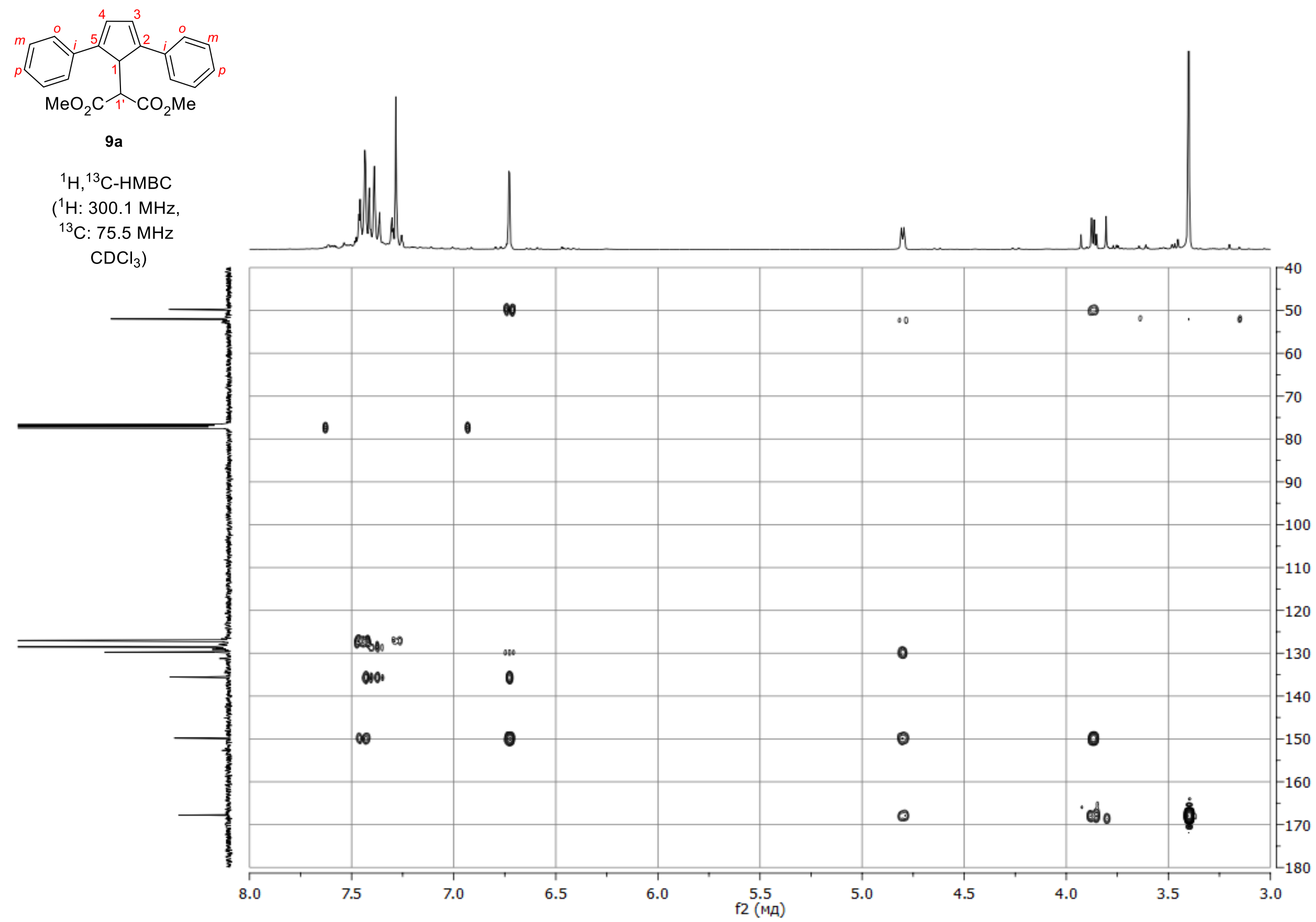

$\sum_{\vec{L}}^{\frac{\pi}{2}}$ 


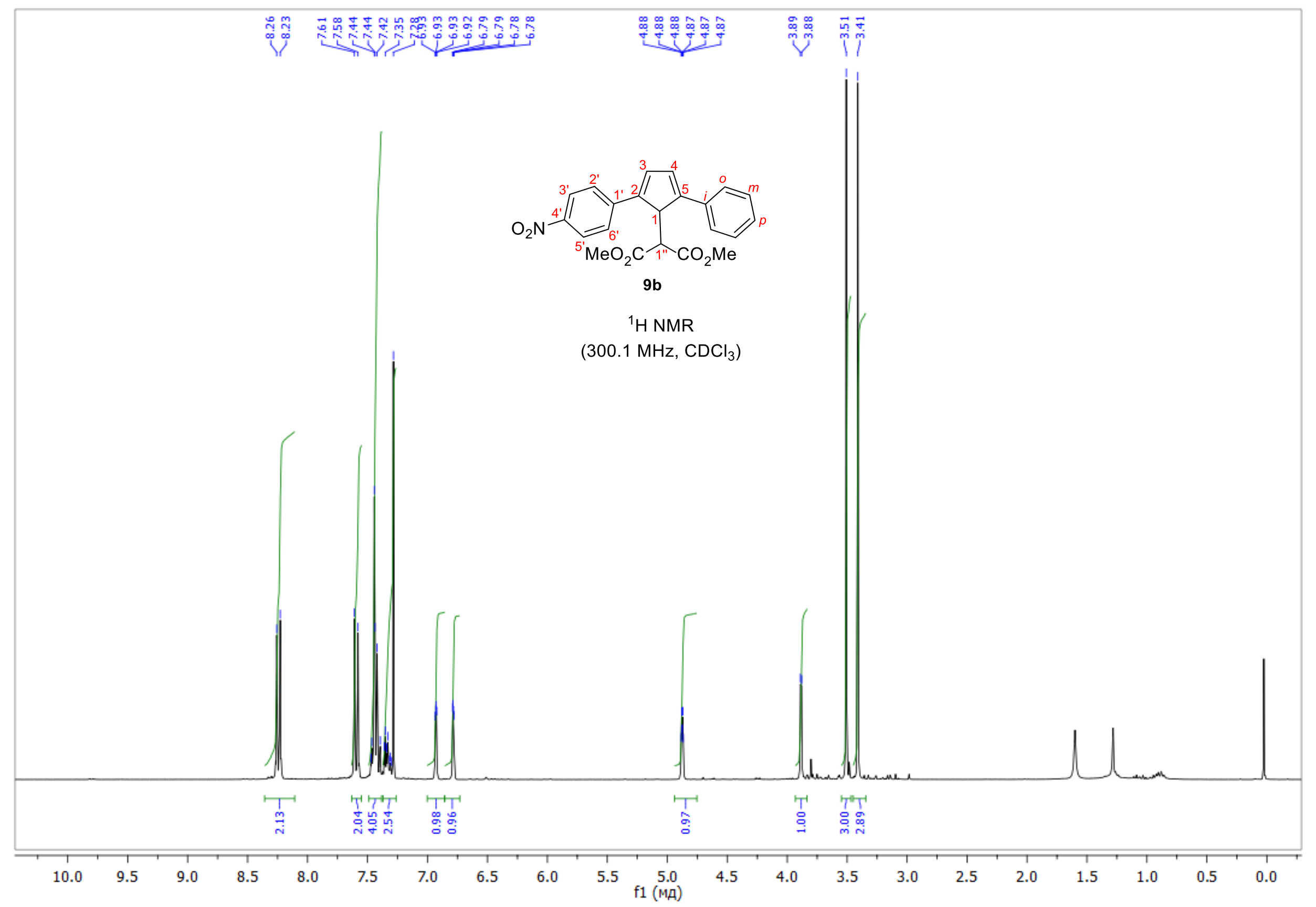




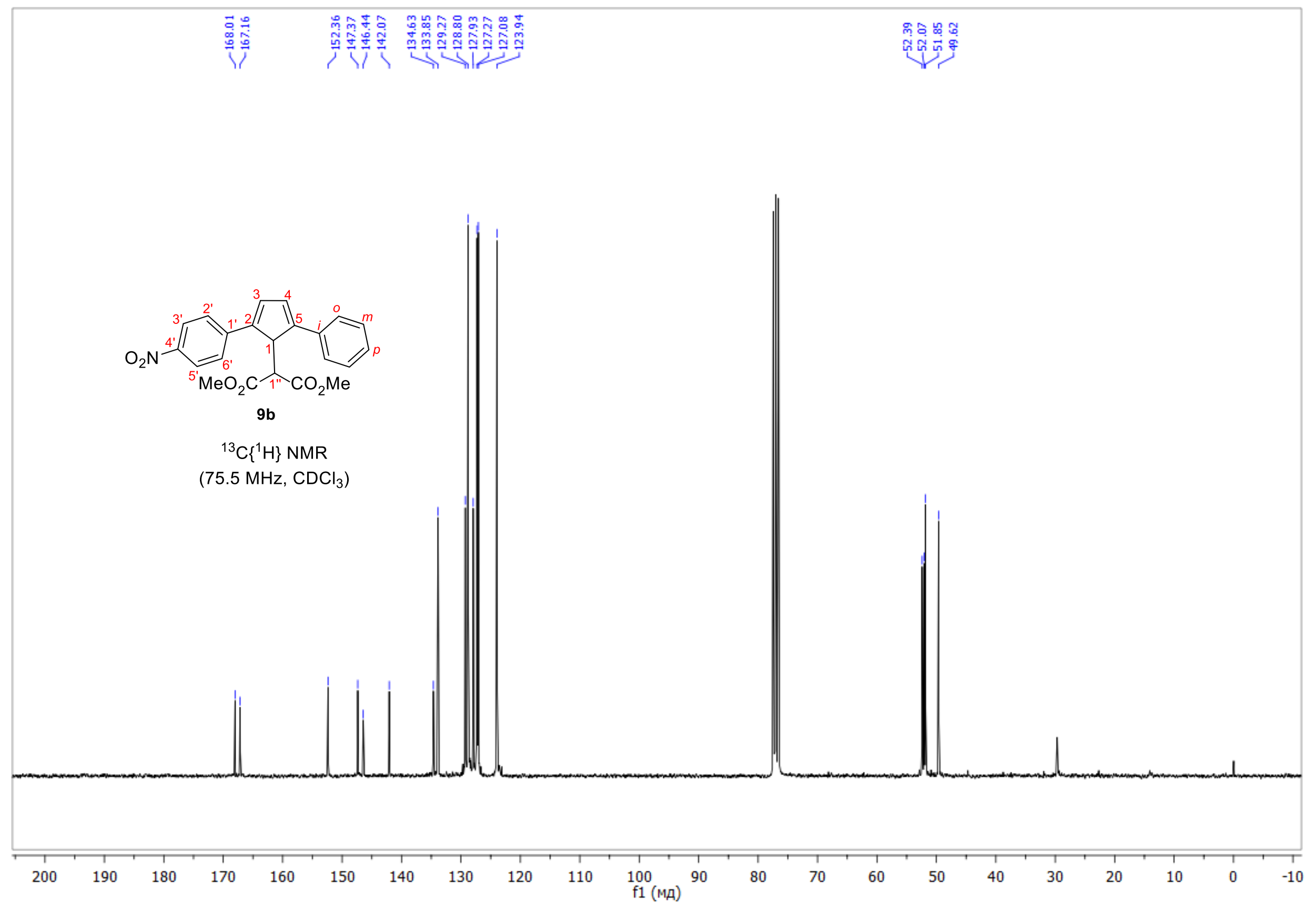




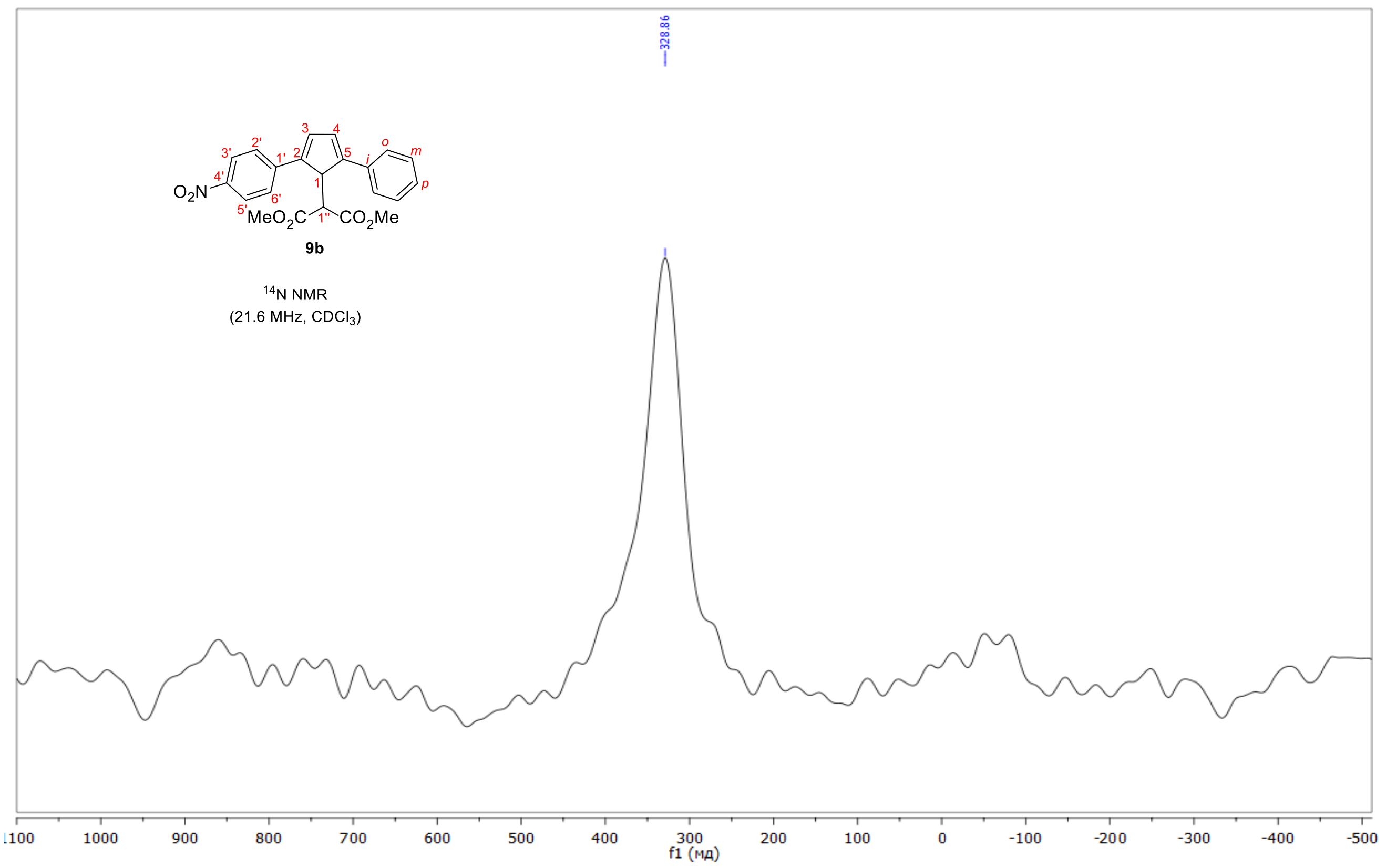




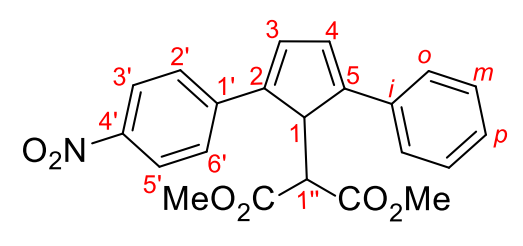

$9 b$

${ }^{1} \mathrm{H},{ }^{1} \mathrm{H}-\mathrm{COSY}$

(300.1 MHz, $\left.\mathrm{CDCl}_{3}\right)$

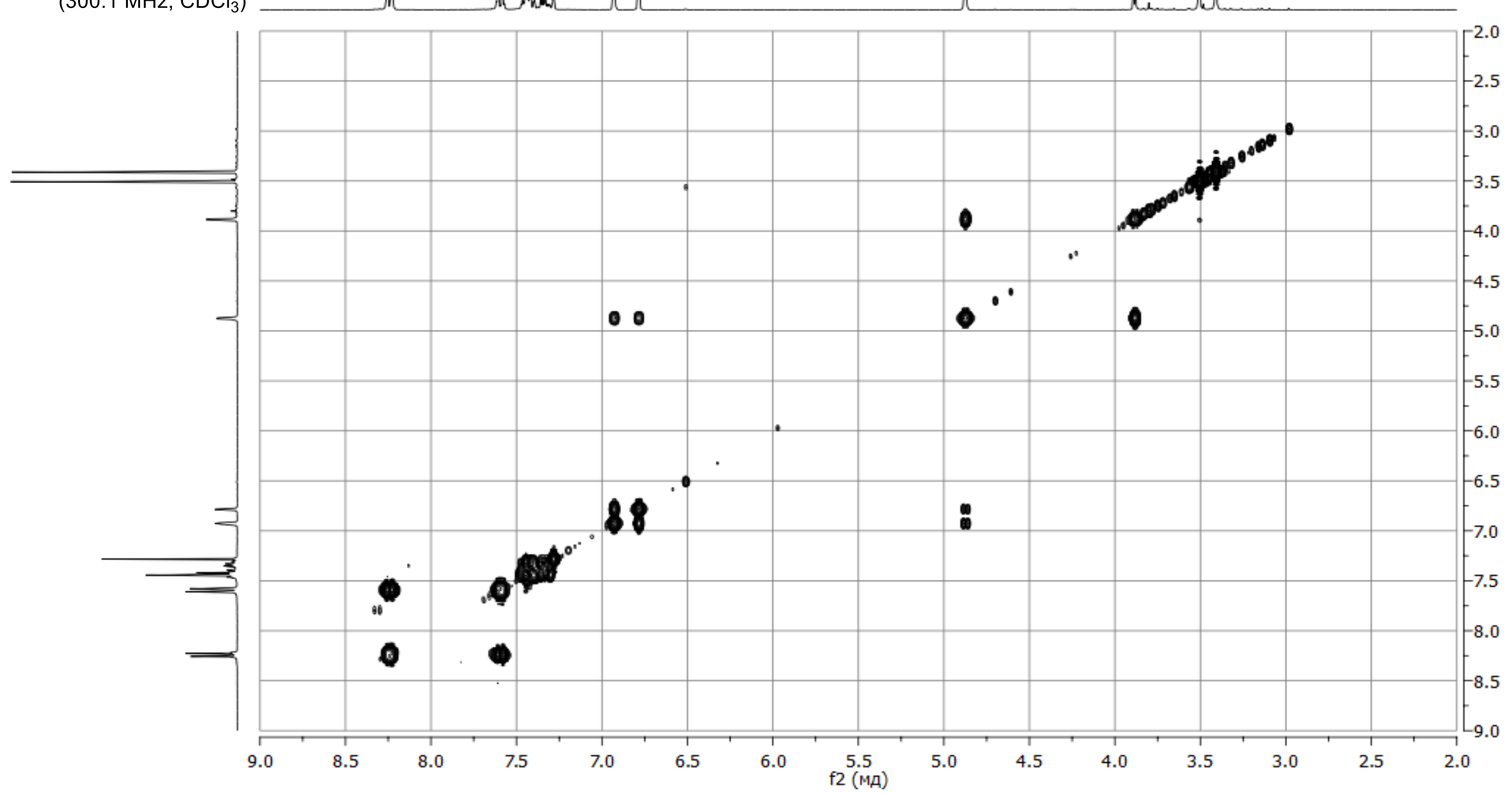




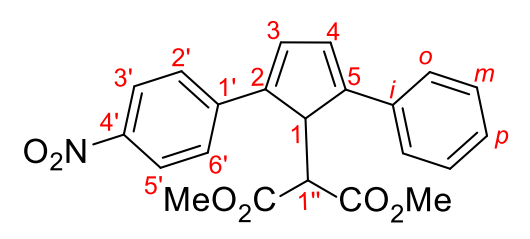

$9 b$

${ }^{1} \mathrm{H},{ }^{13} \mathrm{C}$-edHSQC-SI3

$\left({ }^{1} \mathrm{H}: 300.1 \mathrm{MHz}\right.$,

${ }^{13} \mathrm{C}: 75.5 \mathrm{MHz}$ $\left.\mathrm{CDCl}_{3}\right)$

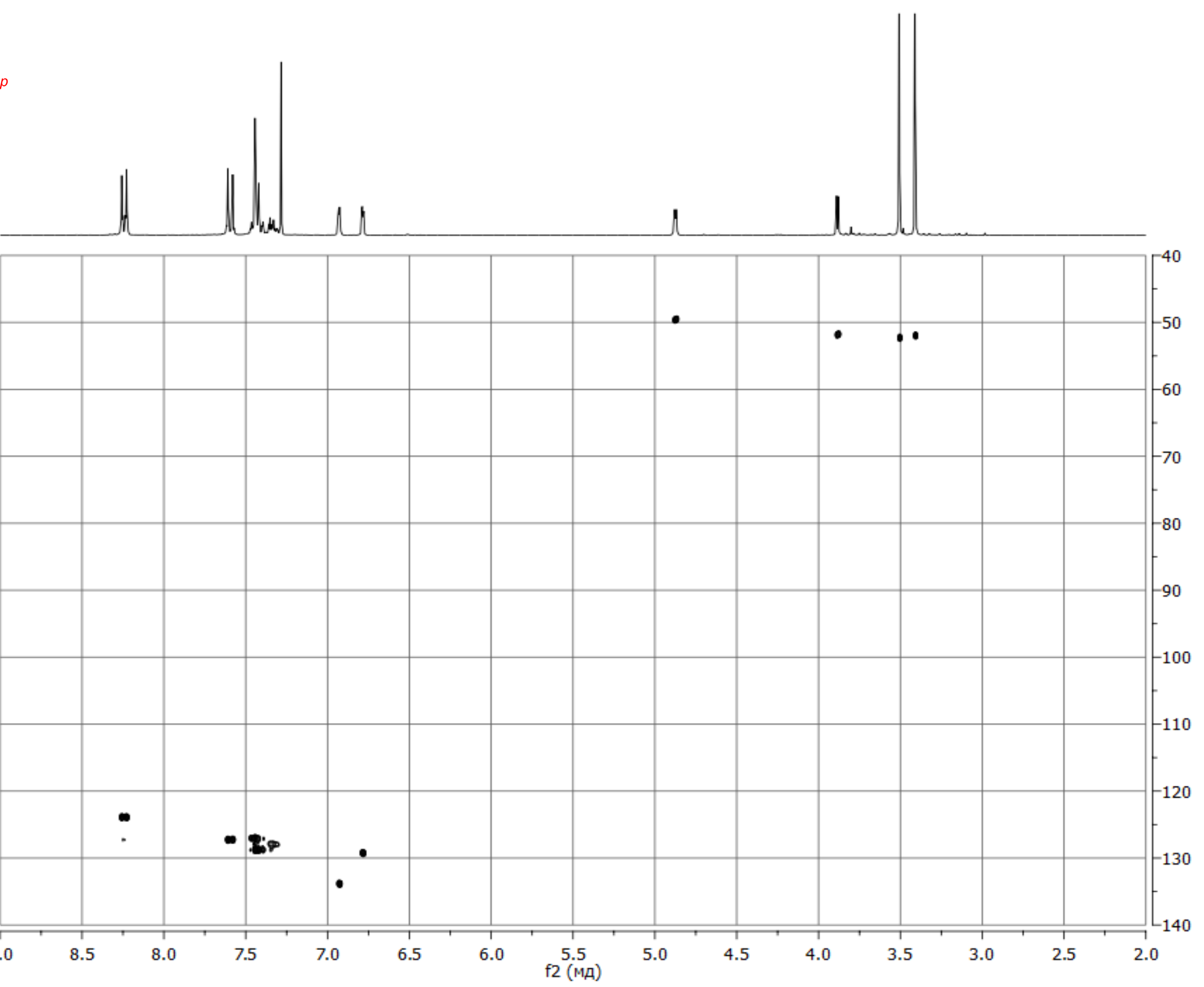




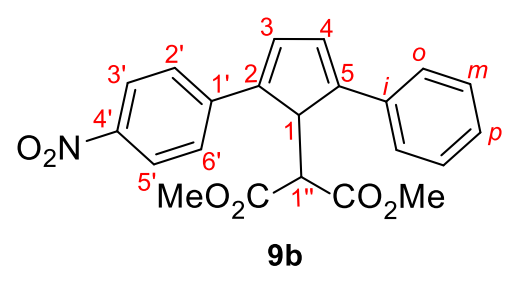

${ }^{1} \mathrm{H},{ }^{13} \mathrm{C}-\mathrm{HMBC}$ $\left({ }^{1} \mathrm{H}: 300.1 \mathrm{MHz}\right.$,

${ }^{13} \mathrm{C}: 75.5 \mathrm{MHz}$

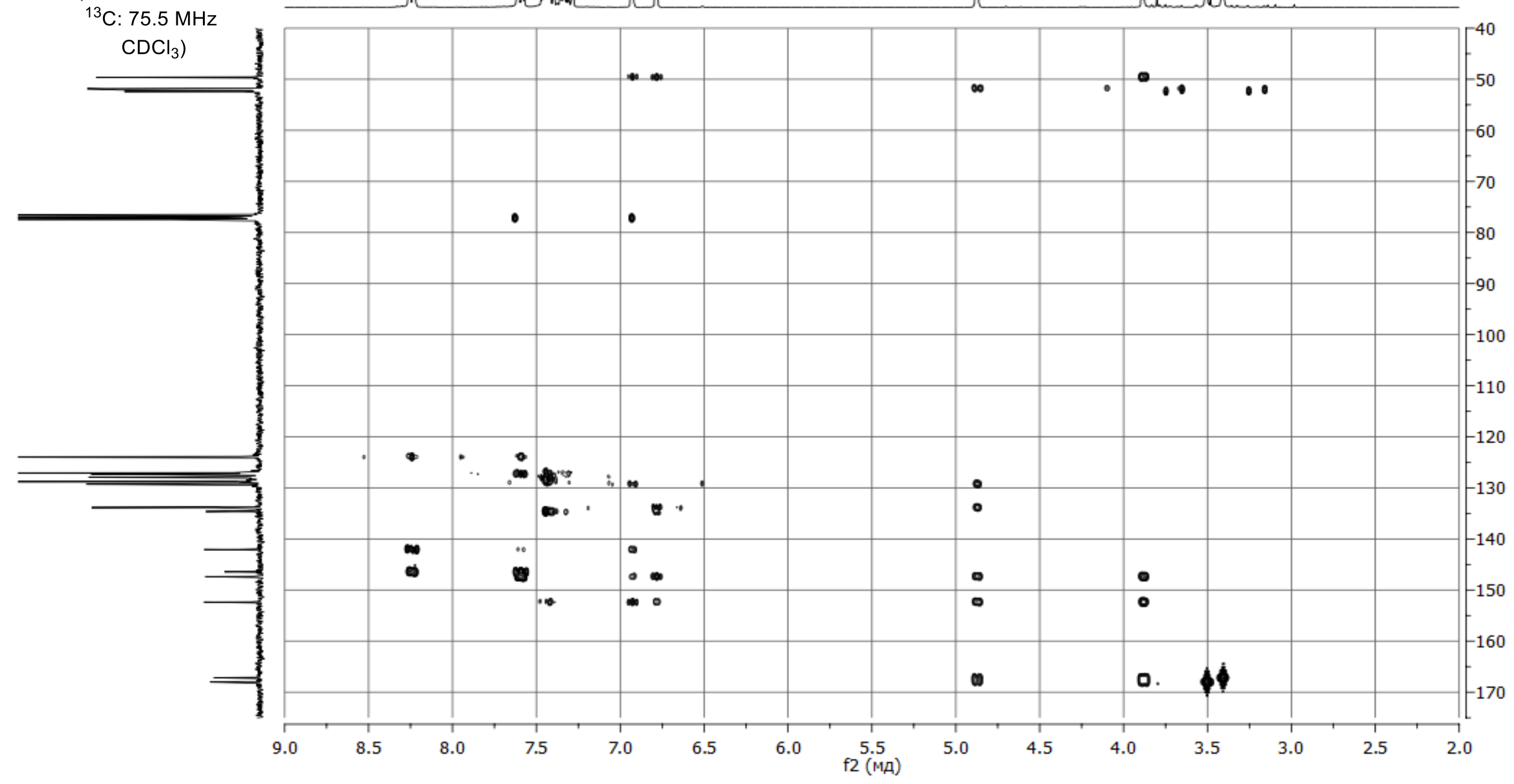




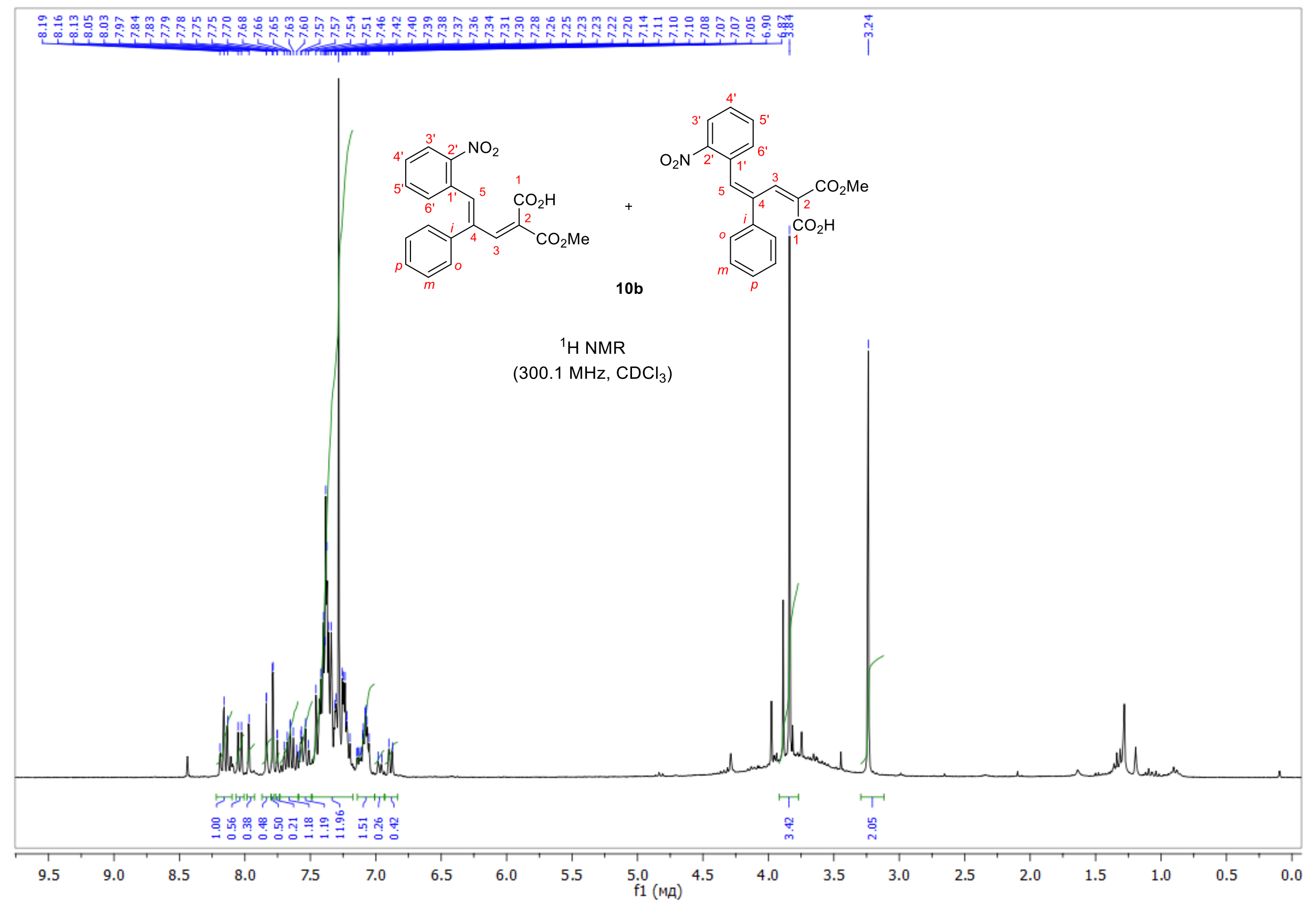




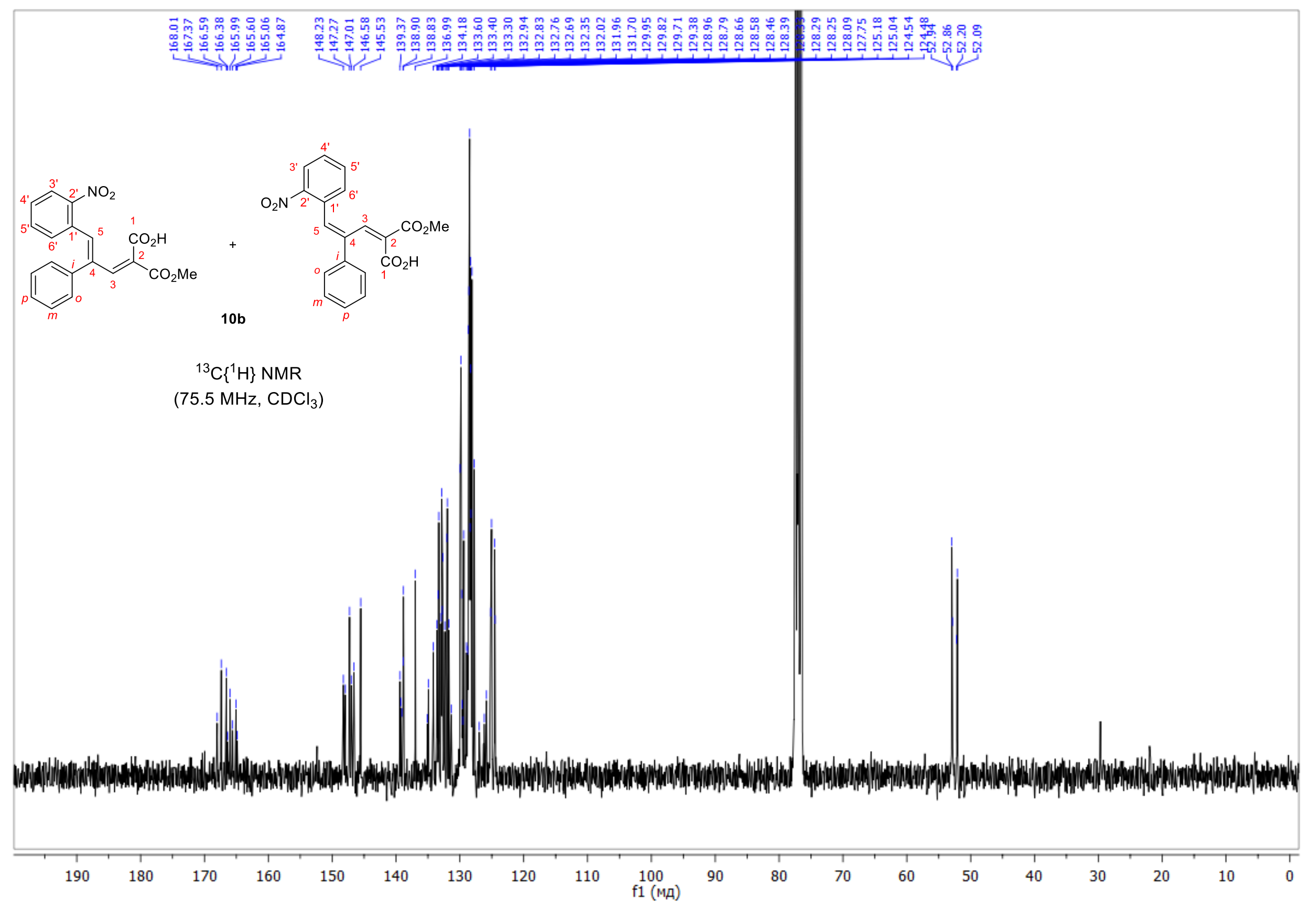



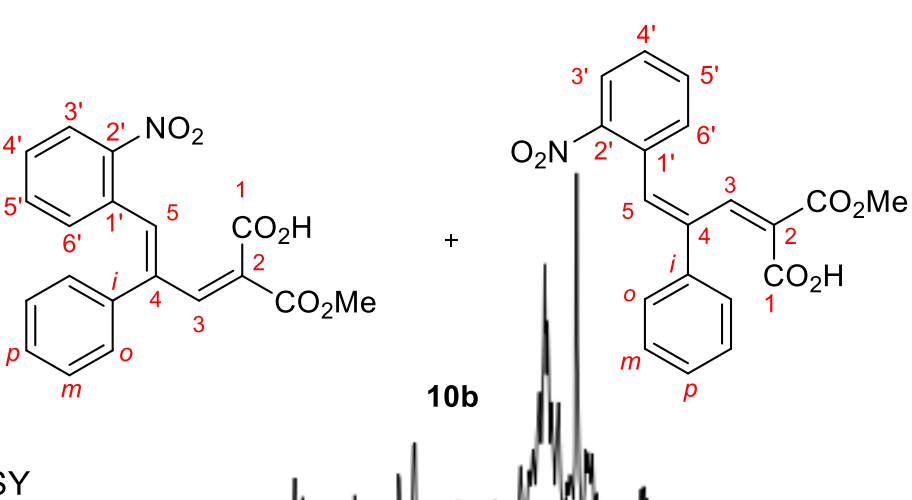

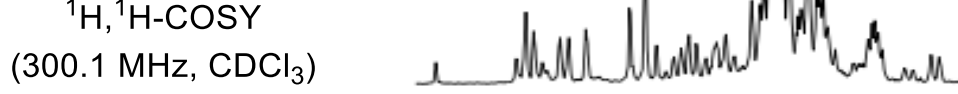
Judvanene

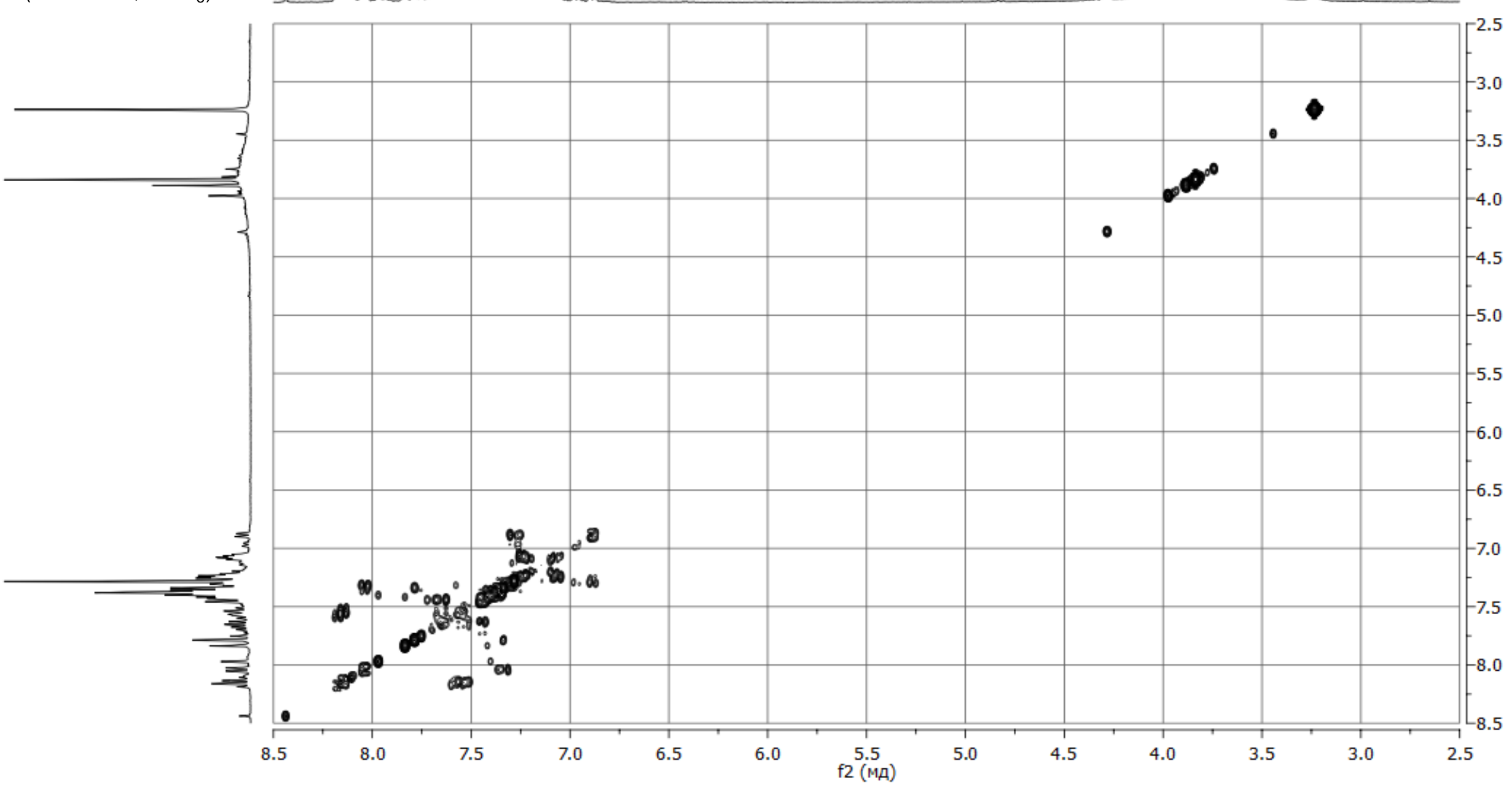




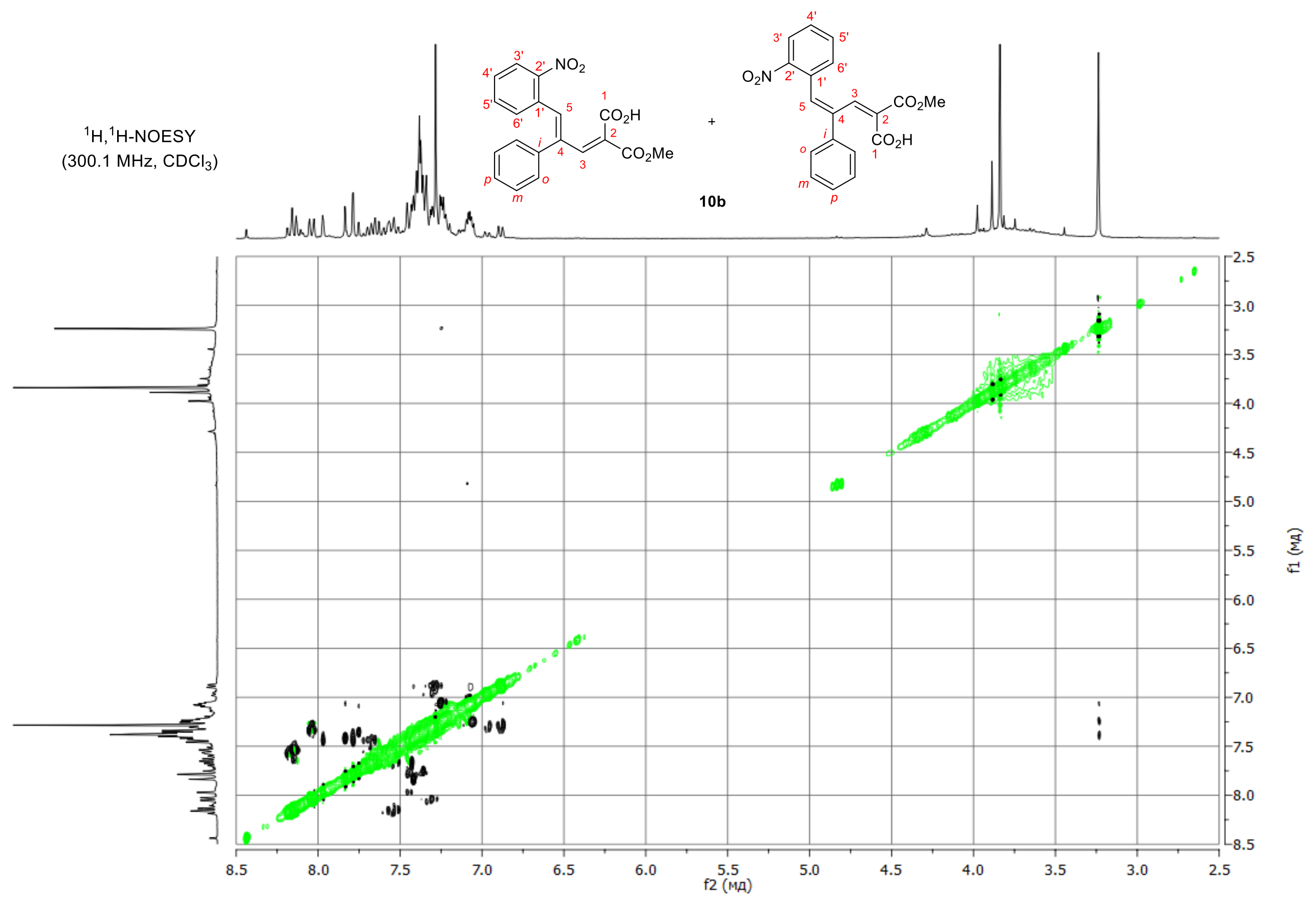




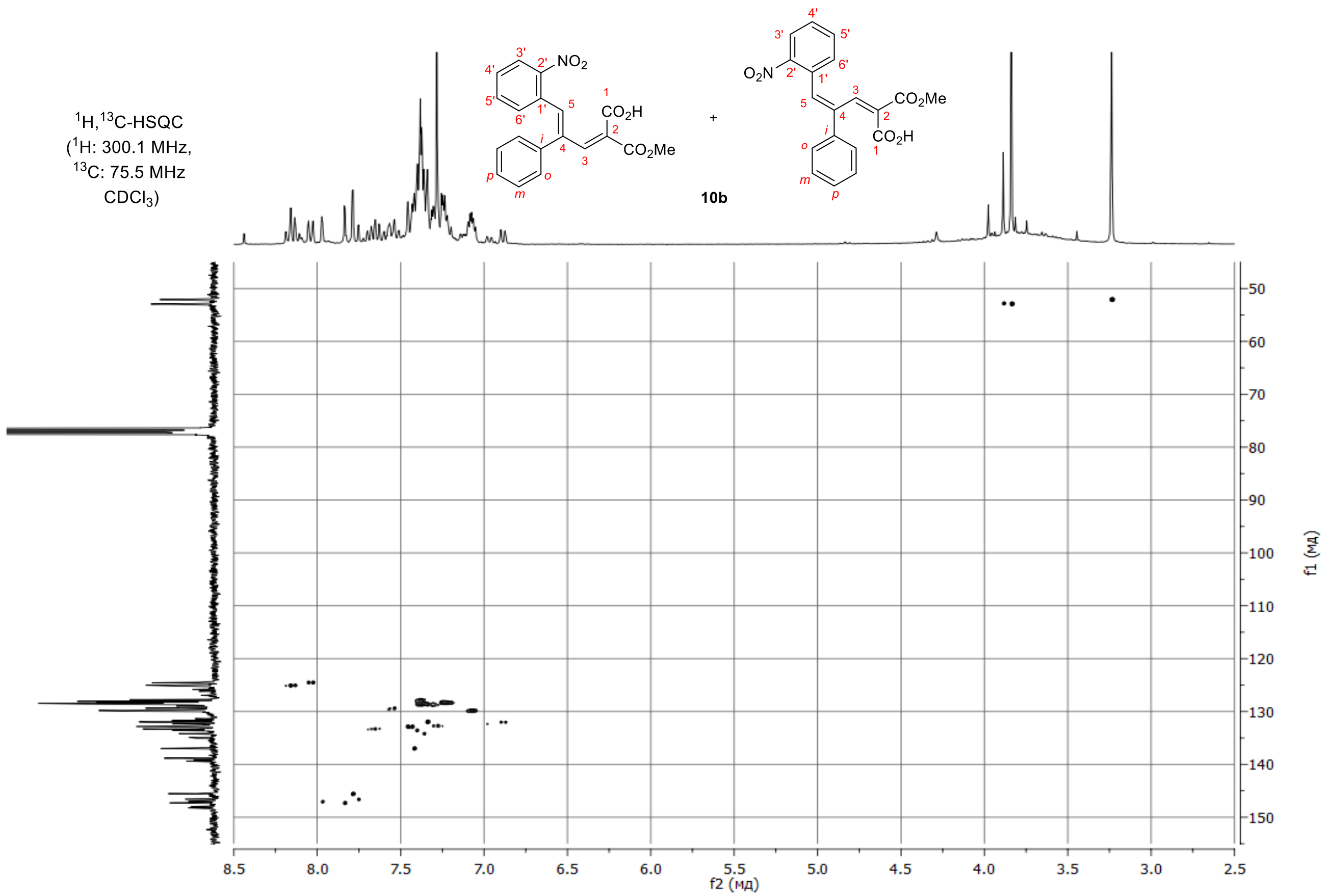

S43 


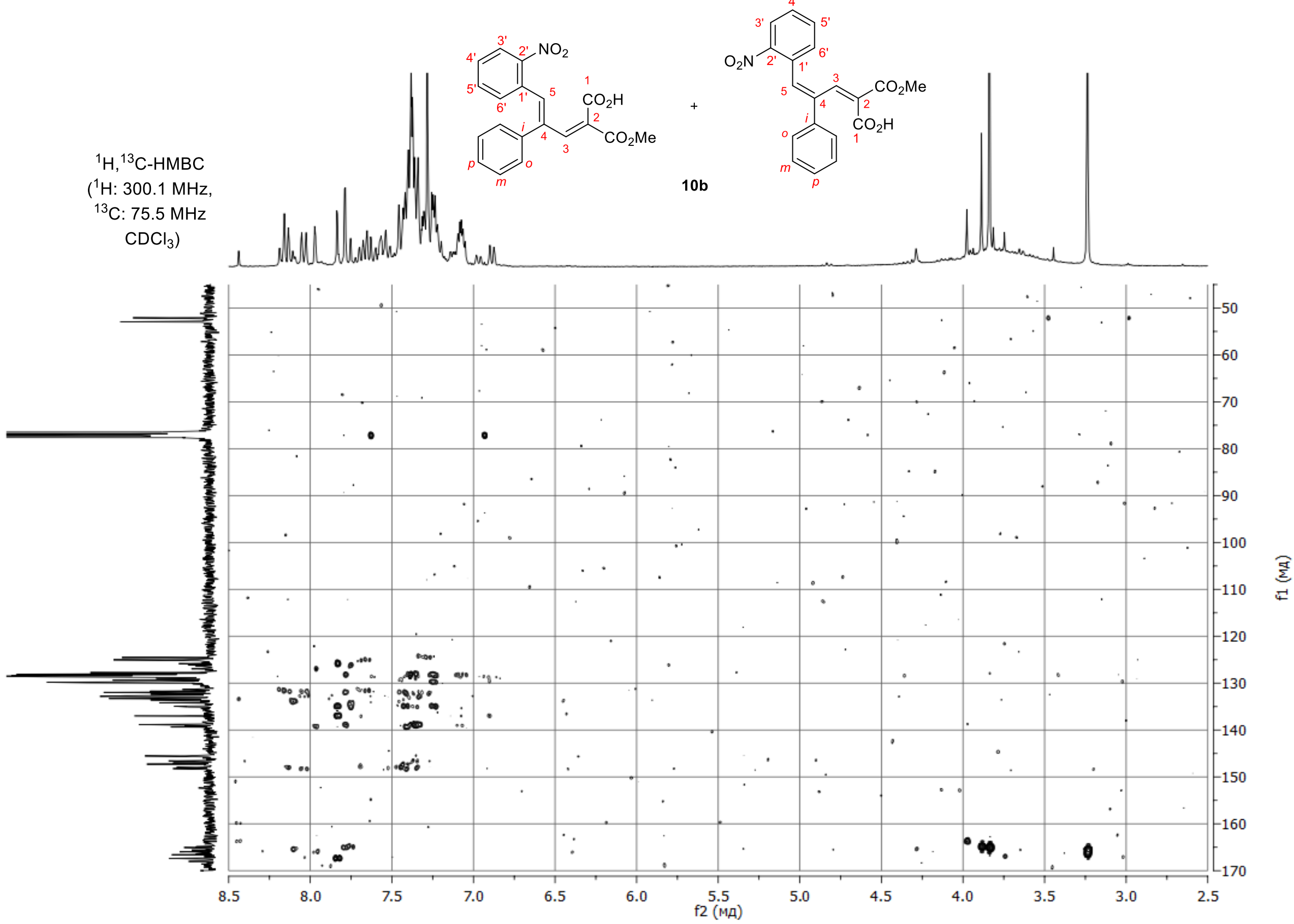

S44 


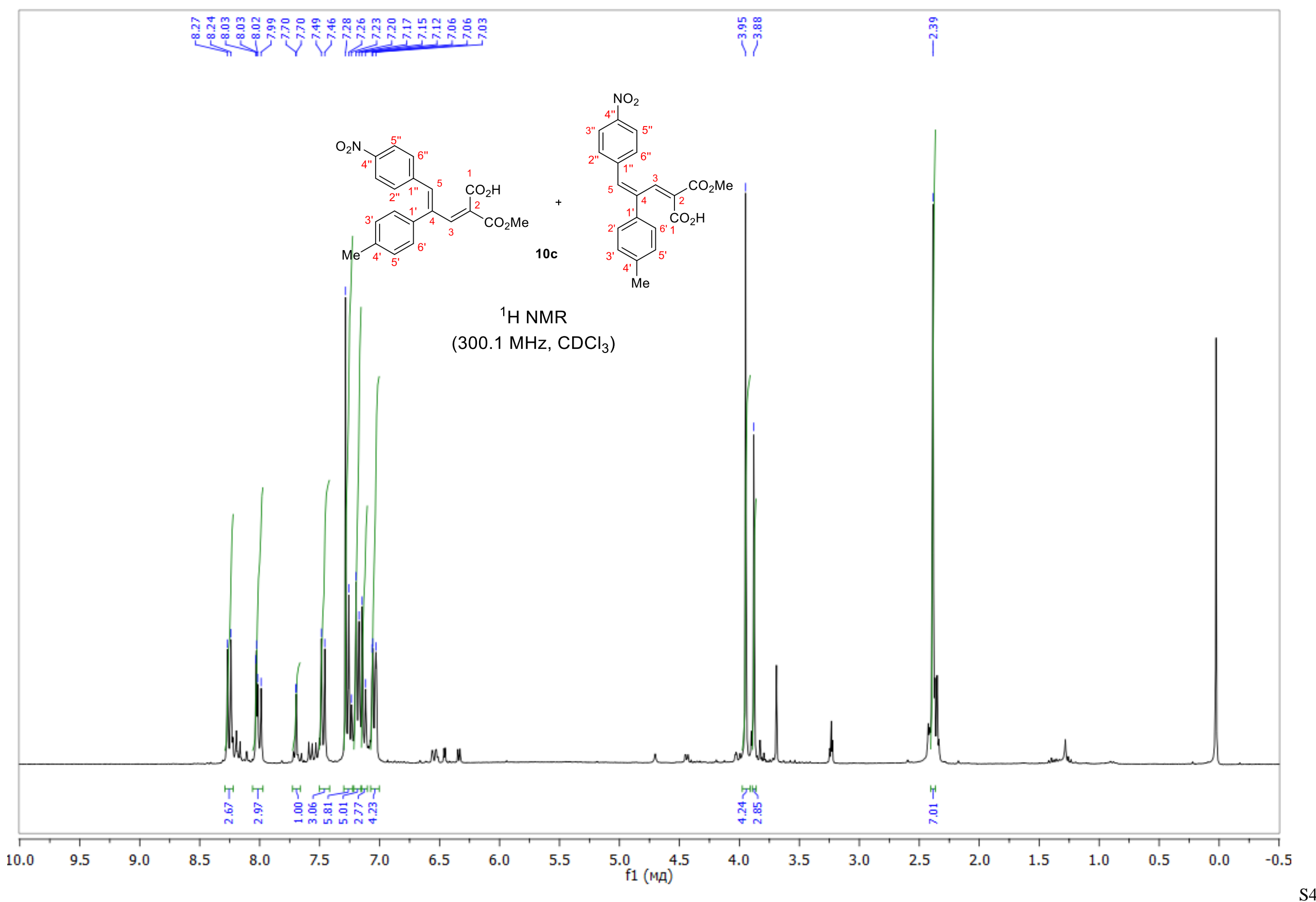




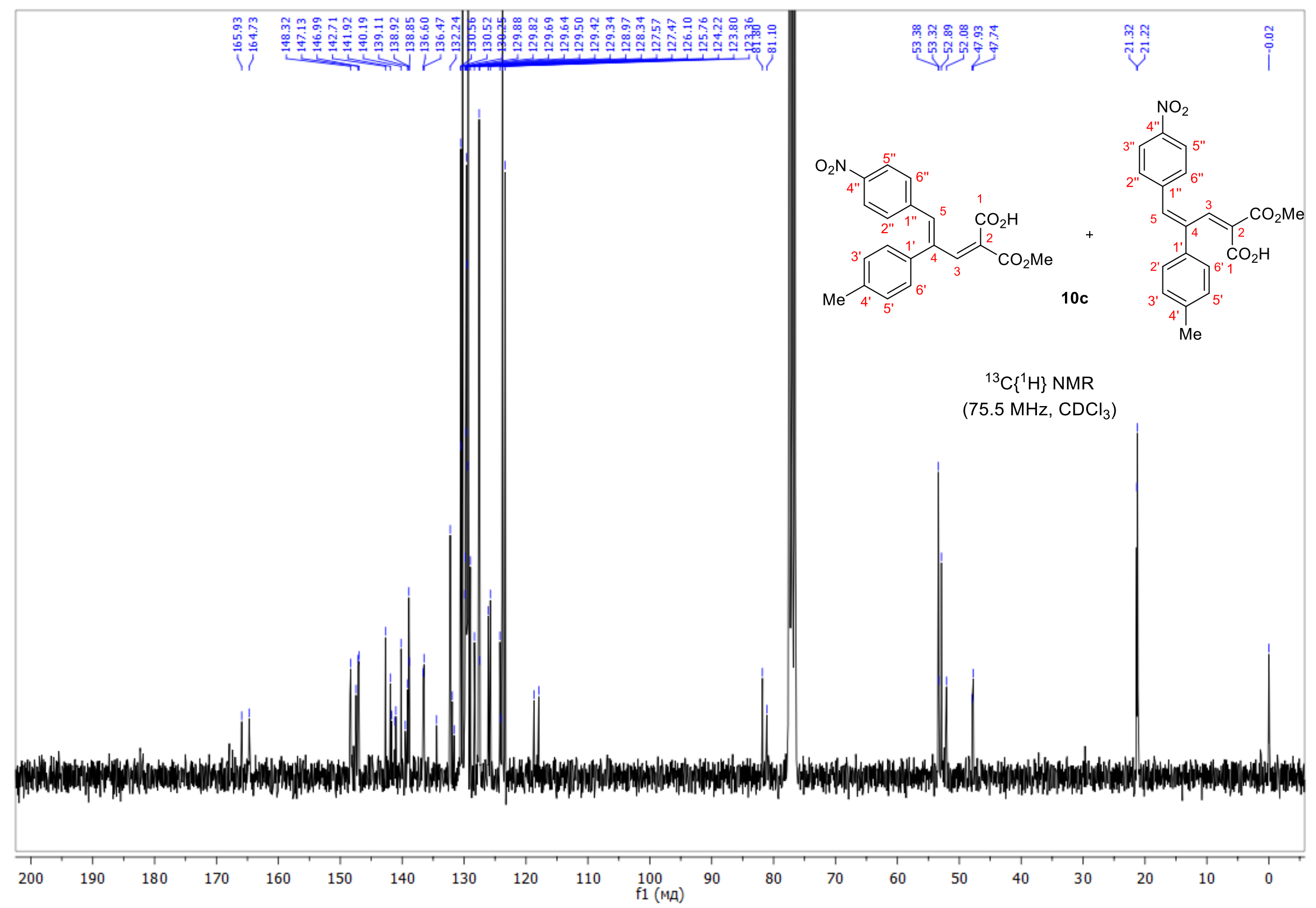




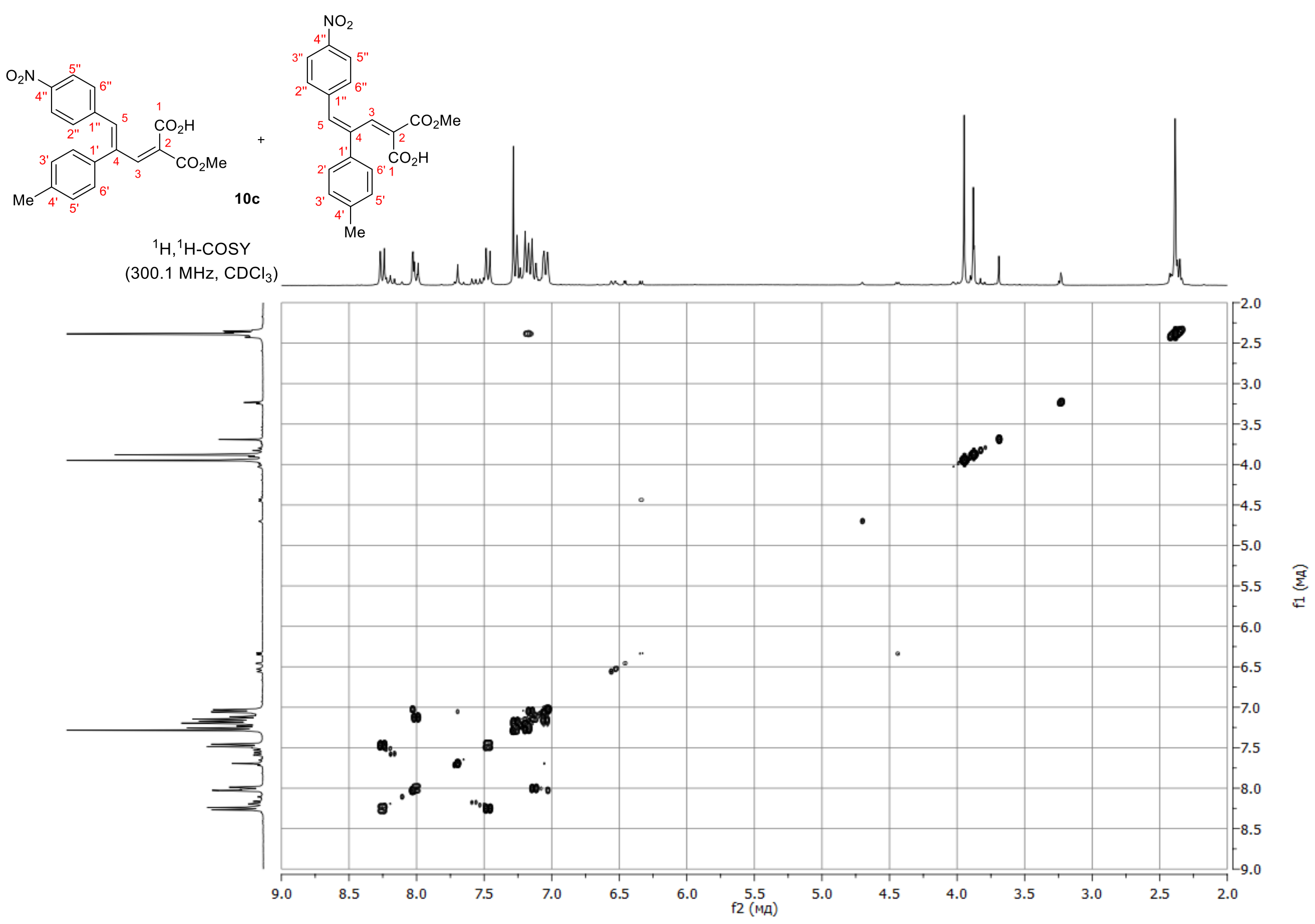




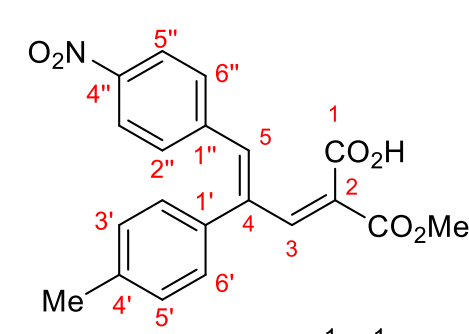

${ }^{1} \mathrm{H}^{1} \mathrm{H}-\mathrm{NOC}$ (300.1 MHz, $\mathrm{CDCl}_{3}$ )
(1"

$\overbrace{4}^{3} \mathrm{CO}_{2} \mathrm{Me}$

${ }^{\prime}{ }_{1}^{\prime} \mathrm{CO}_{2} \mathrm{H}$

$3^{\prime} 5^{\prime}$

$\mathrm{Me}$

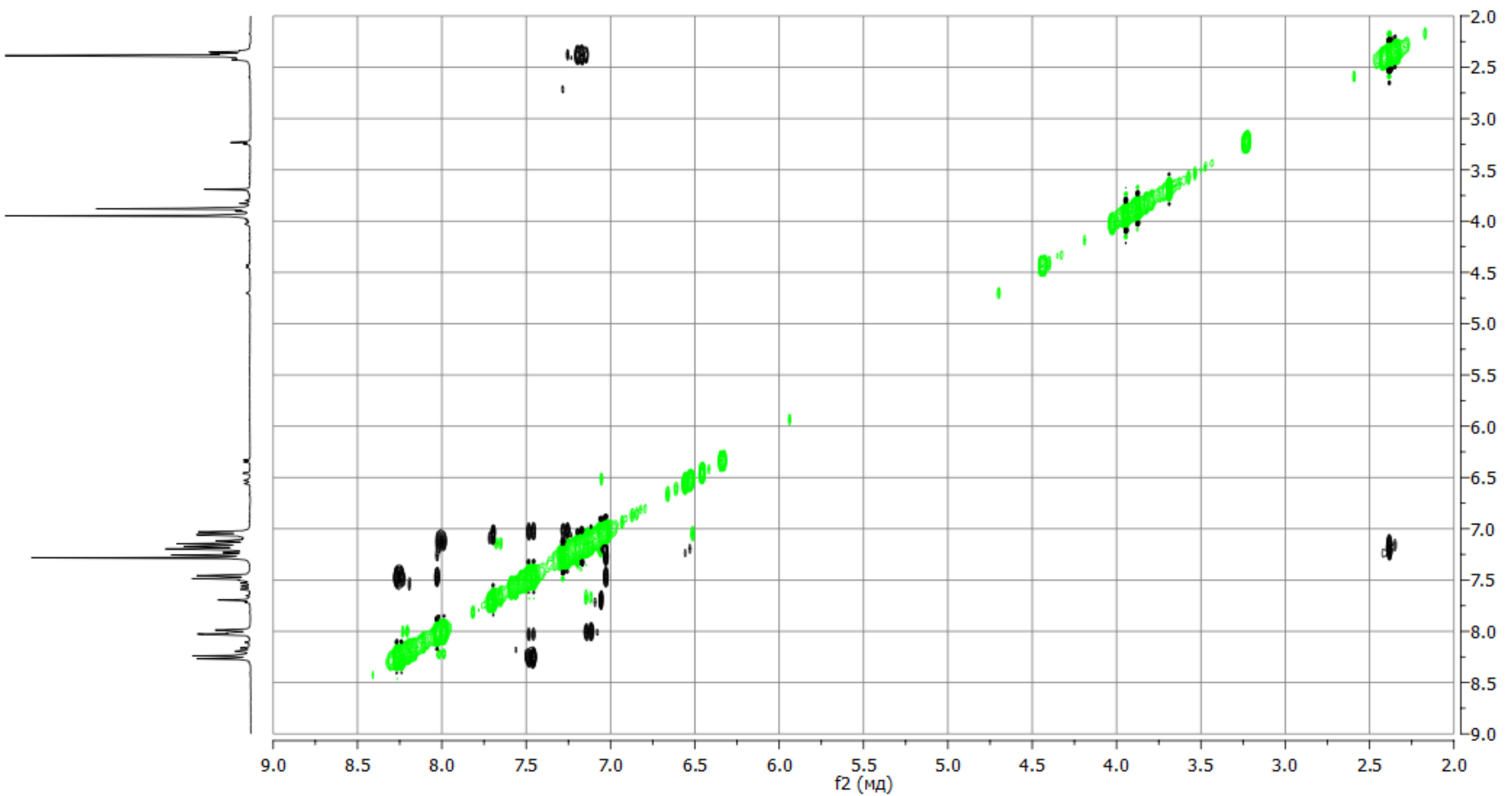



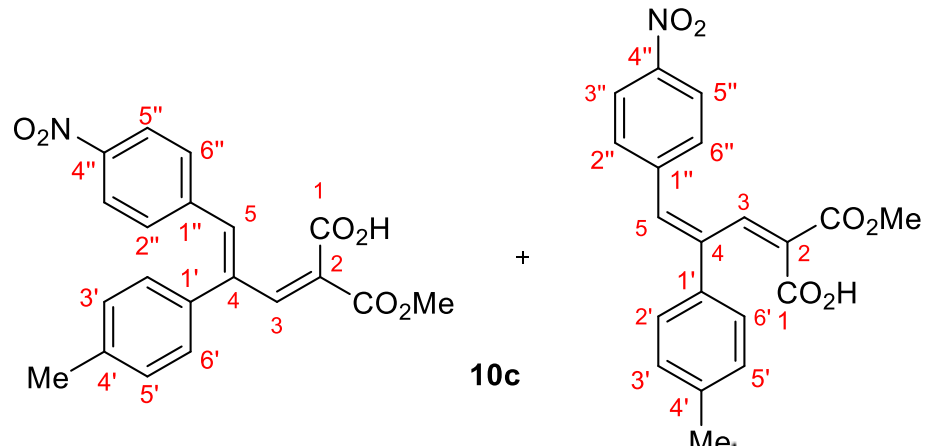

${ }^{1} \mathrm{H},{ }^{13} \mathrm{C}$-edited-HSQC

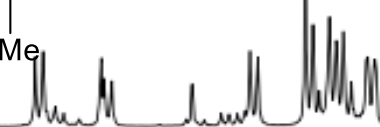
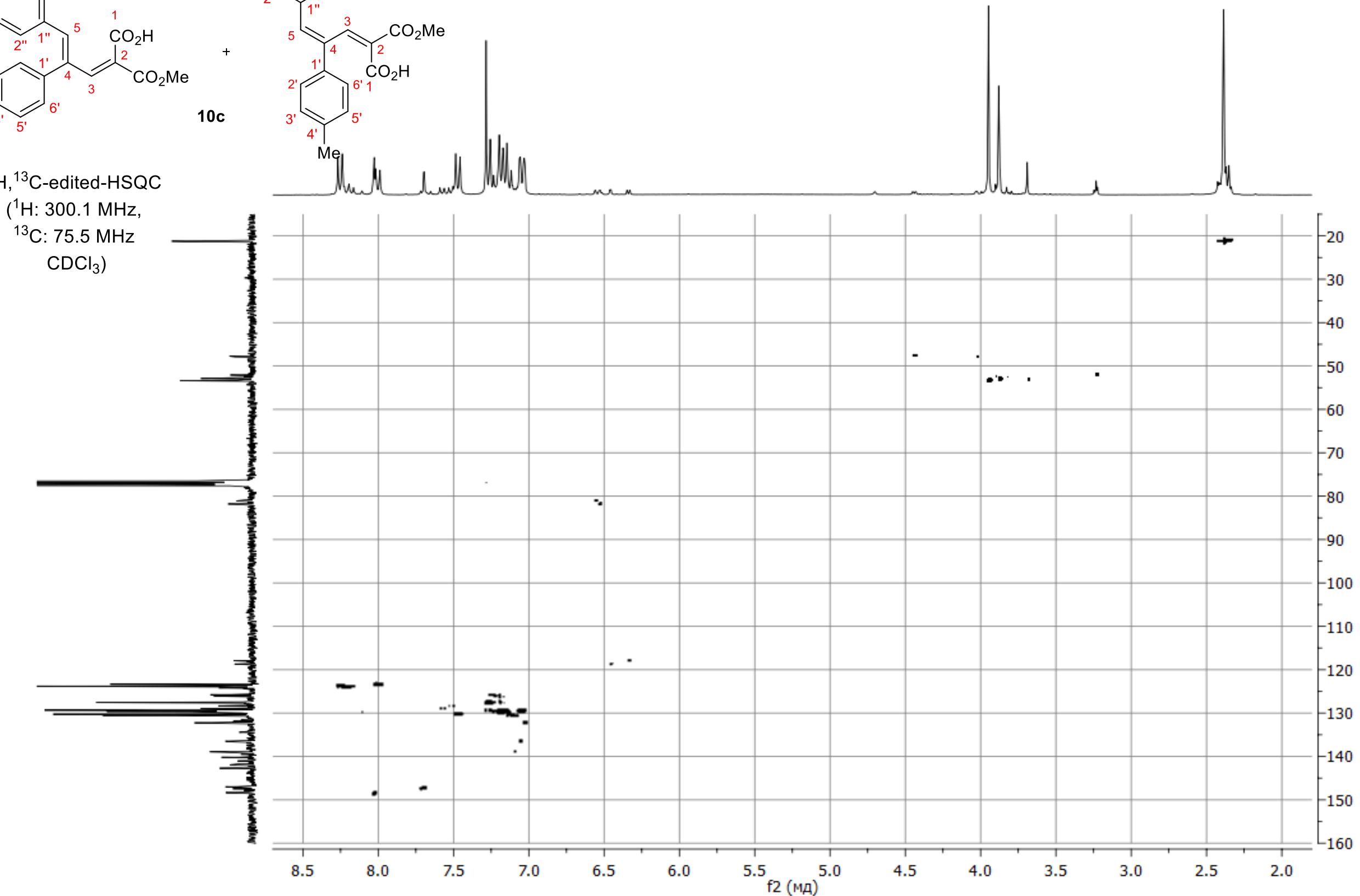


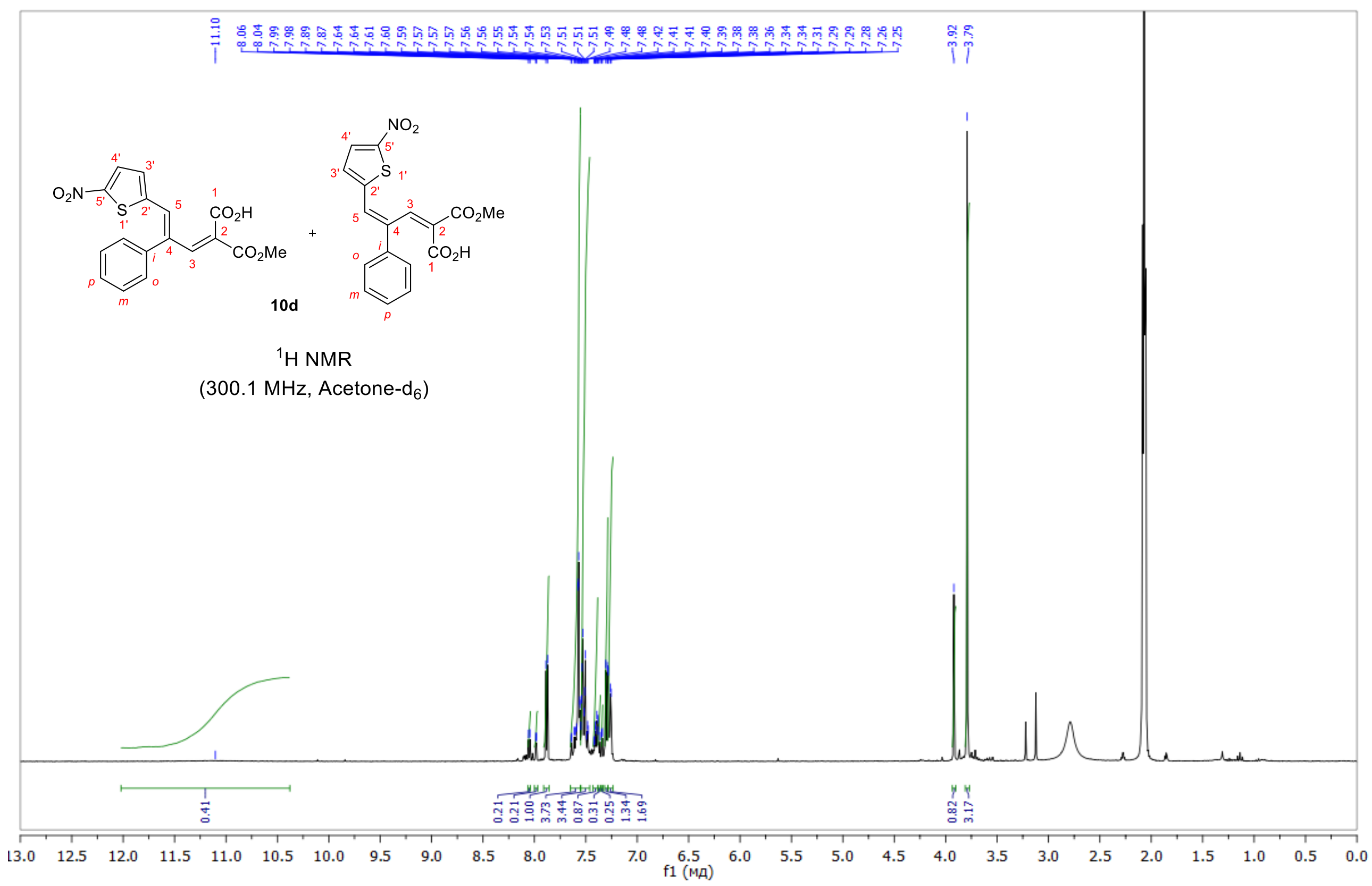




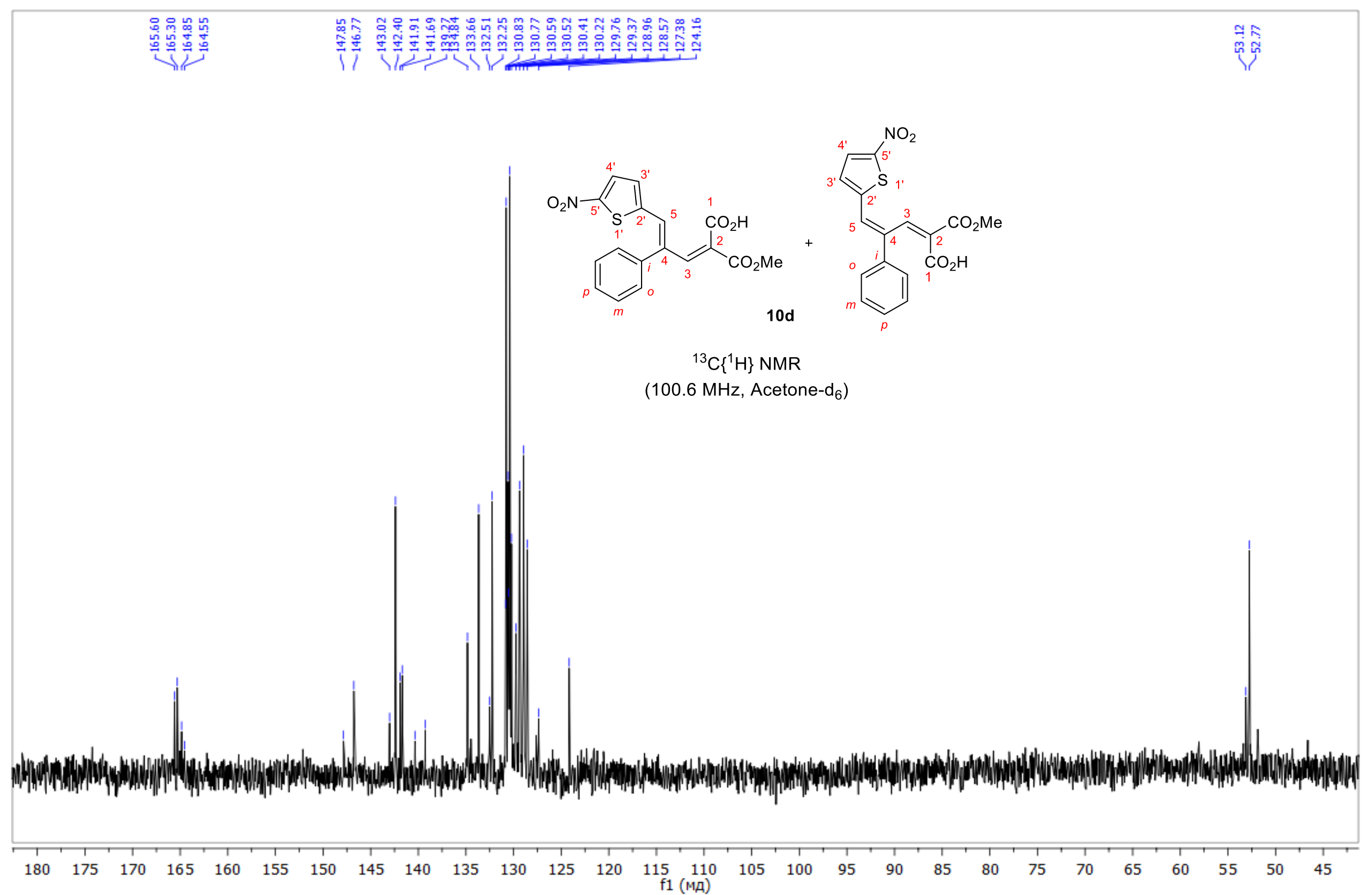


<smiles>CC(=O)CCCCCCC(=O)OC(C)=CC(=Cc1ccc([N+](=O)[O-])s1)c1ccccc1</smiles>

$$
\text { (300.1 MHz, Acetone- } d_{6} \text { ) }
$$

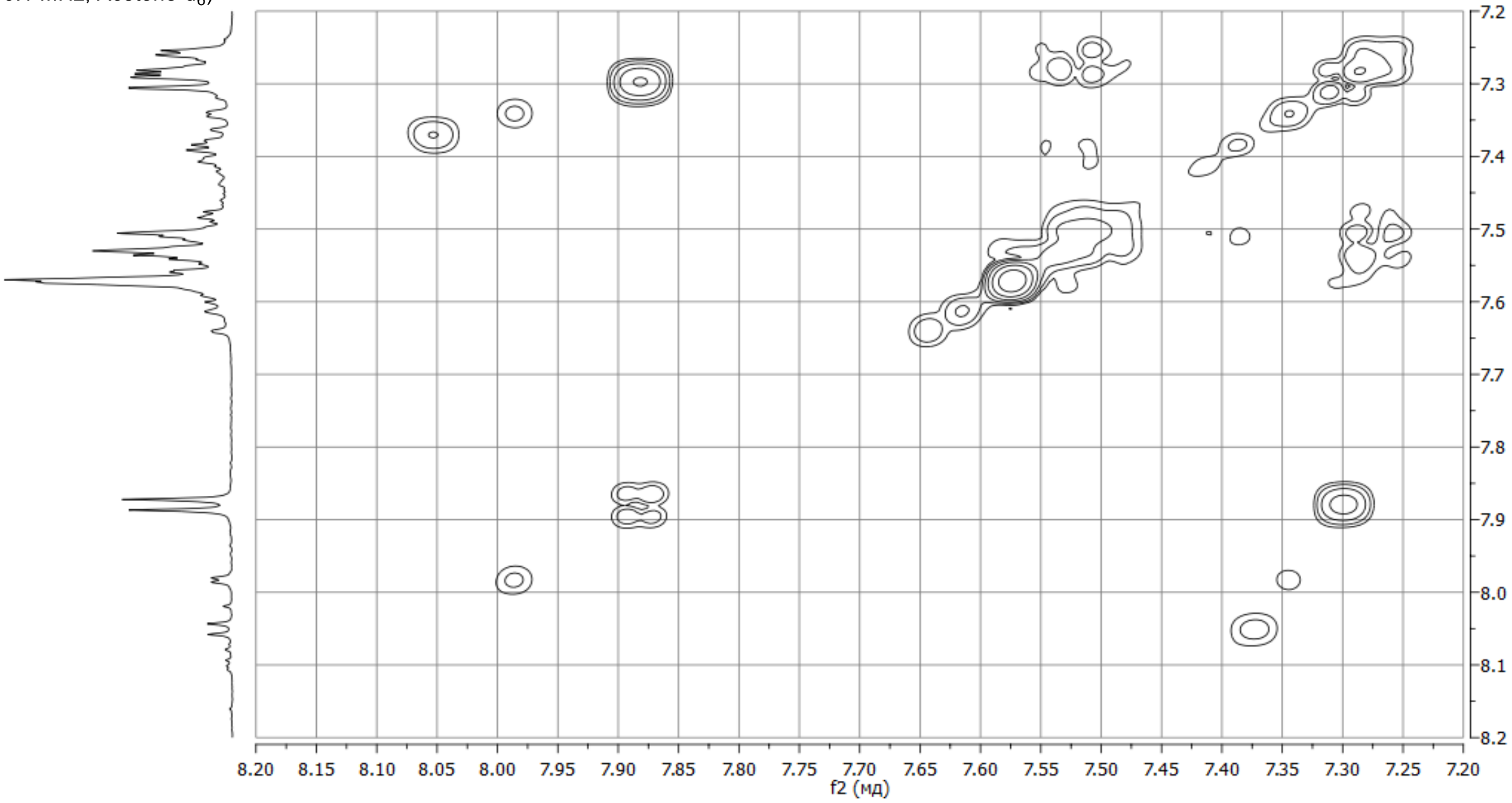

S52 


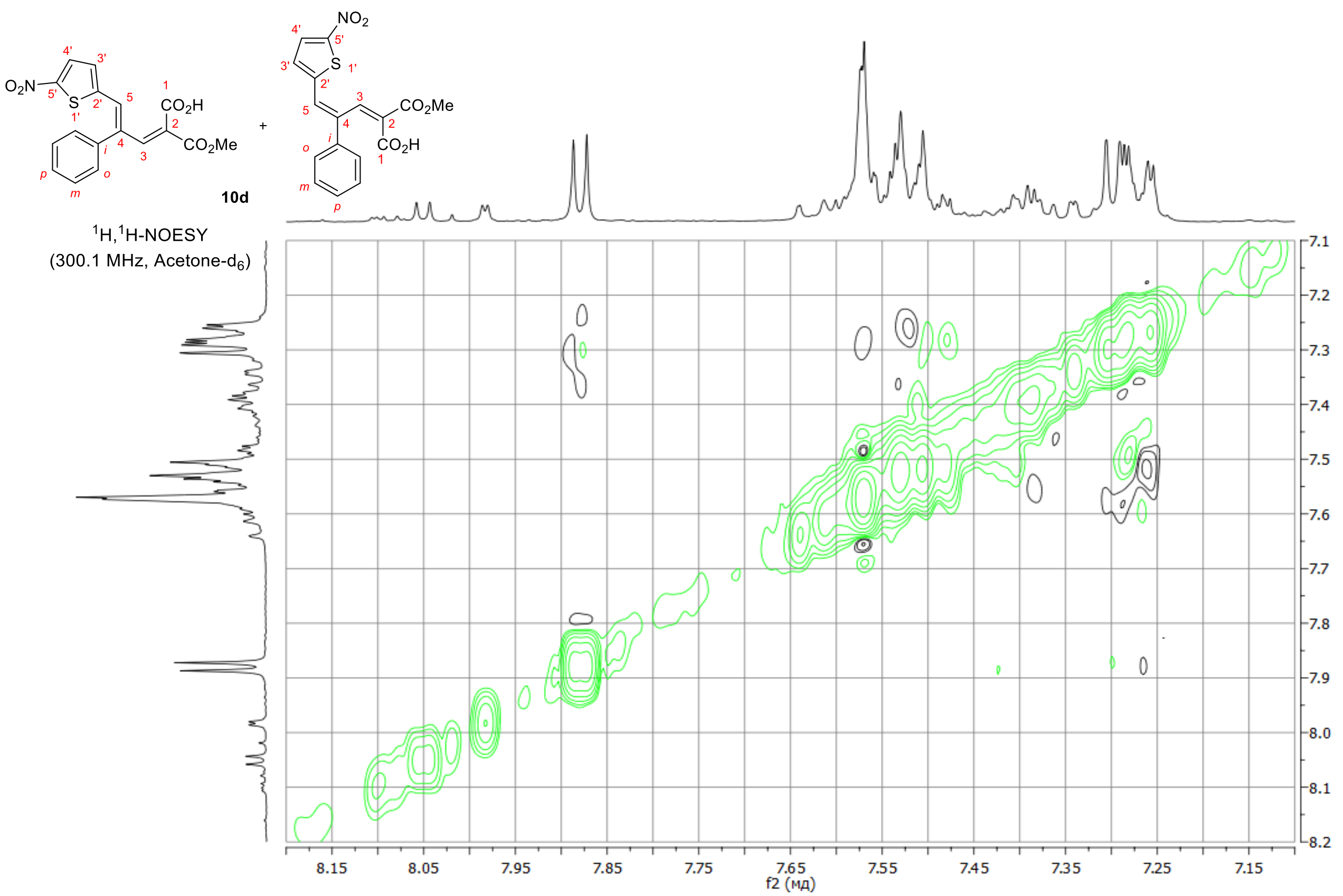




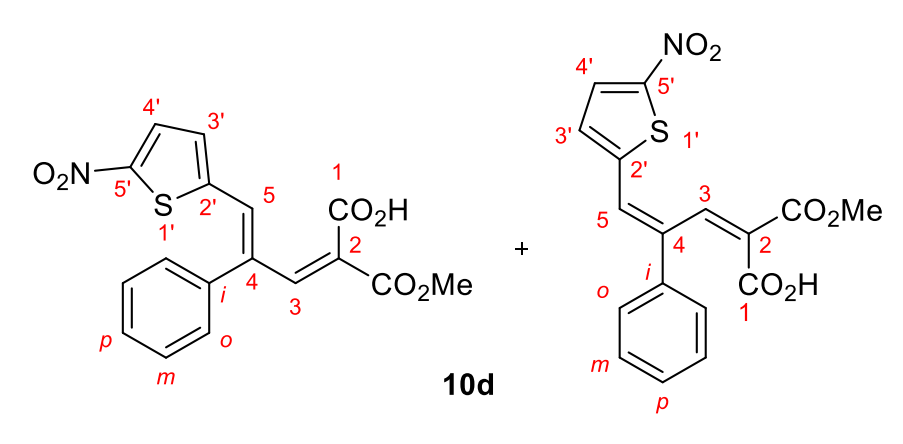

${ }^{1} \mathrm{H},{ }^{13} \mathrm{C}$-edited-HSQC $\left({ }^{1} \mathrm{H}: 300.1 \mathrm{MHz}\right.$,

${ }^{13} \mathrm{C}: 75.5 \mathrm{MHz}$

Acetone- $d_{6}$ )

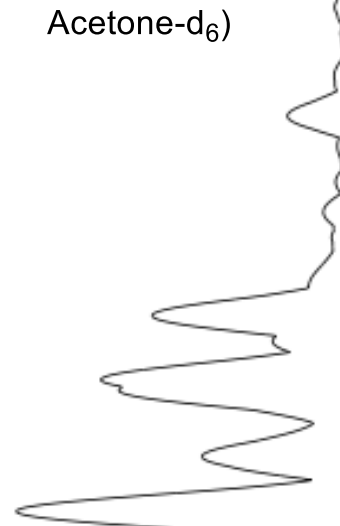

minur M

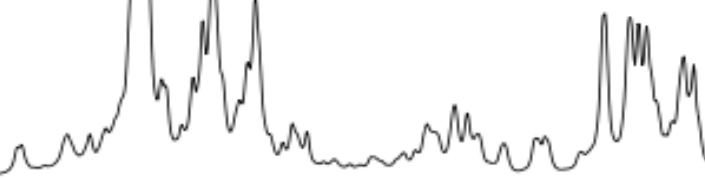
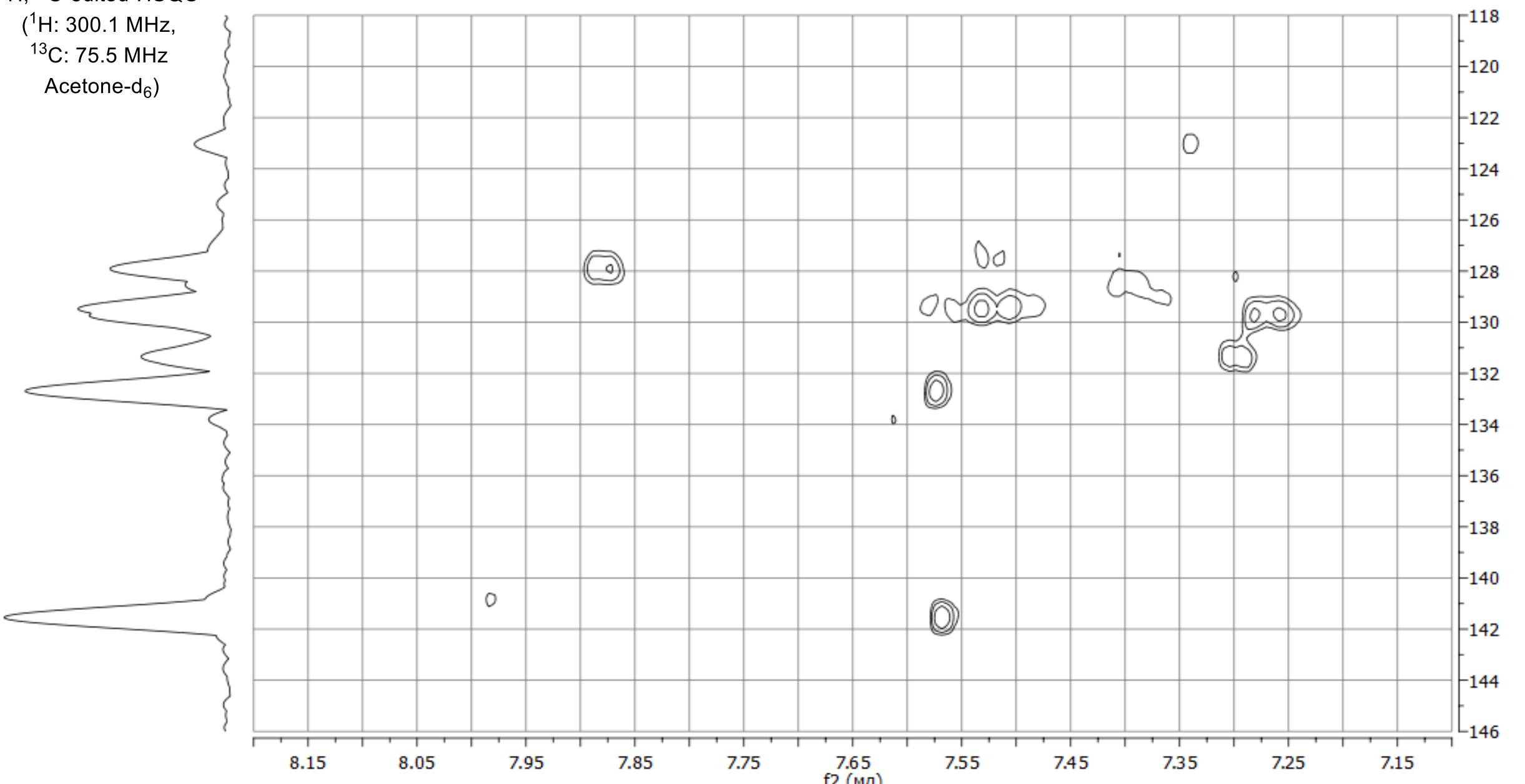


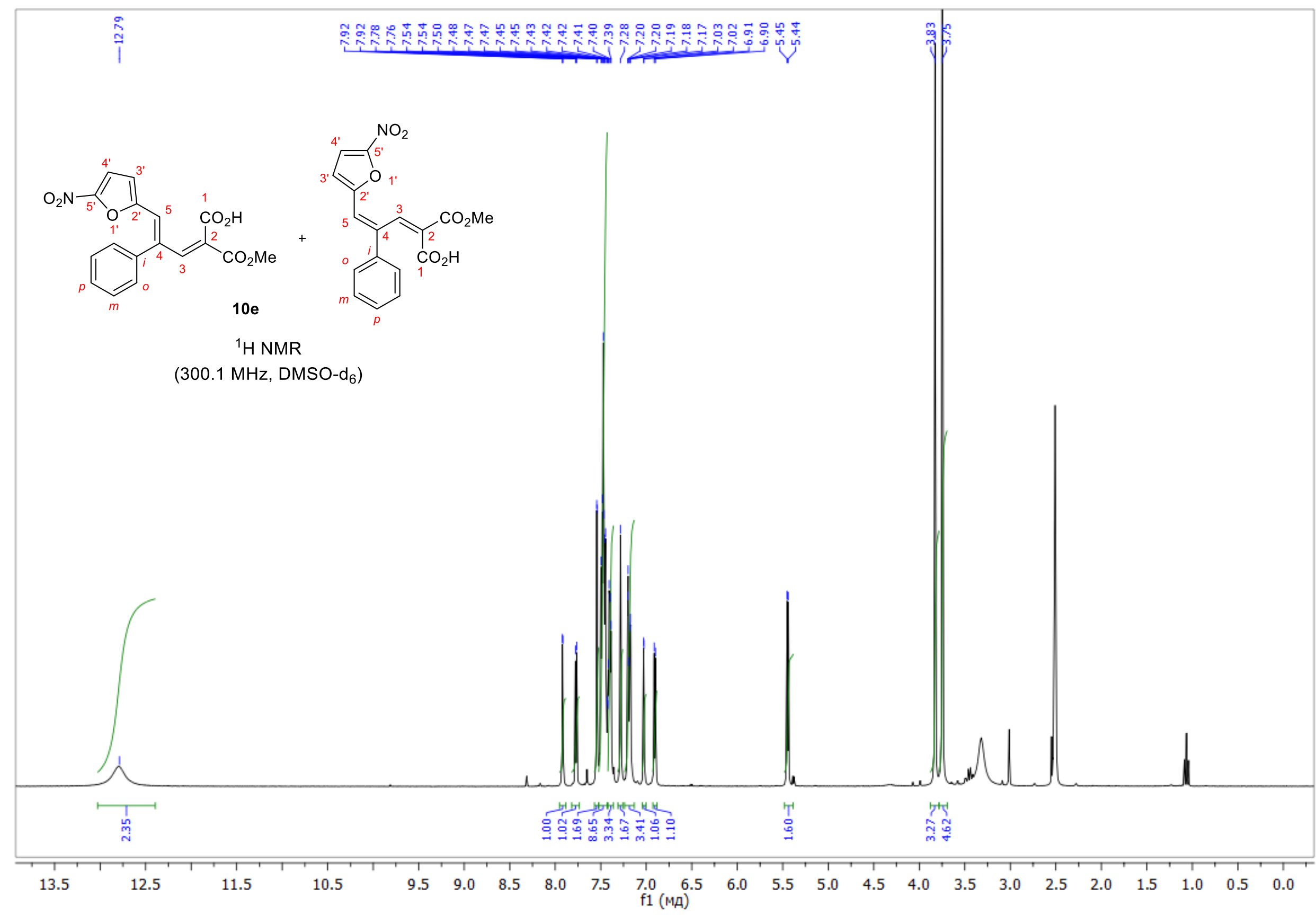




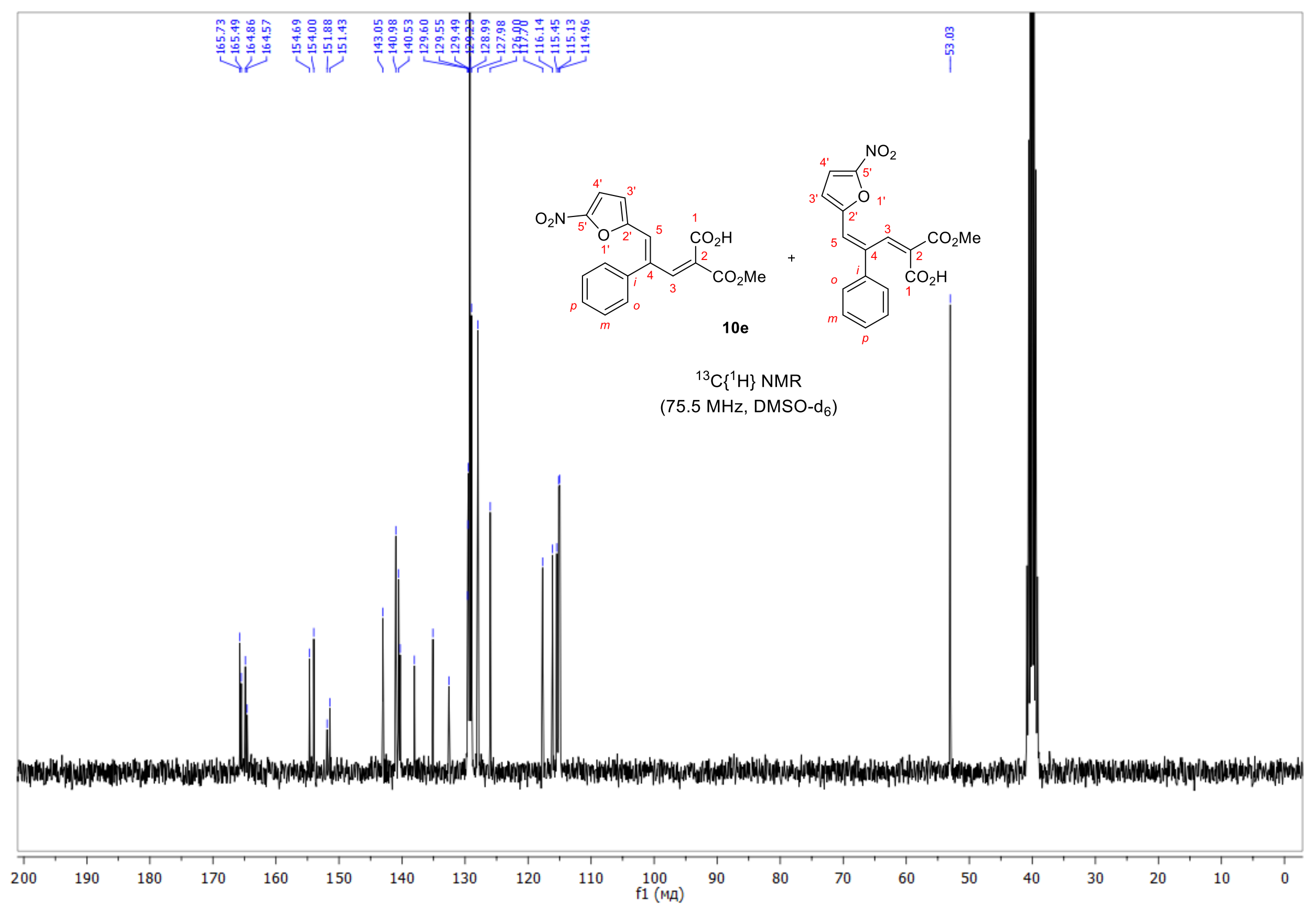




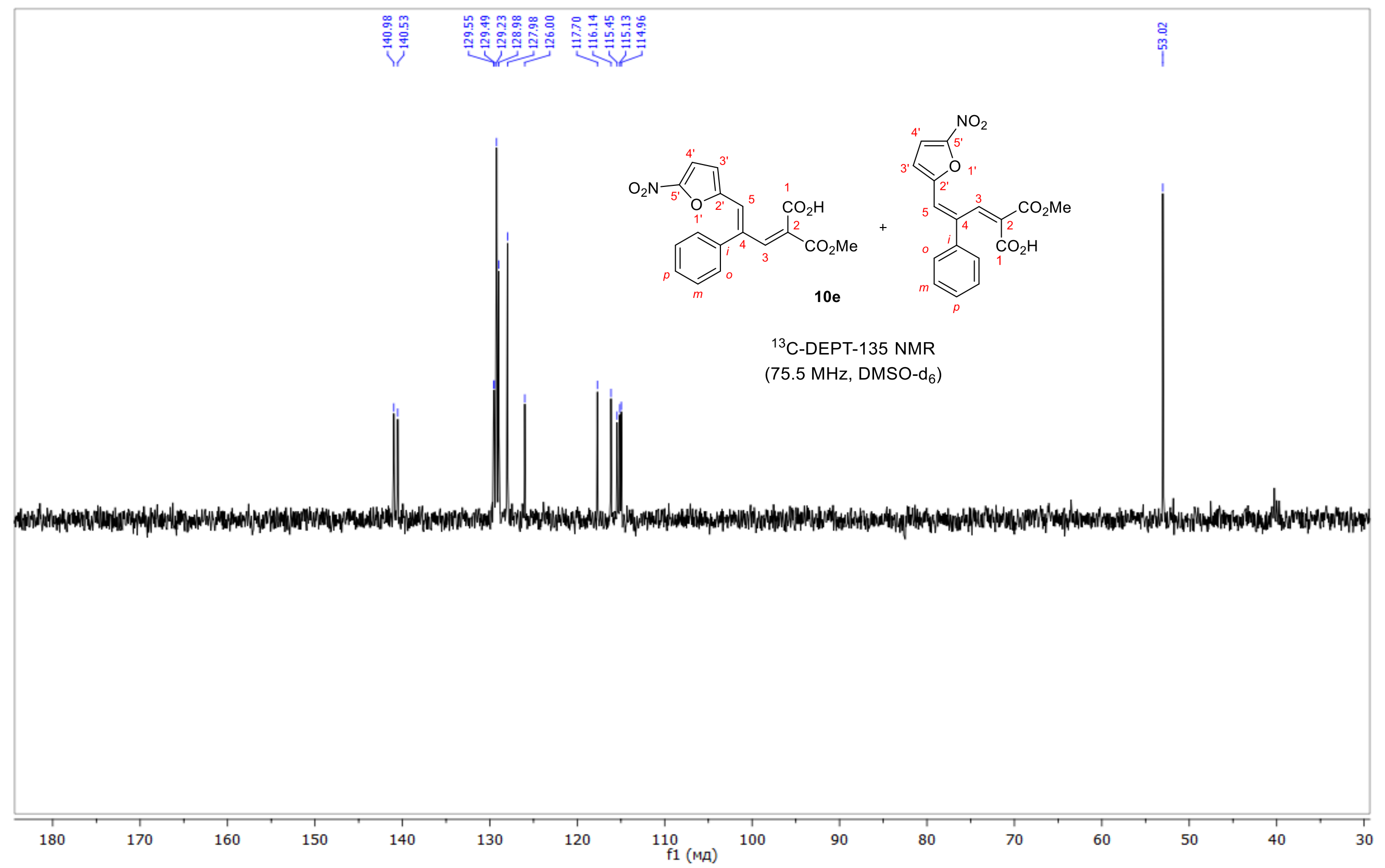




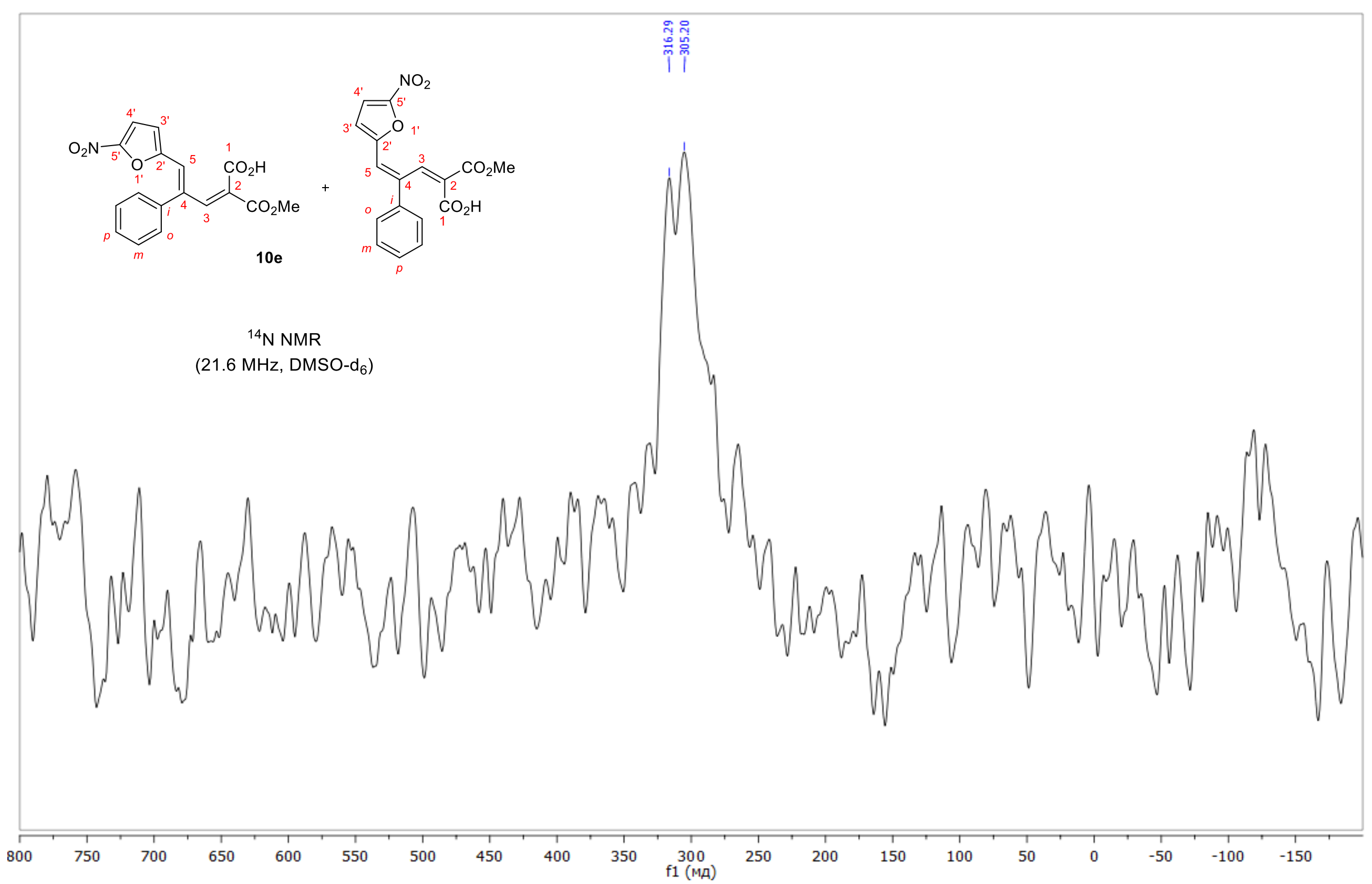




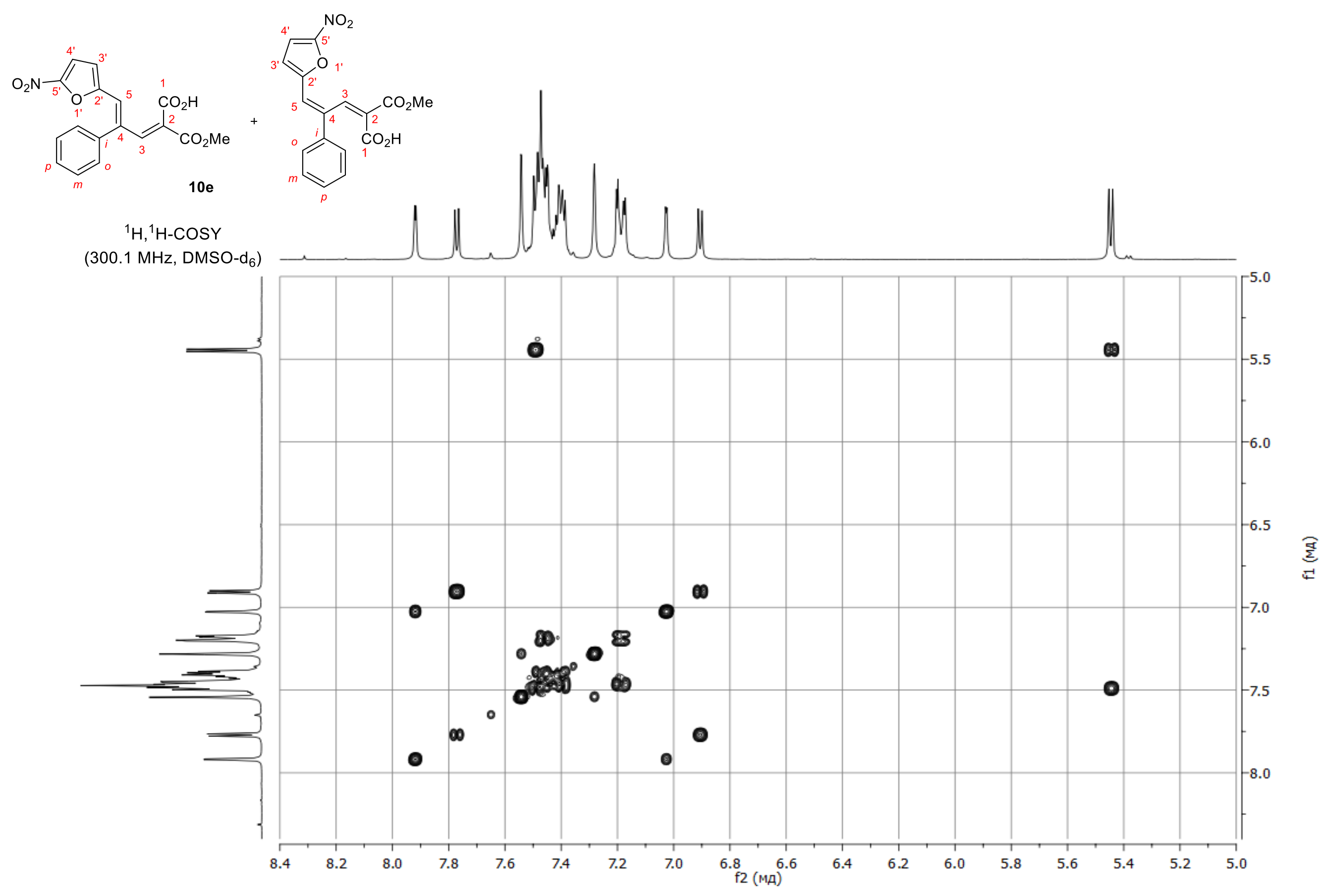




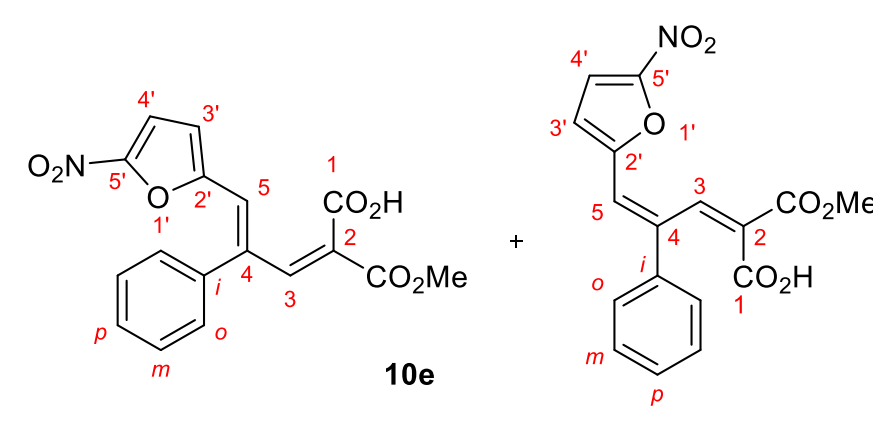

${ }^{1} \mathrm{H},{ }^{1} \mathrm{H}$-NOESY

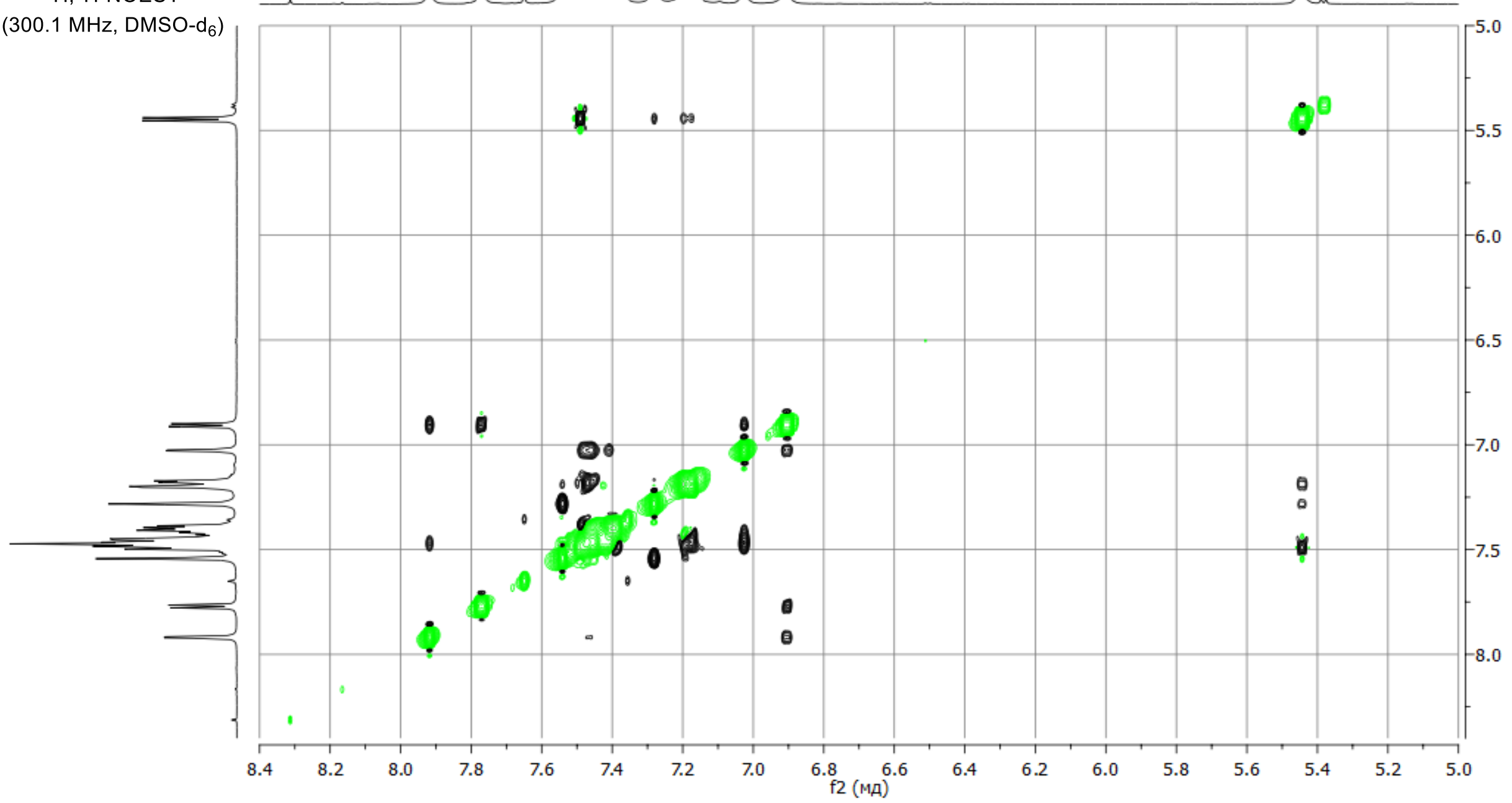




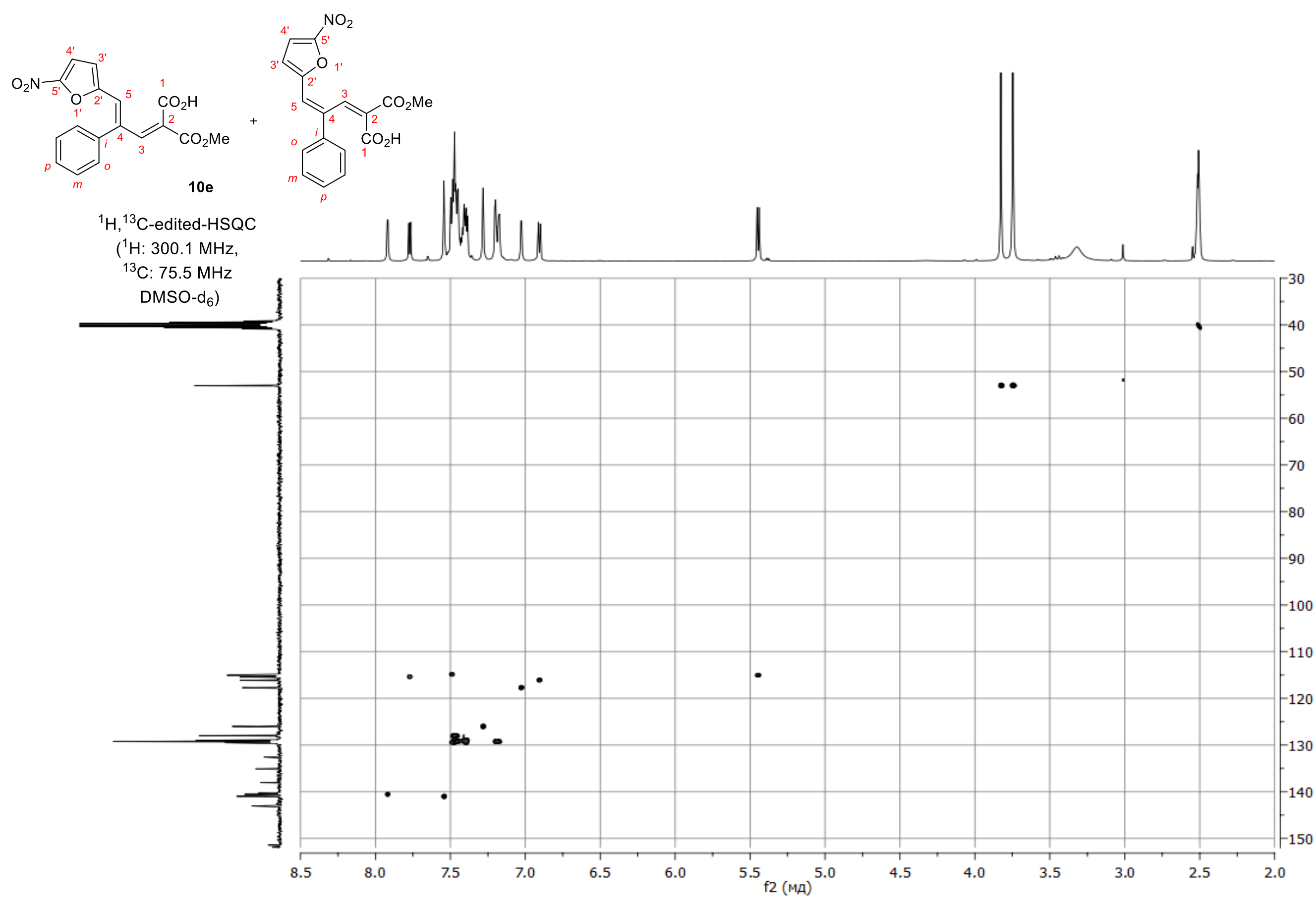




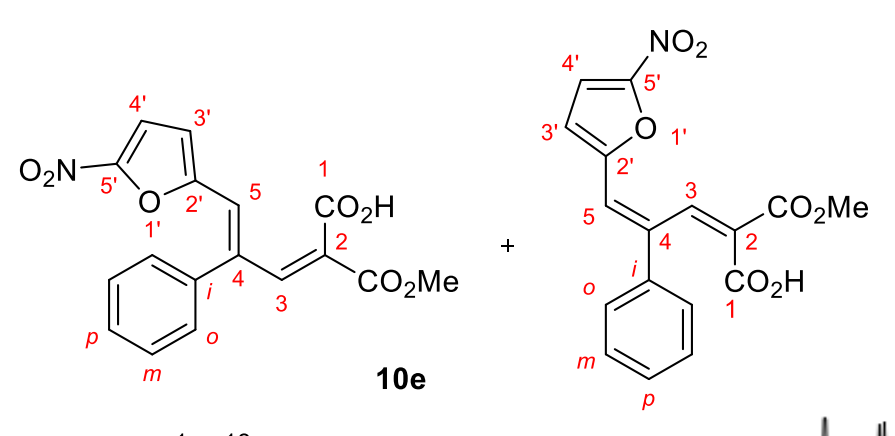

${ }^{1} \mathrm{H},{ }^{13} \mathrm{C}-\mathrm{HMBC}$

( ${ }^{1} \mathrm{H}: 300.1 \mathrm{MHz}$,

${ }^{13} \mathrm{C}: 75.5 \mathrm{MHz}$

DMSO-d $\mathrm{d}_{6}$ )
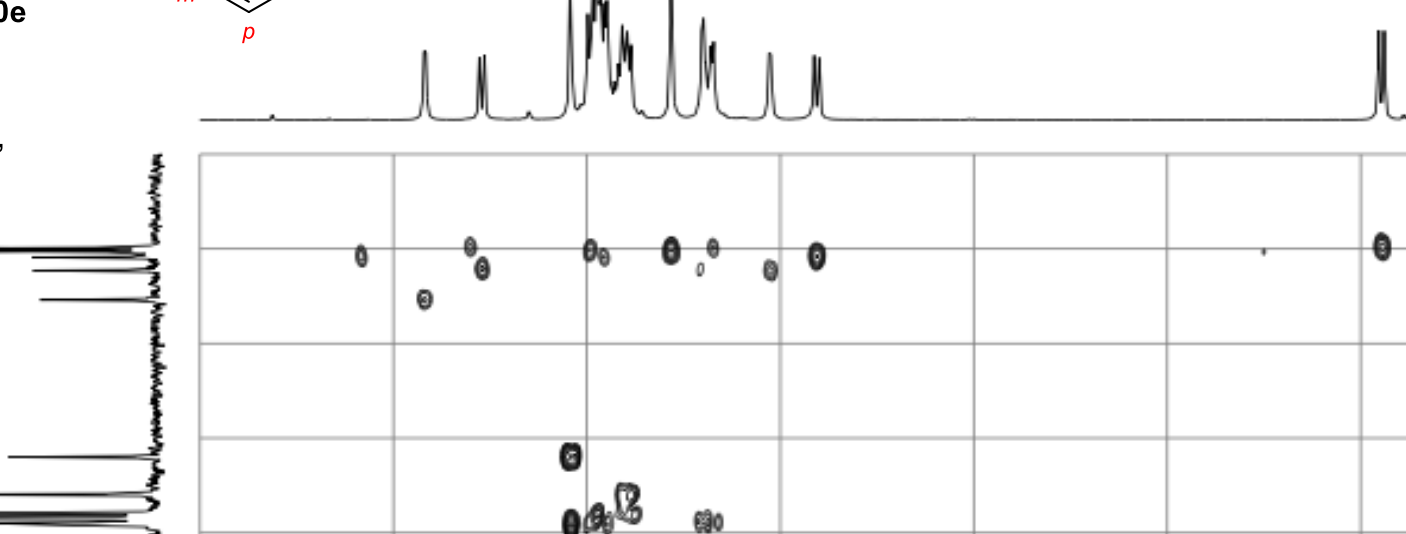


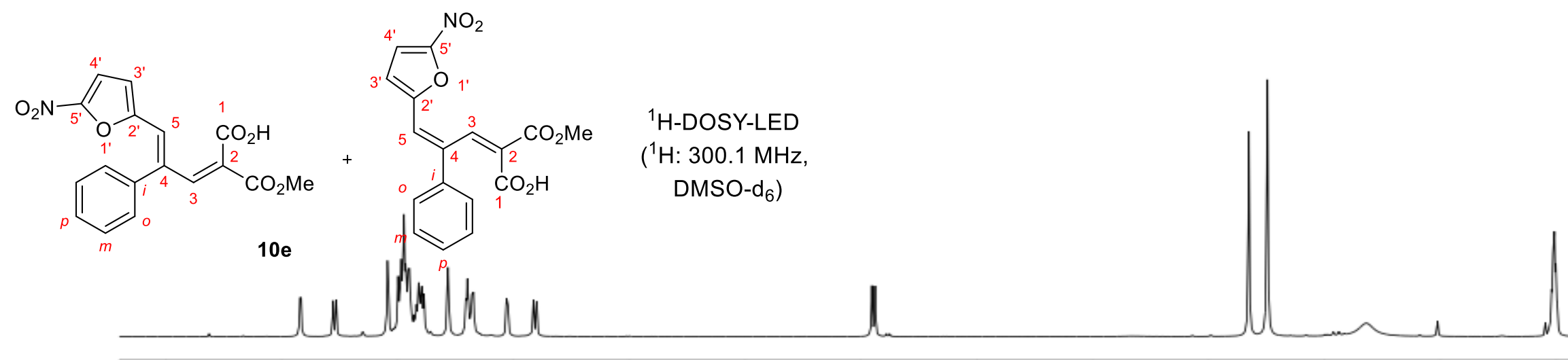

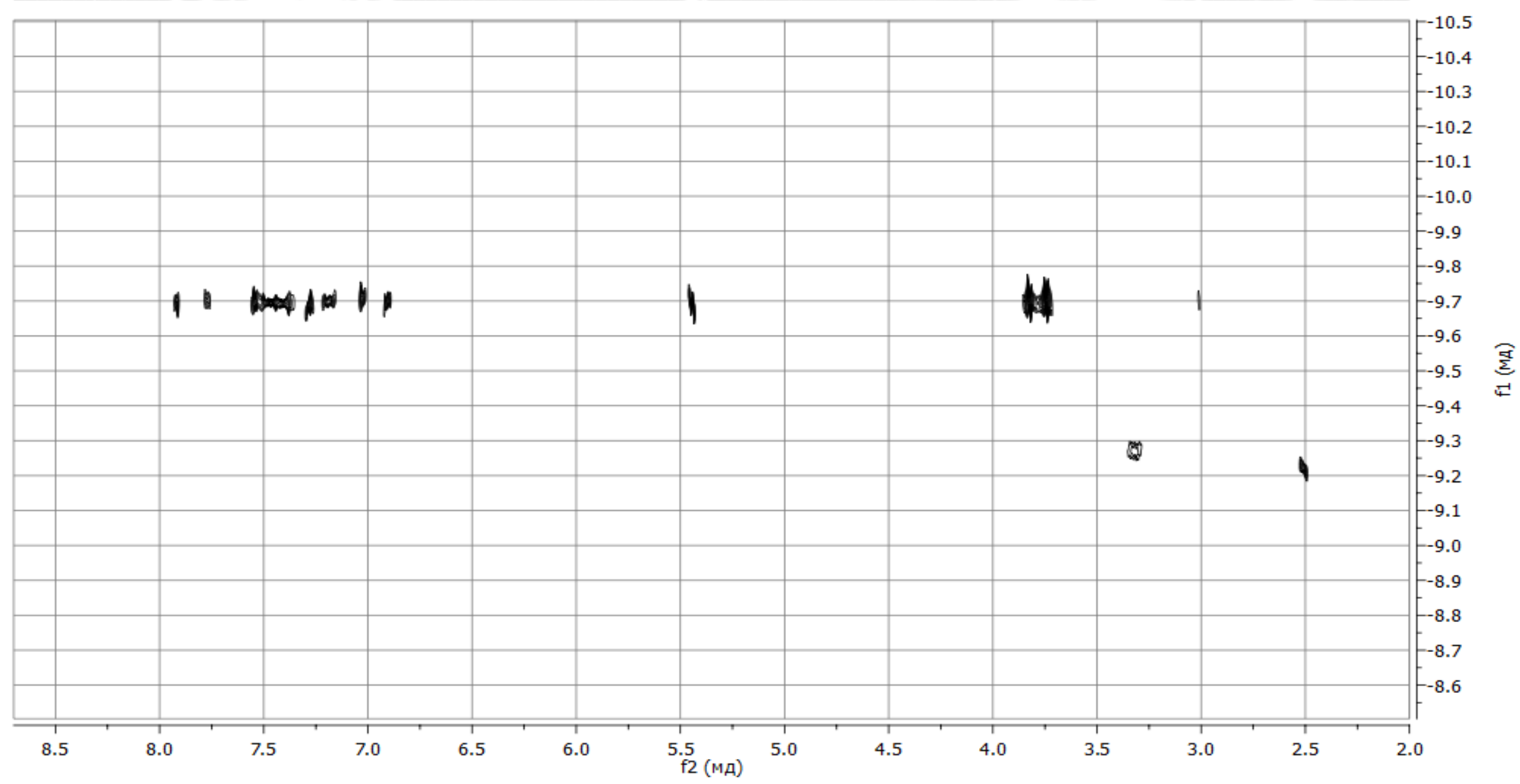




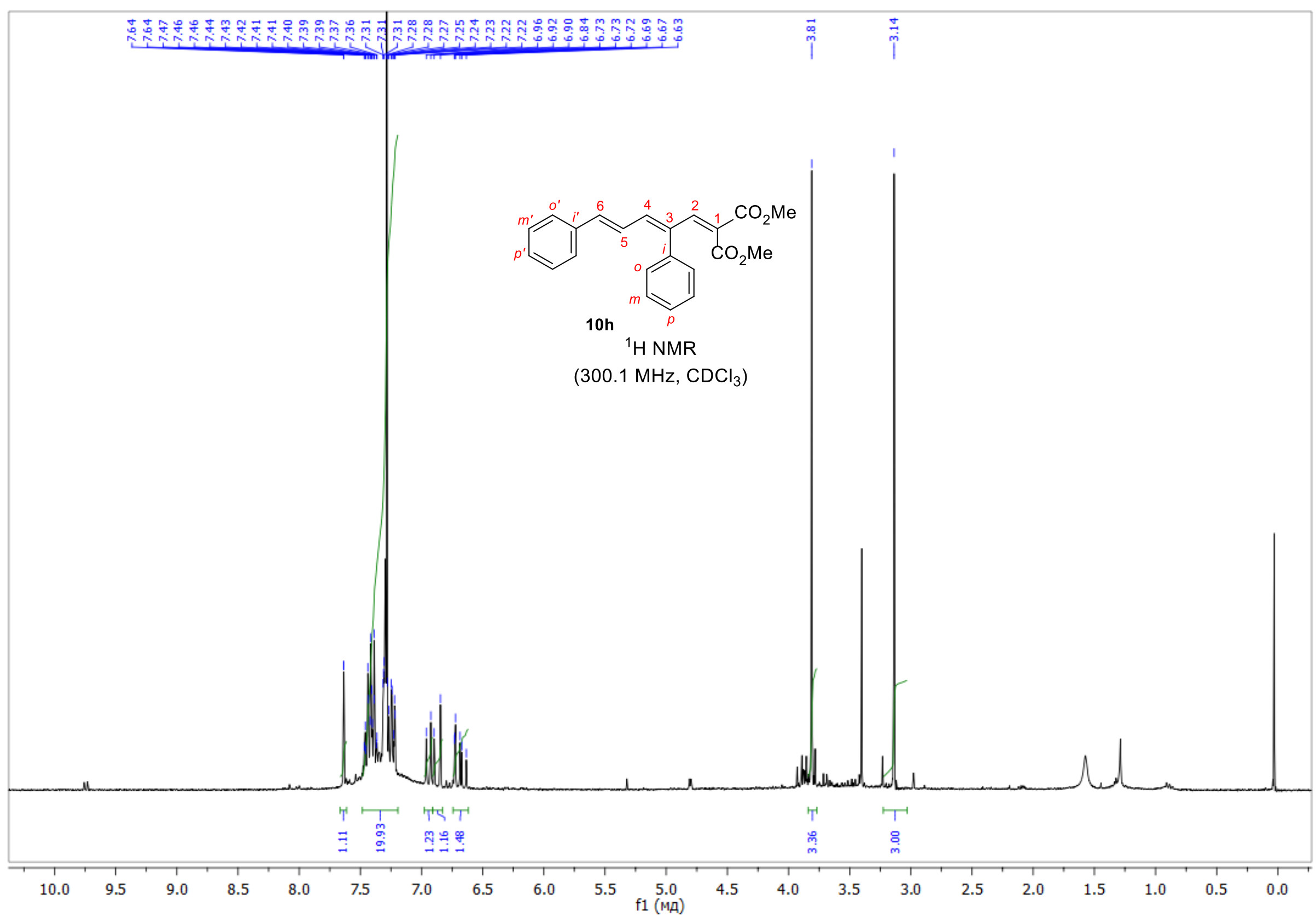




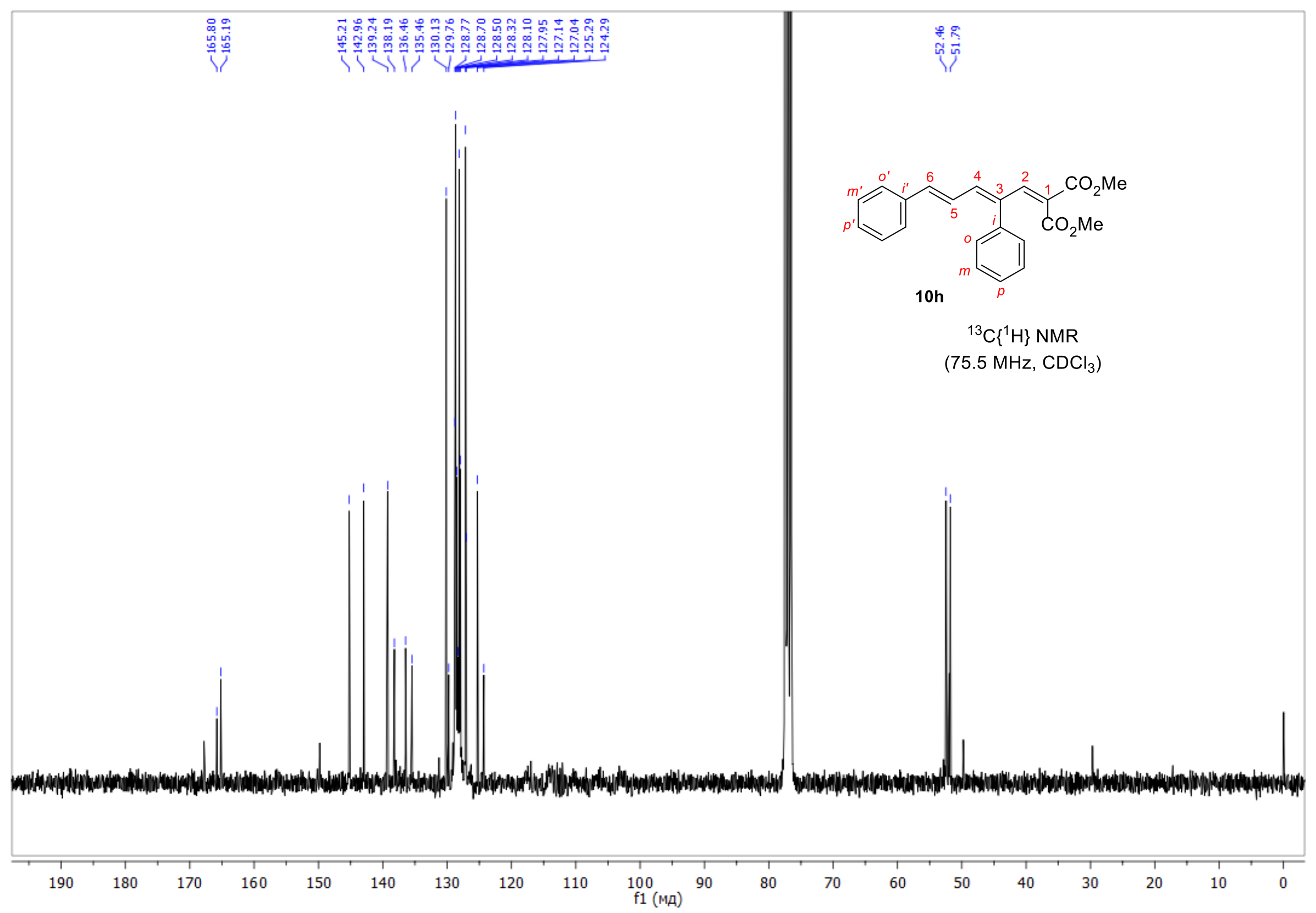




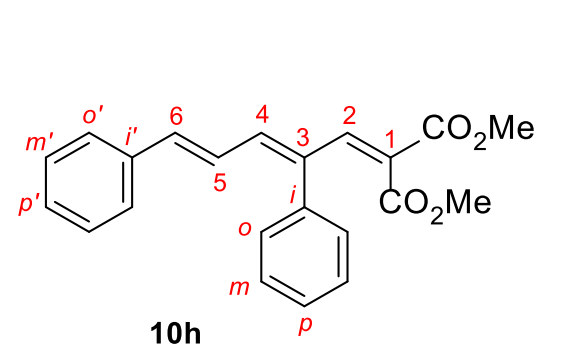

${ }^{1} \mathrm{H},{ }^{1} \mathrm{H}-\mathrm{COSY}$ (300.1 MHz, $\mathrm{CDCl}_{3}$ )

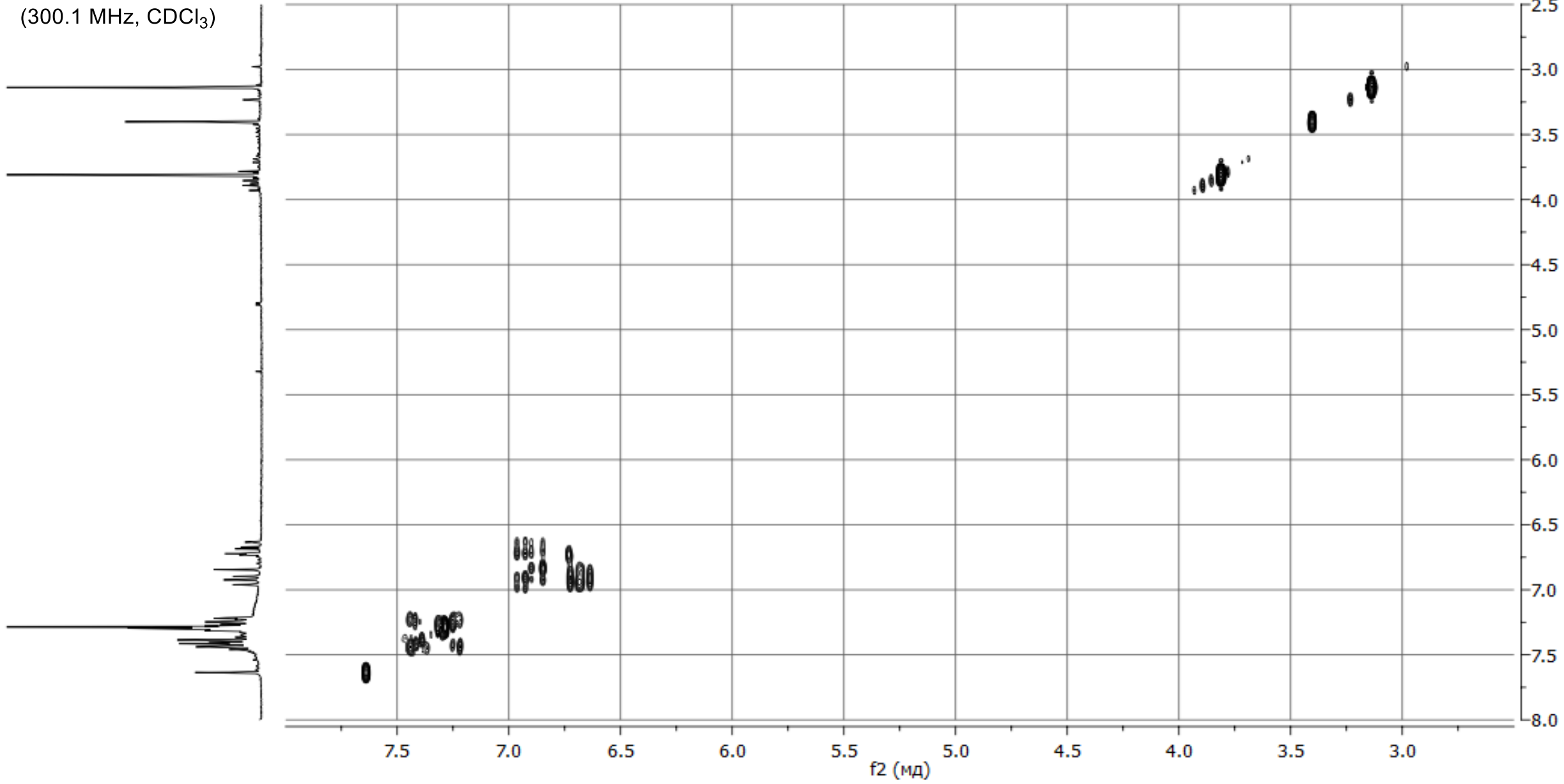




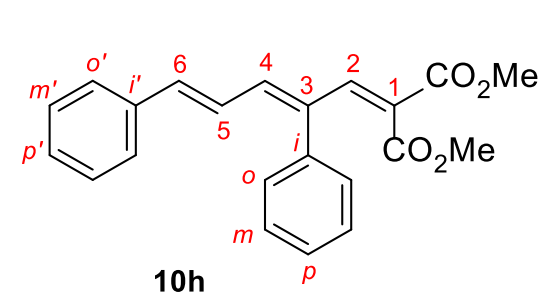

${ }^{1} \mathrm{H},{ }^{1} \mathrm{H}$-NOESY (300.1 MHz, $\mathrm{CDCl}_{3}$ )

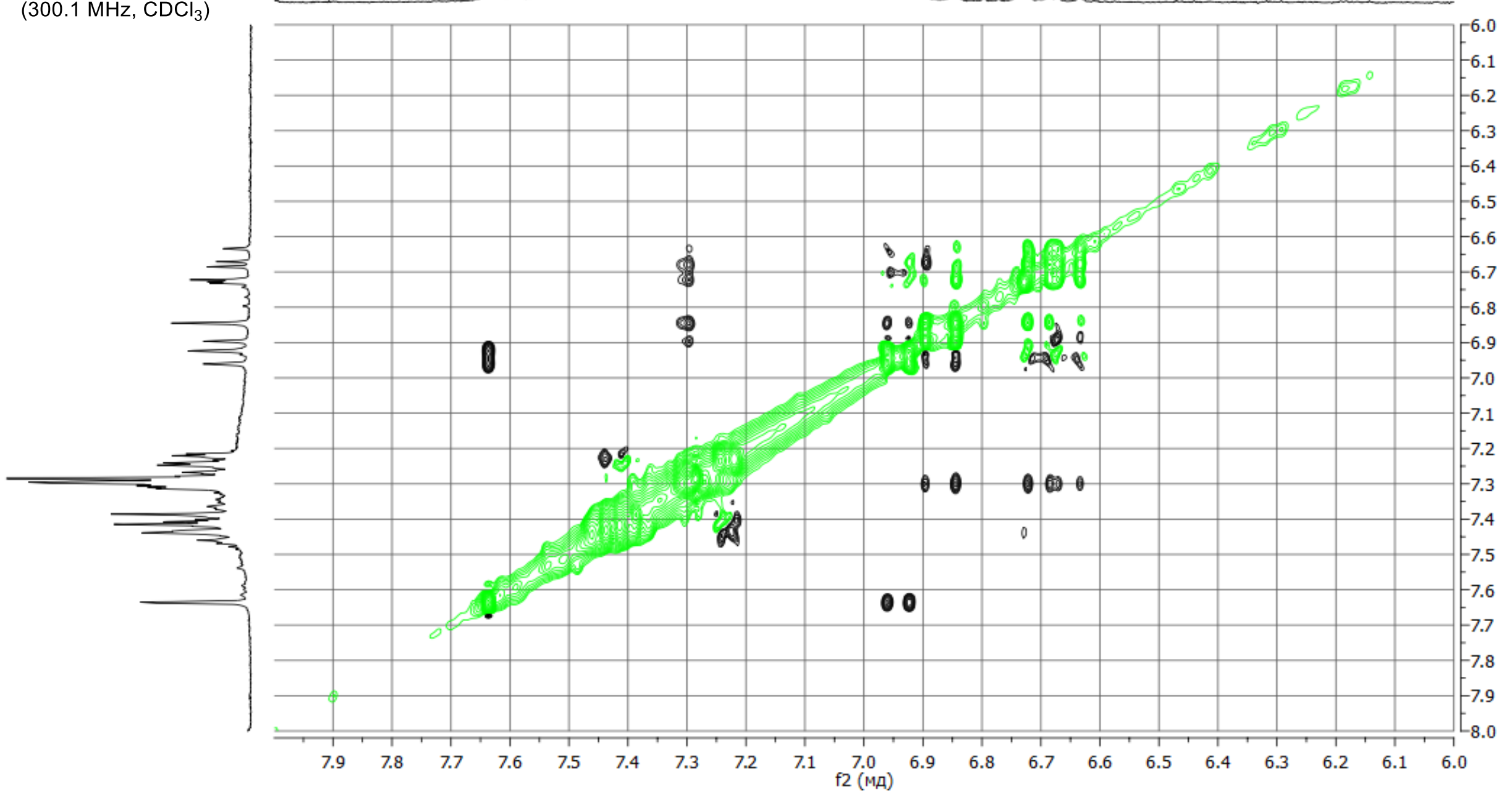




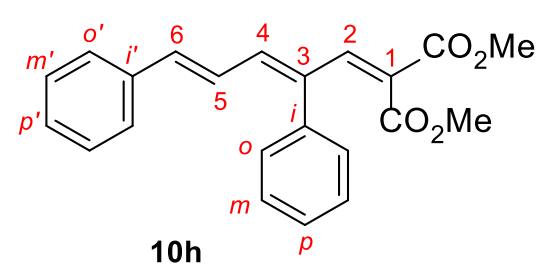

$\mathrm{H},{ }^{13} \mathrm{C}$-edited-HSQC

( ${ }^{1} \mathrm{H}: 300.1 \mathrm{MHz}$,

${ }^{13} \mathrm{C}: 75.5 \mathrm{MHz}$

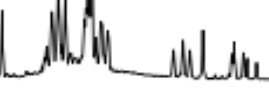
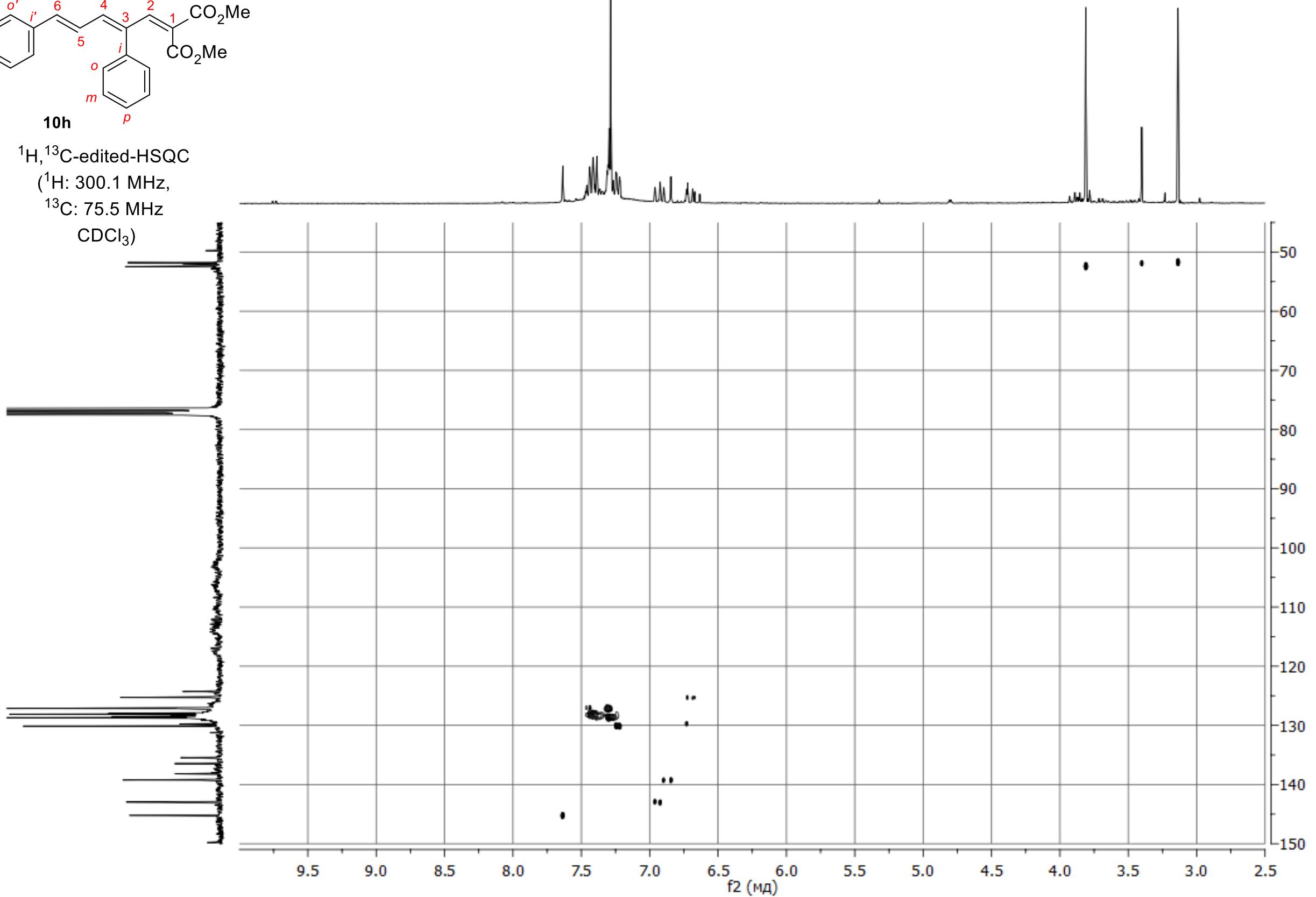


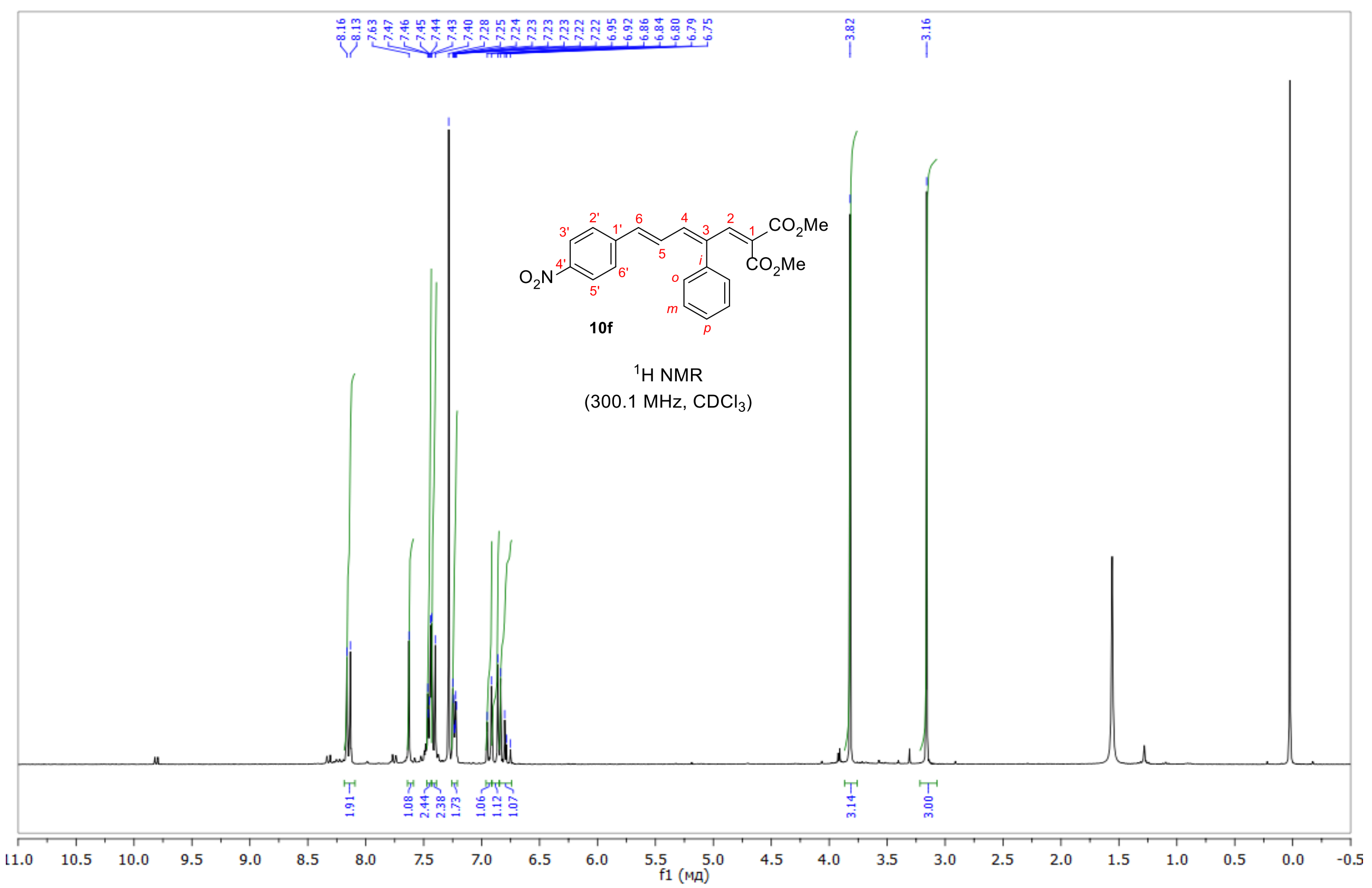




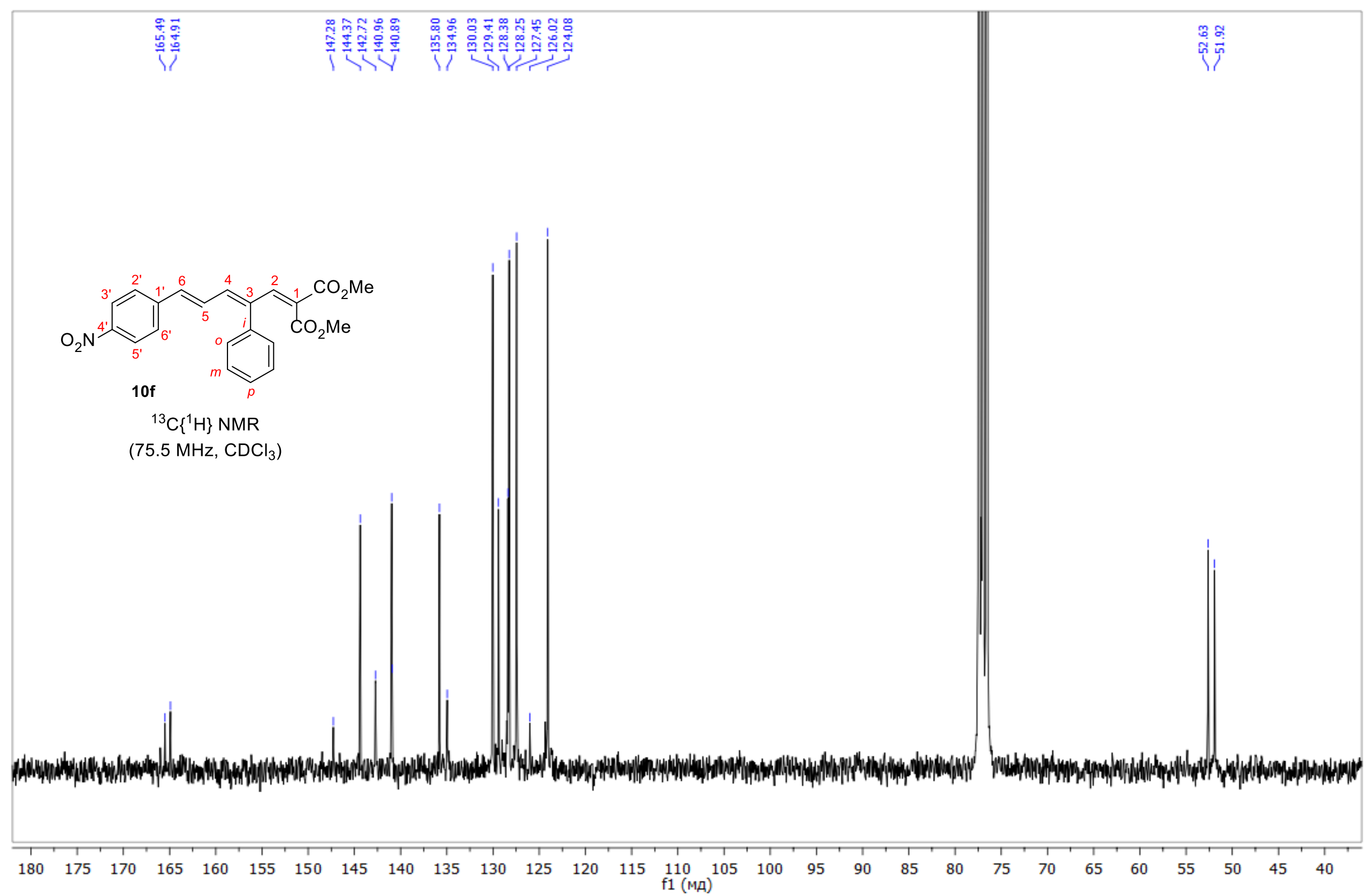




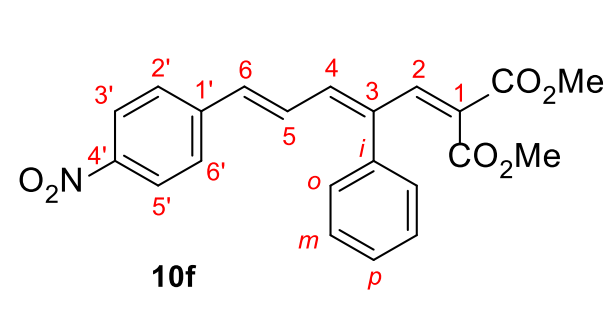

${ }^{1} \mathrm{H},{ }^{1} \mathrm{H}-\mathrm{COSY}$

(300.1 MHz, $\mathrm{CDCl}_{3}$ )

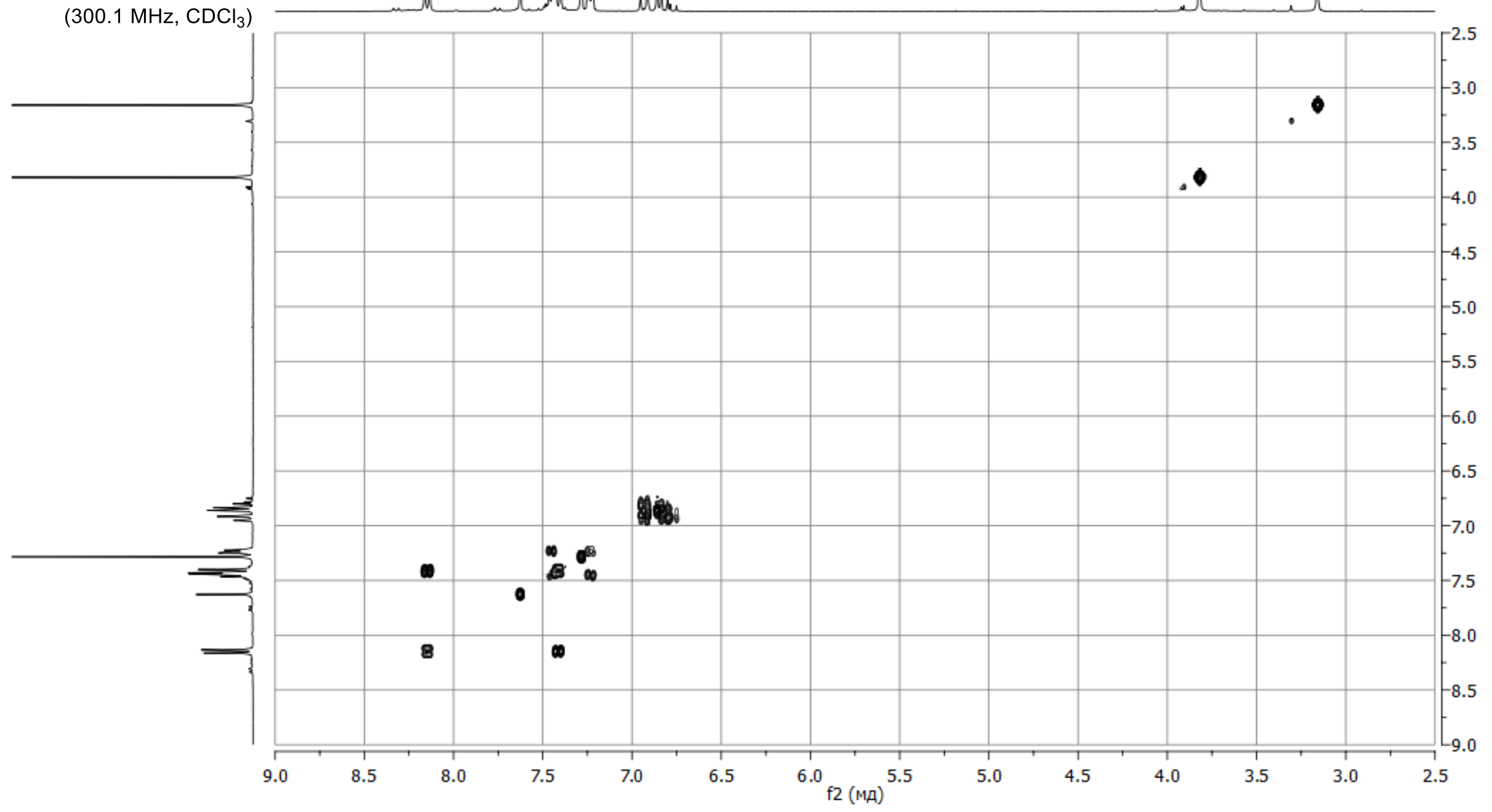




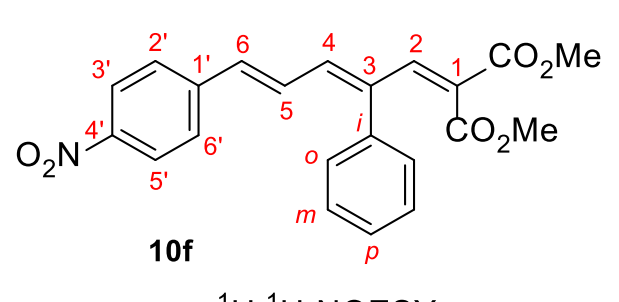

${ }^{1} \mathrm{H},{ }^{1} \mathrm{H}$-NOESY

(300.1 MHz, $\mathrm{CDCl}_{3}$ )

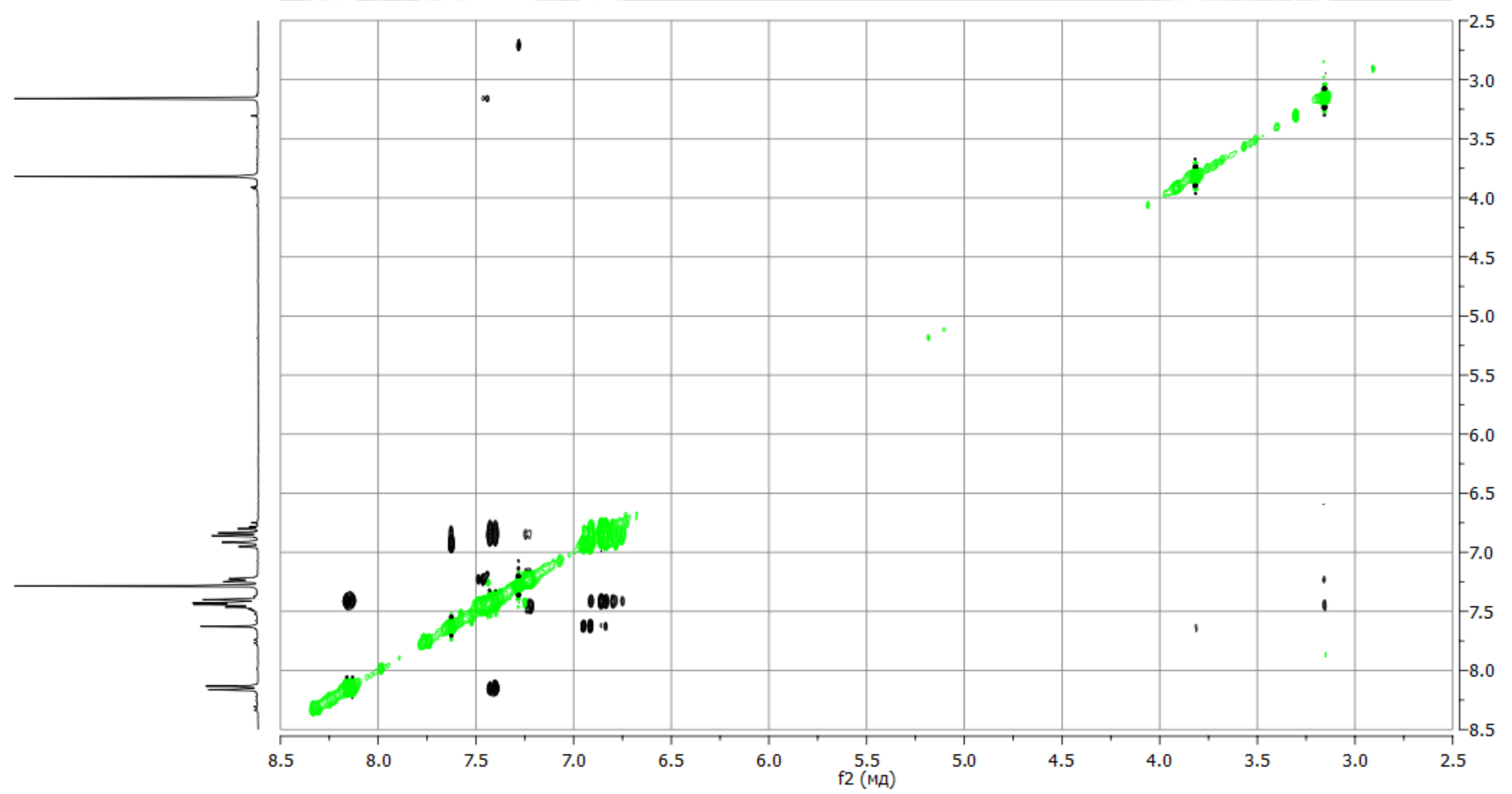




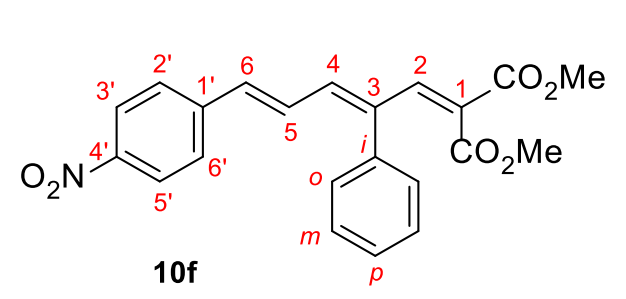

$10 f \quad p$

$\left({ }^{1} \mathrm{H}: 300.1 \mathrm{MHz}\right.$,

${ }^{13} \mathrm{C}: 75.5 \mathrm{MHz}$

$\mathrm{CDCl}_{3}$ )
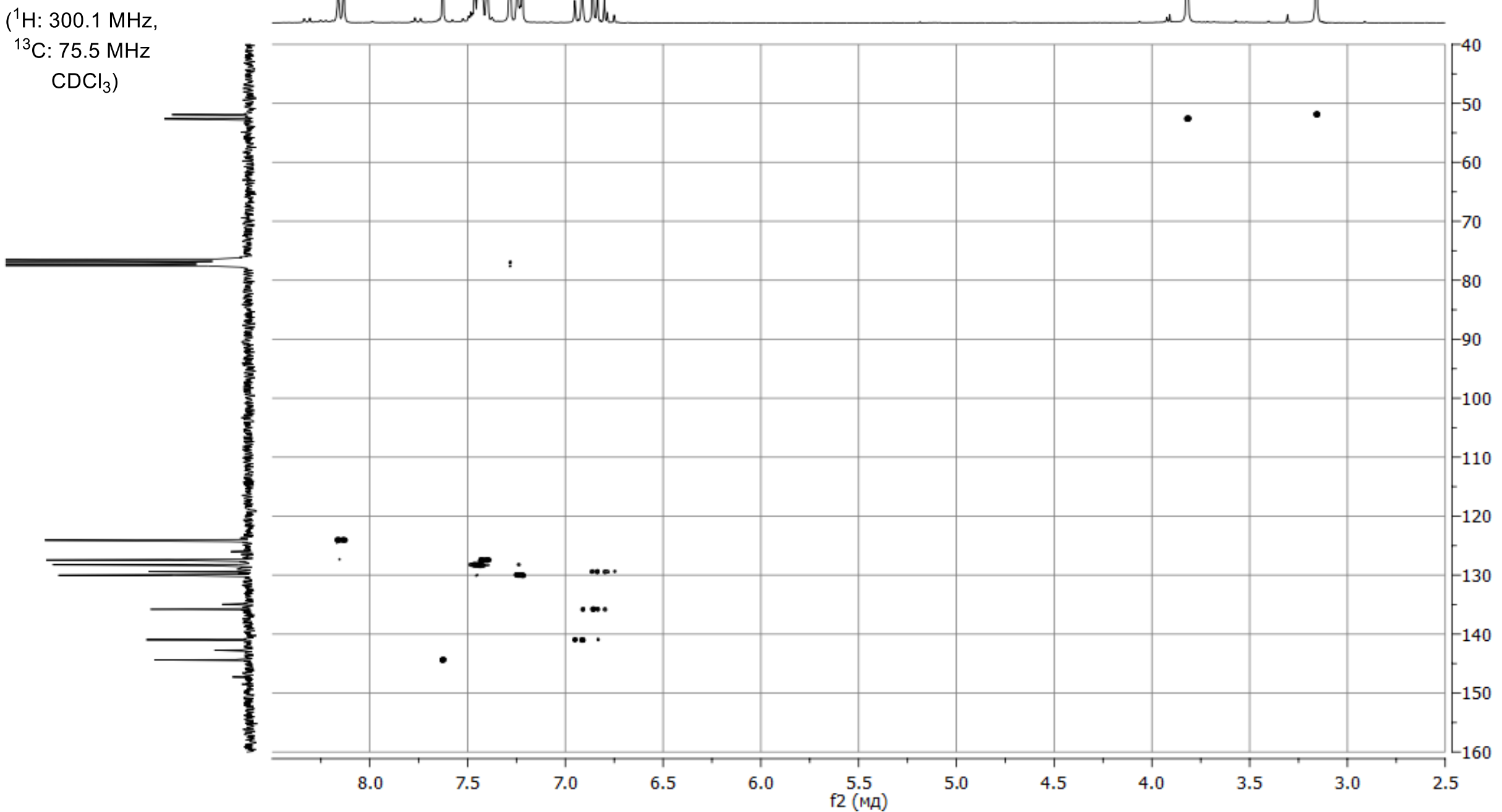


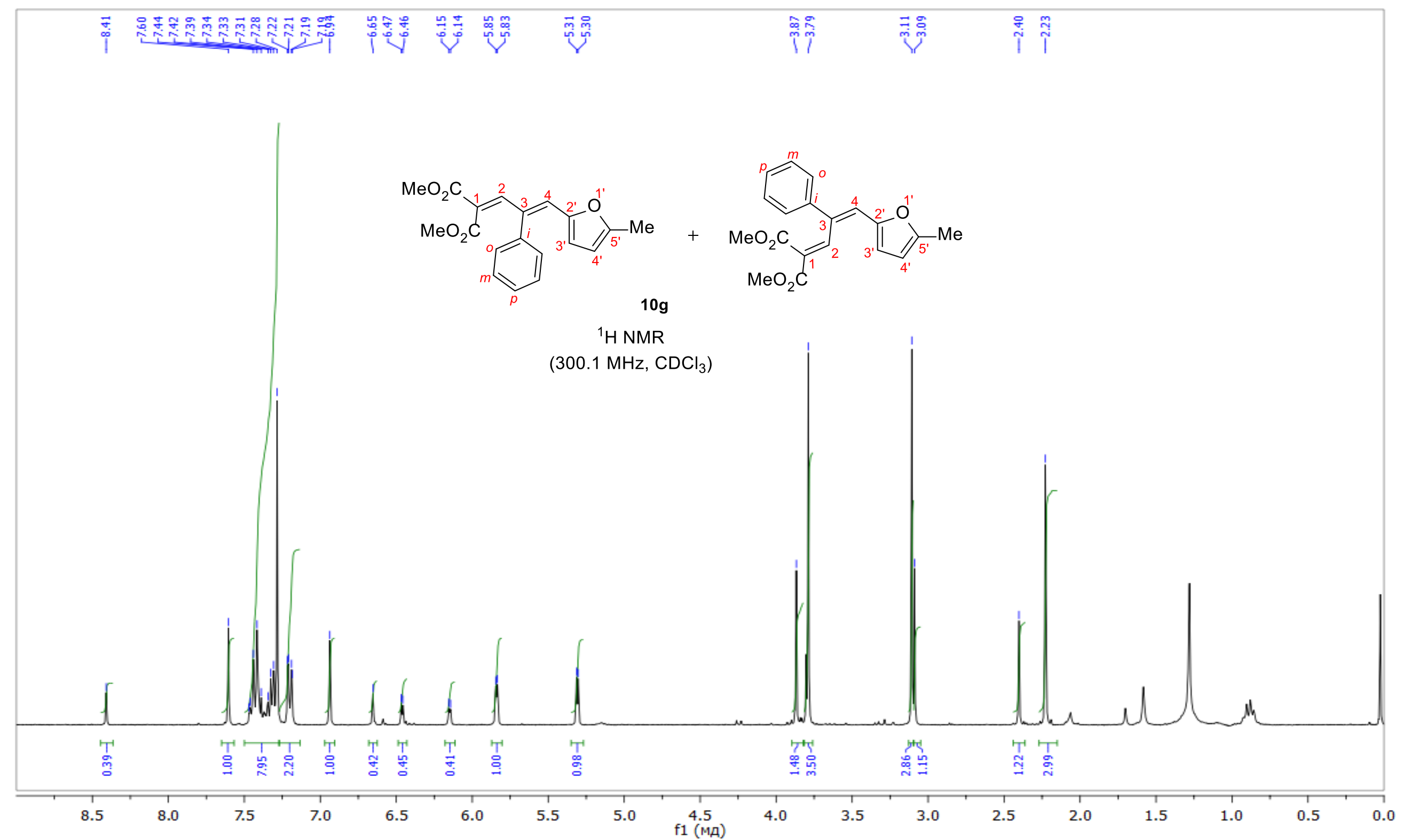




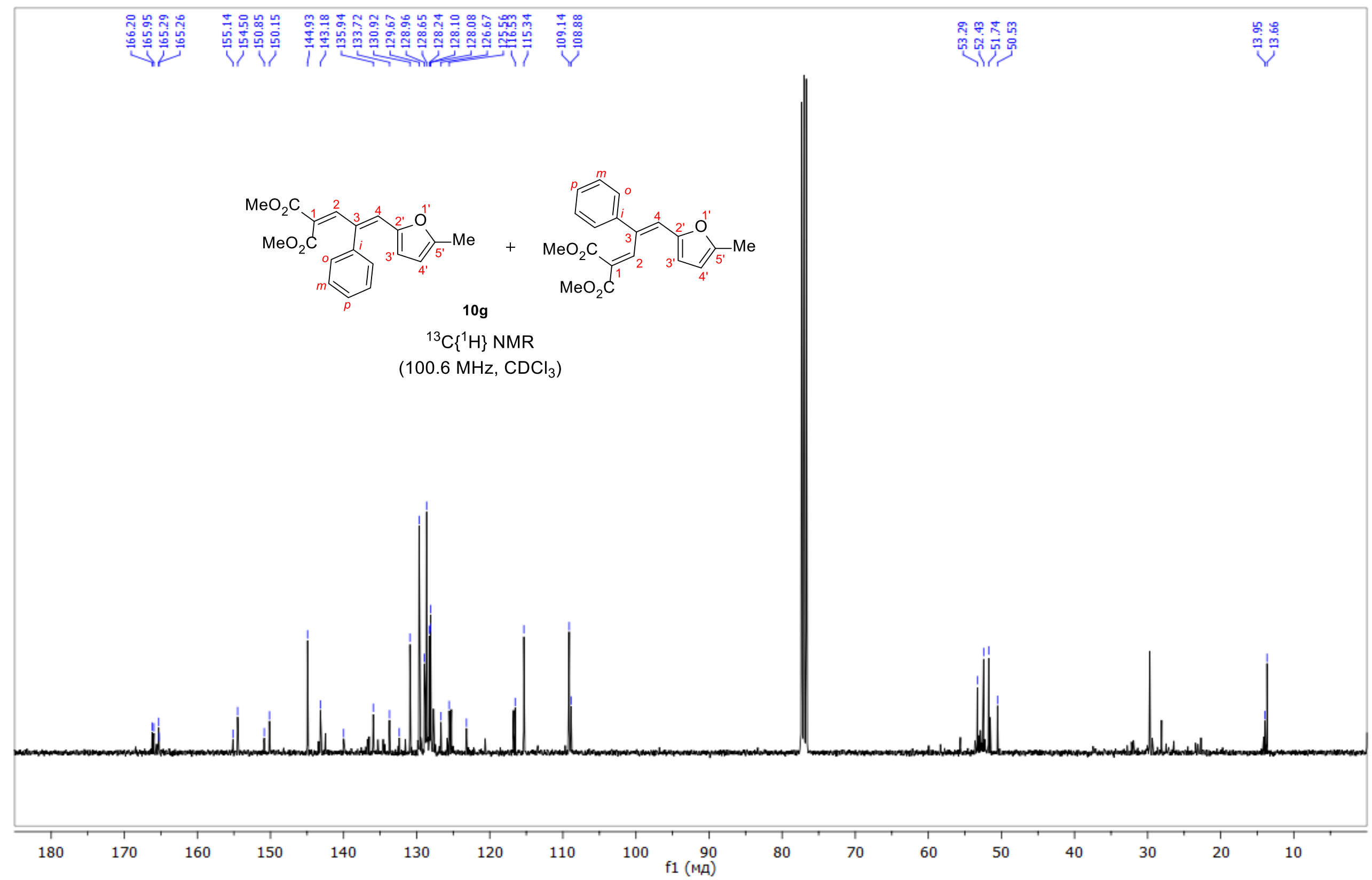


3. Copies of NMR, MS and HRMS spectra for ${ }^{18} \mathrm{O}$ labeled compound $6 \mathrm{a}$

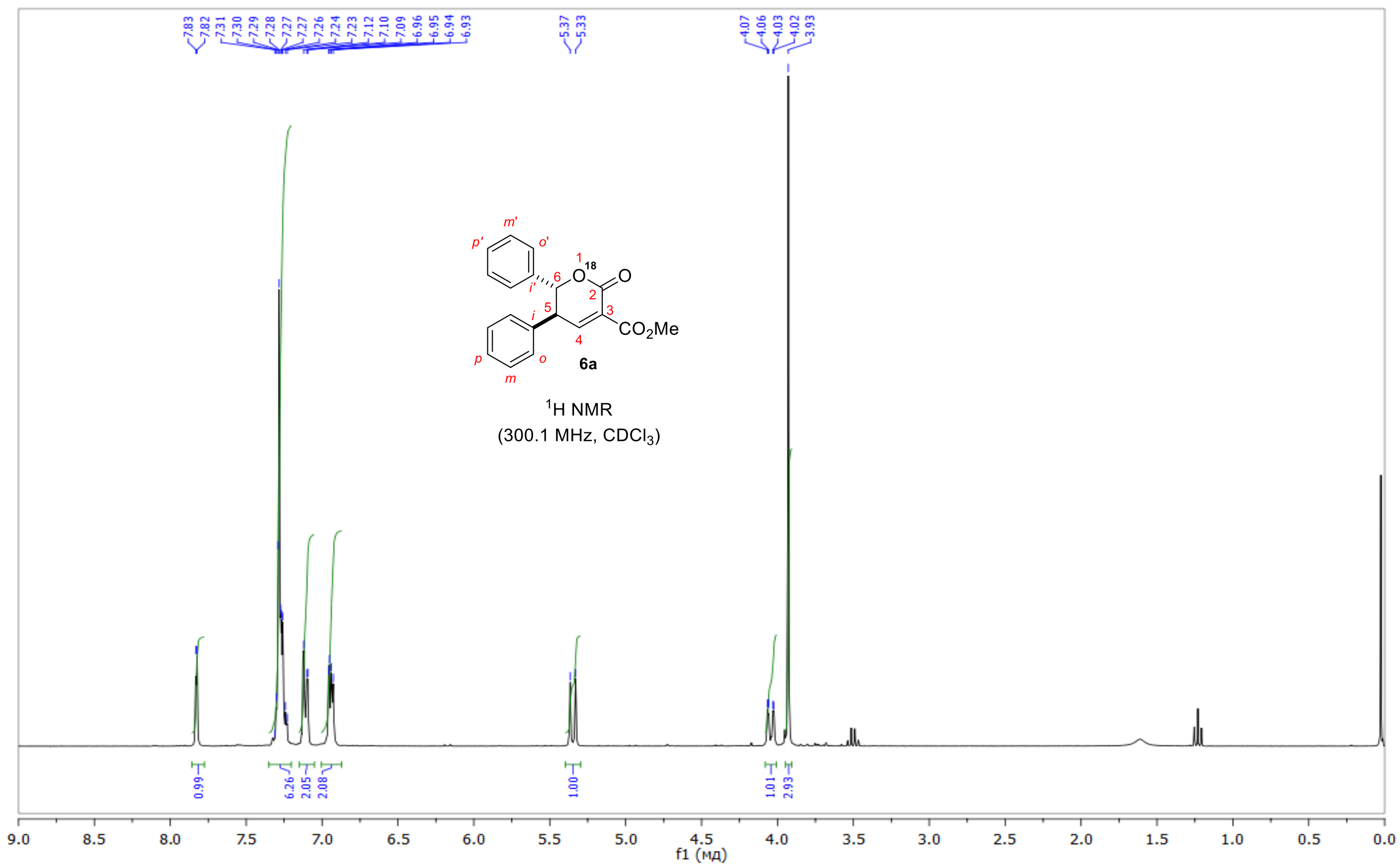




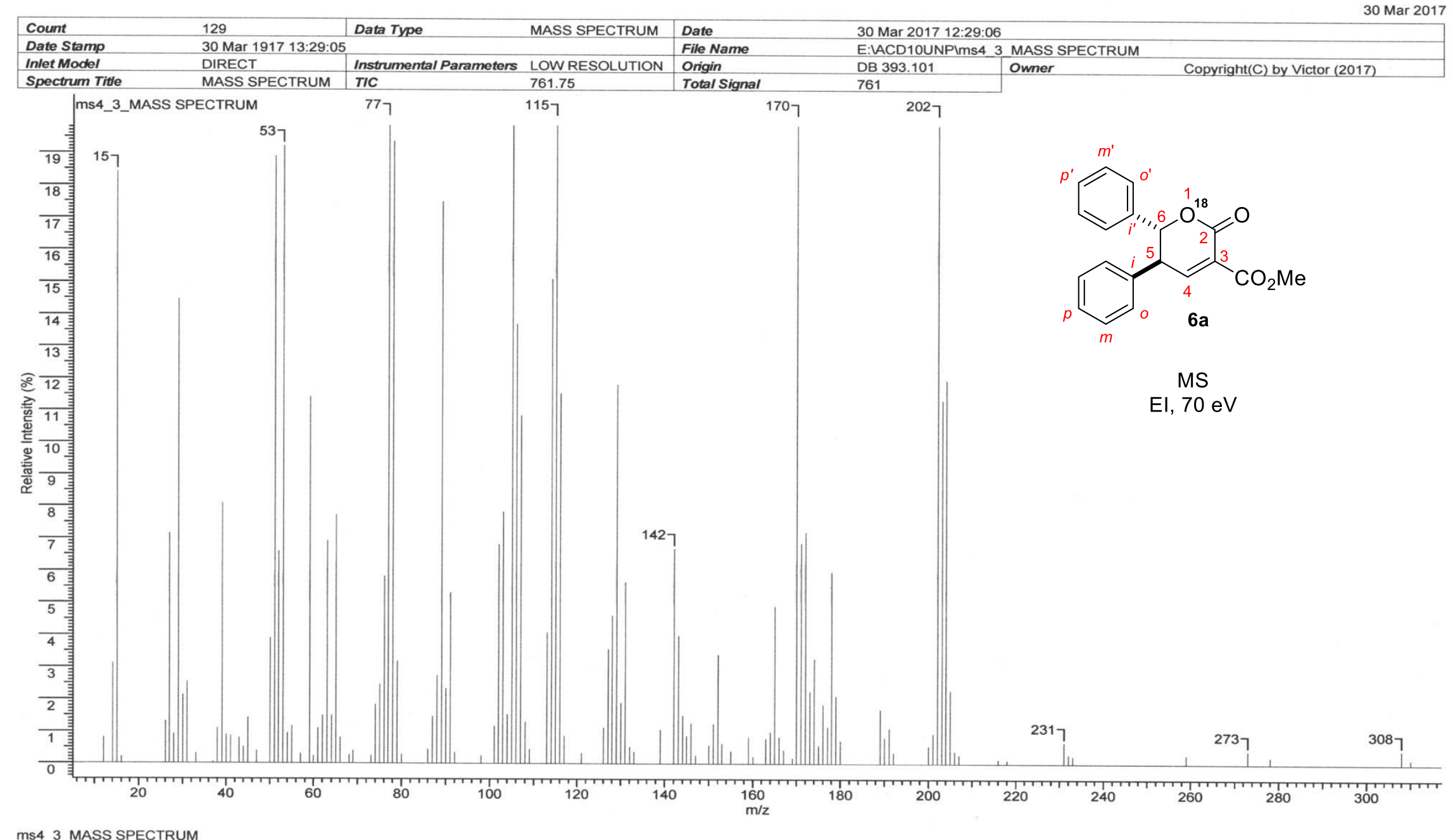


Display Report

\section{Analysis Info}

Analysis Name

Method

Sample Name

Comment
DataichizhovTomilovBorisovedb393_101_sclblow d

tune_low.m

AOMA DB393.101

CH $3 \mathrm{CN} 100 \%$, dil. 200, calibrant added
Acquisition Date 31.03 .2017 13:37:03

Operator BDAL@DE

Instrument / Ser\# micrOTOF 10248
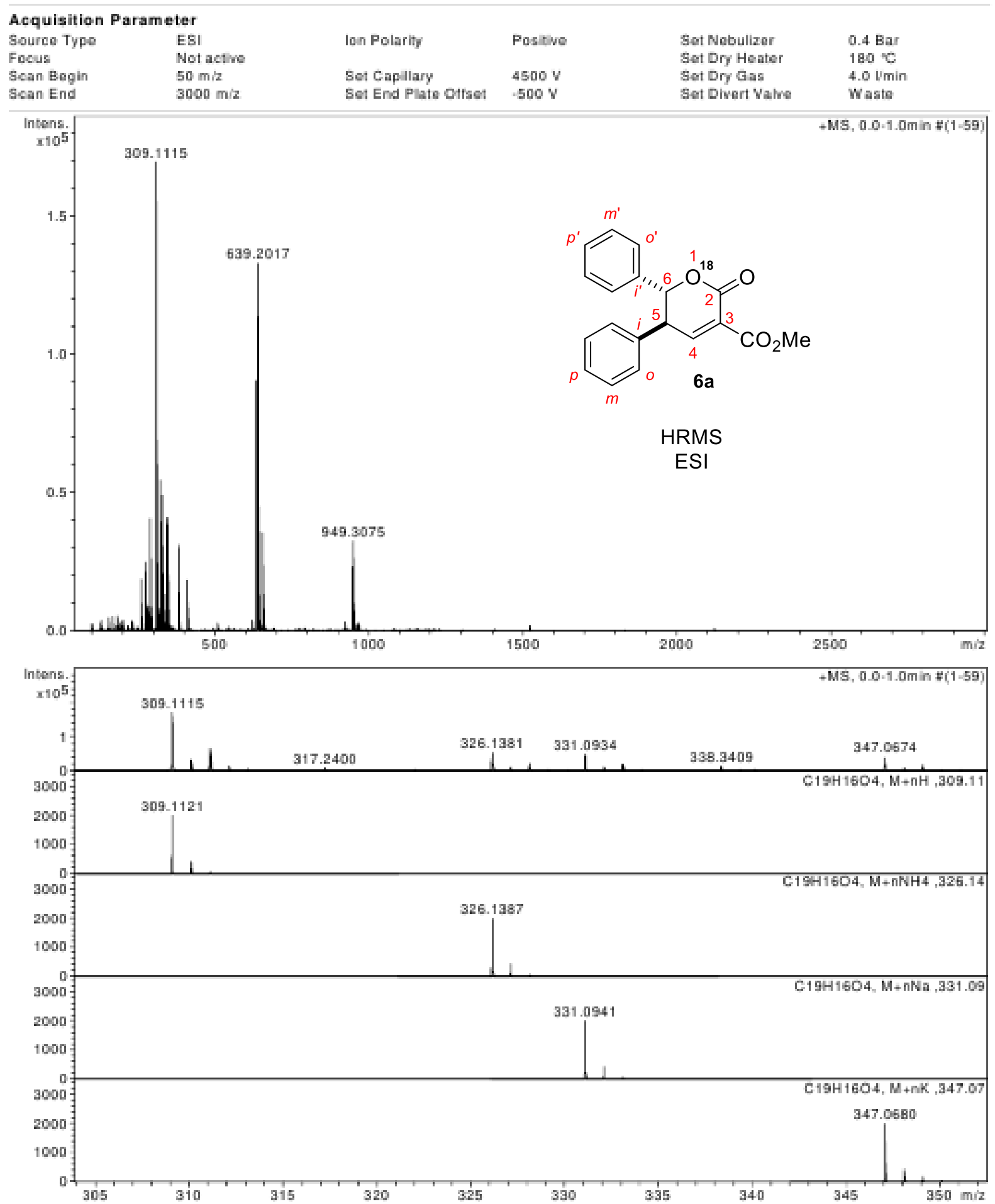